\title{
Congenital Disorder of Glycosylation (CDG)-Ih
}

Identifizierung eines Defekts in der Dol-P-Man:Man ${ }_{1-2}-\mathrm{GlcNAc}_{2}-$ PP-Dol Mannosyltransferase

\author{
Dissertation \\ zur Erlangung des Doktorgrades \\ der Mathematisch-Naturwissenschaftlichen Fakultäten \\ der Georg-August-Universität zu Göttingen
}

vorgelegt von

Christian Thiel

aus Göttingen

Göttingen 2002 
D7

Referent: $\quad$ Prof. Dr. K. von Figura

Korreferent: Prof. Dr. G. Gottschalk

Tag der mündlichen Prüfung: 31. Oktober 2002 
Für meine Frau und meine Kinder 


\section{INHALTSVERZEICHNIS}

1 Einleitung 1

$1.1 \quad$ Glykosylierung von Proteinen 1

1.2 Grundlagen der Protein-Glykosylierung 1

1.2.1 O-Glykane 1

$1.2 .2 \quad N$-Glykane 2

1.3 Defekte in der N-Glykosylierung 4

$\begin{array}{ll}\text { CDG-la } & 6\end{array}$

$\begin{array}{ll}\text { CDG-Ib } & 7\end{array}$

CDG-IC $\quad 8$

CDG-Id 9

$\begin{array}{ll}\text { CDG-le } & 10\end{array}$

CDG-If 10

CDG-Ig 11

CDG-Ila 11

CDG-Ilb 12

CDG-IIC 12

CDG-Ild 13

$2 \quad$ Problemstellung 14

$3 \quad$ Materialien und Methoden 15

$\begin{array}{lll}3.1 & \text { Materialien } & 15\end{array}$

$\begin{array}{lll}3.1 .1 & \text { Geräte } & 15\end{array}$

$\begin{array}{ll}3.1 .2 & \text { Verbrauchsmaterialien } \\ 3.1 .3 & 16\end{array}$

$\begin{array}{lll}3.1 .3 & \text { Chemikalien } & 17\end{array}$

$\begin{array}{ll}3.1 .4 & \text { Detergenzien }\end{array}$

3.1.5 Enzyme, DNA- und Proteinstandards, Antibiotika 20

3.1.6 Kits zur Bearbeitung von DNA und RNA 20

$\begin{array}{lll}3.1 .7 & \text { EDV } & 21\end{array}$

$\begin{array}{lll}3.1 .8 & \text { Antikörper } & 21\end{array}$

3.1.9 Radioaktive Substanzen 21

$\begin{array}{lll}3.1 .10 & \text { Vektoren } & 21\end{array}$

3.1.11 Bakterienstämme 22

$\begin{array}{lll}3.1 .12 & \text { Zellinien } & 22\end{array}$

3.1.13 Standardpuffer und -lösungen 23

3.1.14 Medien zur Anzucht von Escherichia coli 24

$\begin{array}{lll}3.1 .15 & \text { Antibiotikum } & 25\end{array}$

3.1.16 Zellkulturmedien und Lösungen zur Arbeit mit eukaryontischen 25 Zellen 
3.2 Methoden

3.2.1 Methoden zur Arbeit mit bakteriellen Kulturen 26

3.2.1.1 Flüssigkulturen 26

3.2.1.2 Plattenkulturen 26

3.2.1.3 Stammkonservierung und Reaktivierung 26

$\begin{array}{lll}\text { 3.2.1.4 Reinheitskontrollen } & 27\end{array}$

3.2.1.5 Zelldichtebestimmungen 27

3.2.1.6 Zellernte 27

3.2.2 Zellbiologische Methoden zur Arbeit mit eukaryontischen Kulturen 27

3.2.2.1 Kultivierung von eukaryontischen Zellen 27

3.2.2.2 Trypsinieren und Ernten von Zellen 28

3.2.2.3 Kryokonservierung von Zellen 28

$\begin{array}{lll}\text { 3.2.2.4 Auftauen und Revitalisieren von Zellen } & 28\end{array}$

3.2.3 Proteinbiochemische Methoden 29

3.2.3.1 Serumpräparation aus venösem Blut 29

3.2.3.2 Eisensättigung der Serumproben 29

3.2.3.3 Proteinbestimmung nach BRADFORD (1976), modifiziert 29

3.2.3.4 Isoelektrische Fokussierung von Serumtransferrin 30

3.2.3.5 SDS-Polyacrylamidgelelektrophorese (SDS-PAGE) zur 31

3.2.3.6 Coomassie-Färbung von SDS-Polyacrylamid-Gelen 33

3.2.3.7 Transfer von Proteinen auf Nitrozellulose-Membranen ("Western 34 blotting")

3.2.3.8 Detektion von Proteinen auf Nitro-Zellulosemembranen 34

3.2.3.9 Chemilumineszenz-Nachweis 35

3.2.3.10 Herstellung von Fibroblastenextrakten 35

3.2.3.11 Bestimmung der Aktivität der Phosphomannomutase 2 in 35

3.2.3.12 Bestimmung der Aktivität der Phosphomannose Isomerase (PMI) 36 in Patienten- und Kontrollfibroblasten

3.2.3.13 Metabolische Markierung von Fibroblasten mit [2- $\left.{ }^{3} \mathrm{H}\right]$-Mannose 36

3.2.3.14 Milde Säurebehandlung und HPLC-Analyse langkettiger 36 lipidverknüpfter Oligosaccharide

3.2.3.15 Enzymatische Deglykosylierung proteinverknüpfter 37 Oligosaccharide durch PNGase F

3.2.3.16 Milde Säurebehandlung und HPLC-Analyse kurzkettiger, $\quad 37$ lipidverknüpfter Oligosaccharide

3.2.3.17 Markierung von Oligosacchariden mit PMP 38

3.2.3.18 Massenspektrometrische Untersuchungen von abgespaltenen 38 Zuckerketten 
3.2.4 Methoden zur molekularbiologischen Arbeit mit DNA und RNA 39

3.2.4.1 Leukozytenpräparation 39

3.2.4.2 Isolierung genomischer DNA aus Leukozyten und primären, 39

$\begin{array}{lll}\text { 3.2.4.3 Isolierung von Gesamt-RNA } & 40\end{array}$

3.2.4.4 Isolierung von Plasmid-DNA aus Escherichia coli 40

3.2.4.4.1 Mini-Präparation von Plasmid-DNA 40

3.2.4.4.2 Midi-Präparation von Plasmid-DNA 41

3.2.4.5 Phenol-Chloroform-Extraktion 42

3.2.4.6 Alkoholpräzipitation 42

3.2.4.6.1 Alkoholpräzipitation von DNA mit Ethanol 42

3.2.4.6.2 Alkoholpräzipitation von DNA mit Isopropanol 43

3.2.4.7 Lagerung von DNA und RNA 43

$\begin{array}{lll}3.2 .4 .8 & \text { Restriktionsverdau von DNA } & 43\end{array}$

3.2.4.9 Dephosphorylierung von DNA-Fragmenten 44

3.2.4.10 Agarose-Gelelektrophorese 44

3.2.4.11 Größenbestimmung von DNA-Fragmenten durch Agarosegel- 45 Elektrophorese nach SOUTHERN (1979)

3.2.4.12 Isolierung von DNA-Fragmenten aus Agarosegelen 45

3.2.4.13 Konzentrationsbestimmungen von DNA und RNA 46

3.2.4.14 Ligation 46

3.2.4.15 Herstellung kompetenter E.coli -Zellen nach (INOUE et al., 1990) 46 und Transformation von kompetenten Zellen

$\begin{array}{lll}\text { 3.2.4.16 DNase I-Verdau } & 48\end{array}$

3.2.4.17 Reverse Transkription von mRNA in cDNA 48

3.2.4.18 Polymerase-Chain-Reaction (PCR) nach SAIKI et al. (1985), 49

3.2.4.19 In vitro-Mutagenese 50

3.2.4.20 DNA-Sequenzierung 51

3.2.4.21 Northern Blot von Gesamt-RNA der Patientin und Kontrollen 52

3.2.4.22 DNA-Markierung mit $\alpha-{ }^{32} \mathrm{P}-\mathrm{dCTP}$

3.2.4.23 Hybridisierung der Hybond-N-Filter mit radioaktiv markierten DNA- 54 Sonden

3.2.4.24 Transfektion von FNX-Eco-Zellen mit FuGENE6- 55 Transfektionsreagenz

3.2.4.25 Produktion retroviraler Partikel zur Transduktion primärer, $\quad 56$ humaner Fibroblasten

3.2.4.26 Verwendete Primer für PCR und Sequenzierung 57

4 Ergebnisse 58

4.1 Patientenanamnese 58 
4.2 Proteinbiochemische Untersuchungen

4.2.1 Isoelektrische Fokussierung und Western Blot Analyse des Serum-Transferrins

4.2.2 Bestimmung der Aktivität der Phosphomannomutase $2 \quad 60$

4.2.3 Bestimmung der Aktivität der Phosphomannose Isomerase 62

4.2.4 HPLC-Analyse Dolichol-verknüpfter Oligosaccharide der Patientin 62 M.S. zum Ausschluß der CDG-Typen Ic, Id, le, If und Ig

4.2.5 HPLC-Analyse Protein-verknüpfter Oligosaccharide der Patientin 64 M.S.

4.2.6 Dünnschichtchromatographie kurzkettiger Lipid-verknüpfter Oligosaccharide

4.2.7 HPLC-Auftrennung kurzkettiger, Lipid-verknüpfter Oligosaccharide 67 der Patientin M.S. und massenspektrometrische Analyse der Verbindungen

4.3 Molekularbiologische Untersuchungen $\quad 69$

4.3.1 Orthologe zum ALG2-Protein der Hefe 69

4.3.2 Überprüfung des humanen alg2-Locus' durch Sequenzierung 71

4.3.3 Identifizierung einer Mutation auf dem paternalen Allel $\quad 75$

4.3.4 Überprüfung der Expression der langen und kurzen alg2-Form 78 mittels Northern Blot

4.3.5 Expression der WT-cDNA und der $\triangle 1040 \mathrm{G}-\mathrm{cDNA}$ für die lange $\quad 80$ ALG2-Isoform in den Hautfibroblasten der Patientin

4.3.6 Zusammenfassung der Ergebnisse 81

5 Diskussion $\quad 82$

5.1 Die Unterglykosylierung von Glykanen der Patientin M.S. 82 basiert auf keinem der bisher bekannten CDG-Typen

5.2 Die molekulare Ursache der Erkrankung der Patientin M.S. ist 84 auf einen frühen Defekt in der Biosynthese Dolicholverknüpfter Oligosaccharide zurückzuführen

5.3 Die Überprüfung des humanen Orthologs zum Hefe alg2-Gen 89 der Patientin M.S. zeigte zwei Mutationen

5.4 Die Expression der WT-cDNA für die lange hALG2-Isoform in 92 den Patientenfibroblasten führte zur Normalisierung des Glykosylierungsmusters

6 Zusammenfassung 94

$7 \quad$ Ausblick 97

$8 \quad$ Literaturverzeichnis 98 


\section{Abkürzungsverzeichnis}

\begin{tabular}{|c|c|}
\hline Abb. & Abbildung \\
\hline Acc. No. & Accession Number \\
\hline ALG & Asparagine linked glycosylation \\
\hline Amp & Ampicillin \\
\hline$A P$ & Alkalische Phosphatase \\
\hline ATP & Adenosintriphosphat \\
\hline bp & Basenpaare \\
\hline BSA & Rinderserumalbumin \\
\hline bspw. & beispielsweise \\
\hline bzw. & beziehungsweise \\
\hline${ }^{\circ} \mathrm{C}$ & Grad Celsius \\
\hline CDG & Congenital Disorder(s) of Glycosylation \\
\hline CDGS & Carbohydrate Deficient Glycoprotein Syndrome \\
\hline cDNA & komplementäre DNA \\
\hline $\mathrm{Ci}$ & Curie $\left(2,22 \times 10^{6}\right.$ counts per minute $)$ \\
\hline cpm & counts per minute \\
\hline CTP & Cytidintriphosphat \\
\hline $\mathrm{Da}$ & Dalton \\
\hline $\mathrm{H}_{2} \mathrm{O}_{\text {bidest }}$ & doppelt destilliertes Wasser \\
\hline DMEM & Dulbecco's Modified Eagle Medium \\
\hline DNA & Desoxyribonukleinsäure \\
\hline dNTPs & Desoxyribonukleotide \\
\hline Dol & Dolichol \\
\hline Fuc & Fucose \\
\hline Gal & Galaktose \\
\hline GDP & Guanosindiphosphat \\
\hline GlcNAc & N-Acetylgalaktosamin \\
\hline GMP & Guanosinmonophosphat \\
\hline${ }^{3} \mathrm{H}$ & Tritium \\
\hline E.coli & Escherichia coli \\
\hline ER & Endoplasmatisches Retikulum \\
\hline et al. & et alii (lat. und andere) \\
\hline FKS & fötales Kälberserum \\
\hline G418 & Geneticin $^{\circledR} 418$ \\
\hline Glc & Glucose \\
\hline h & Stunde(n) \\
\hline${ }^{3} \mathrm{H}$ & Tritium \\
\hline HEPES & N-2-Hydroxyethylenpiperazin-N'-2-Ethansulfonsäure \\
\hline IPTG & Isopropylthio- $\beta-D-G a l a c t o p y r a n o s i d$ \\
\hline kbp & kilobasenpaare \\
\hline $\mathrm{kDa}$ & Kilo Dalton \\
\hline LB & Luria Broth \\
\hline LLO & lipid linked oligosaccharides \\
\hline $\mathrm{m}$ & milli \\
\hline M & molar \\
\hline Man & Mannose \\
\hline $\mathrm{mA}$ & milli Ampere \\
\hline
\end{tabular}




\begin{tabular}{|c|c|}
\hline MCS & multiple cloning site \\
\hline $\min$ & Minute(n) \\
\hline MOPS & Morpholinopropansulfonsäure \\
\hline$\mu$ & mikro \\
\hline mRNA & messenger-Ribonukleinsäure \\
\hline $\mathrm{n}$ & nano \\
\hline NANA & Sialinsäure \\
\hline neo & Neomycin \\
\hline OD & Optische Dichte \\
\hline${ }^{32} \mathrm{P}$ & Phosphor 32 \\
\hline$p$ & pico \\
\hline $\mathrm{P}$ & Phosphat \\
\hline p.a. & pro analysi (lat. zur Analyse) \\
\hline PBS & Phosphat-gepufferte Kochsalzlösung \\
\hline PCR & Polymerase-Ketten-Reaktion \\
\hline Pen/Strep & Penicillin/Streptomycin \\
\hline Pfu & Pyrococcus furiosus \\
\hline $\mathrm{pH}$ & negativer dekadischer Logarithmus der Protonenkonzentration \\
\hline PMI & Phosphomannose Isomerase \\
\hline PMM2 & Phosphomannomutase 2 \\
\hline PNS & Postnukleärer Überstand \\
\hline PP & Pyrophosphat \\
\hline RNA & Ribonukleinsäure \\
\hline RT & Raumtemperatur \\
\hline SDS & Natriumdodecylsulfat \\
\hline SSC & standard saline citrate \\
\hline Tab. & Tabelle \\
\hline Taq & Thermophilus aquaticus \\
\hline TBS & Tris-gepufferte Kochsalzlösung \\
\hline TCA & Trichloressigsäure \\
\hline TE & Tris-EDTA \\
\hline Tris & Tris(hydroxymethyl)-aminoacetat \\
\hline U & Unit \\
\hline ü. N. & über Nacht \\
\hline UDP & Uridindiphosphat \\
\hline $\mathrm{U} / \mathrm{min}$ & Umdrehungen pro Minute \\
\hline UTR & untranslated region (nicht-codierender Bereich) \\
\hline UV & ultraviolett \\
\hline V & Volt \\
\hline Vol. & Volumen \\
\hline $\mathrm{v} / \mathrm{v}$ & Volumenverhältnis \\
\hline WT & Wildtyp \\
\hline$w / v$ & Gewicht zu Volumen \\
\hline$x g$ & x-fache Erdbeschleunigung \\
\hline z.B. & zum Beispiel \\
\hline
\end{tabular}

Die chemischen Elemente wurden mit den üblichen Symbolen abgekürzt. Die Aminosäuren wurden entweder im Drei- oder im Ein-Buchstabencode angegeben.

Bei einigen Begriffen wurden die englischen Fachtermini verwendet, da auch in der deutschsprachigen Fachliteratur eine Übersetzung diese Begriffe unüblich und unzureichend ist. 


\section{Einleitung}

\subsection{Glykosylierung von Proteinen}

Die Glykosylierung von Proteinen stellt eine der häufigsten Formen der Proteinmodifikation in Tieren, Pflanzen und Bakterien dar. Glykoproteine treten in subzellulären Organellen wie dem endoplasmatischen Retikulum, dem Golgi, den Lysosomen, den Peroxisomen aber auch im Cytoplasma auf. Sie sind sowohl in zellulären Membranen als auch in extrazellulären Flüssigkeiten und Matrices vertreten. Glykoproteine greifen in eine Vielzahl lebenswichtiger Vorgänge wie Wachstum, Differenzierung, Entwicklung von Organen, Signalübertragung, Abwehr, Entzündung und maligne Entartung ein. Im Rahmen der Glykoproteinbiosynthese werden Kohlenhydratketten schrittweise durch eine Reihe von Glykosyltransferasereaktionen erzeugt und anschließend kovalent an Aminosäurereste eines Glykoproteins angeheftet. An der Glykosylierung von Proteinen sind mehr als 300 verschiedene Glykosyltransferasen, Glykosidasen und Transportproteine beteiligt. Die an ein Glykoprotein angehängten Kohlenhydratketten schützen das Protein vor Proteasen, sind für die Funktionalität, die korrekte Faltung, die Löslichkeit sowie den gerichteten Transport eines Proteins innerhalb einer Zelle als auch zu spezifischen Zielzellen mitverantwortlich (Varki et al., 1993). In interzellulären Prozessen sind die Kohlenhydratseitenketten beispielsweise bei der Fertilisation (Gabius et al., 1987), der Embryogenese (Lennarz et al., 1993) oder der Zelladhäsion von großer Bedeutung. Die Aufklärung einer ganzen Reihe von vererbten $\mathrm{N}$-Glykosylierungsdefekten beim Menschen in den letzten Jahren (s.u.) verdeutlicht die wichtige Funktion des Oligosaccharidanteils der Glykoproteine.

\subsection{Grundlagen der Protein-Glykosylierung}

Die Glykananteile von Glykoproteinen können in zwei Gruppen eingeteilt werden, die O-verknüpften Glykane und die N-verknüpften Glykane. Da die vorliegende Arbeit lediglich auf die $\mathrm{N}$-Glykansynthese eingeht, wird im Folgenden nur eine kurze Zusammenfasung zu den O-Glykanen gegeben.

\subsubsection{O-Glykane}

O-Glykane lassen sich abhängig von der Verknüpfung zwischen ihren Zucker- und Aminosäurereste in drei Hauptgruppen unterteilen. Bei der häufigsten Form der O- 
Glykane in tierischen Zellen, handelt es sich um Glykane des Muzin-Typs, bei denen die N-Acetylgalaktosaminreste auf Serin- oder Threoninreste übertragen werden. Der Muzin-Typ ist beispielsweise für die glatte Beschaffenheit von Epithelien sowie für die Ausbildung einer Barriere zwischen epithelialem Gewebe und Körperflüssigkeiten verantwortlich. Darüberhinaus gibt es den O-GlcNAc-Typ, bei dem NAcetylglucosamin mit Serin oder Threonin verknüpft wird sowie den Xylulose-Typ, bei dem dieser Zucker an Serin- oder Threoninreste in Proteoglykanen gebunden ist.

\subsubsection{N-Glykane}

Die Biosynthese N-glykosidisch verknüpfter Glykoproteine erfolgt kotranslational am endoplasmatischen Retikulum sowie im Golgi-Apparat. Zunächst wird ein komplexes Oligosaccharid an dem Isoprenderivat Dolicholphosphat (Dol-P), das in die Membran des endoplasmatischen Retikulums inseriert ist, schrittweise zusammengesetzt (siehe Abb. 1).

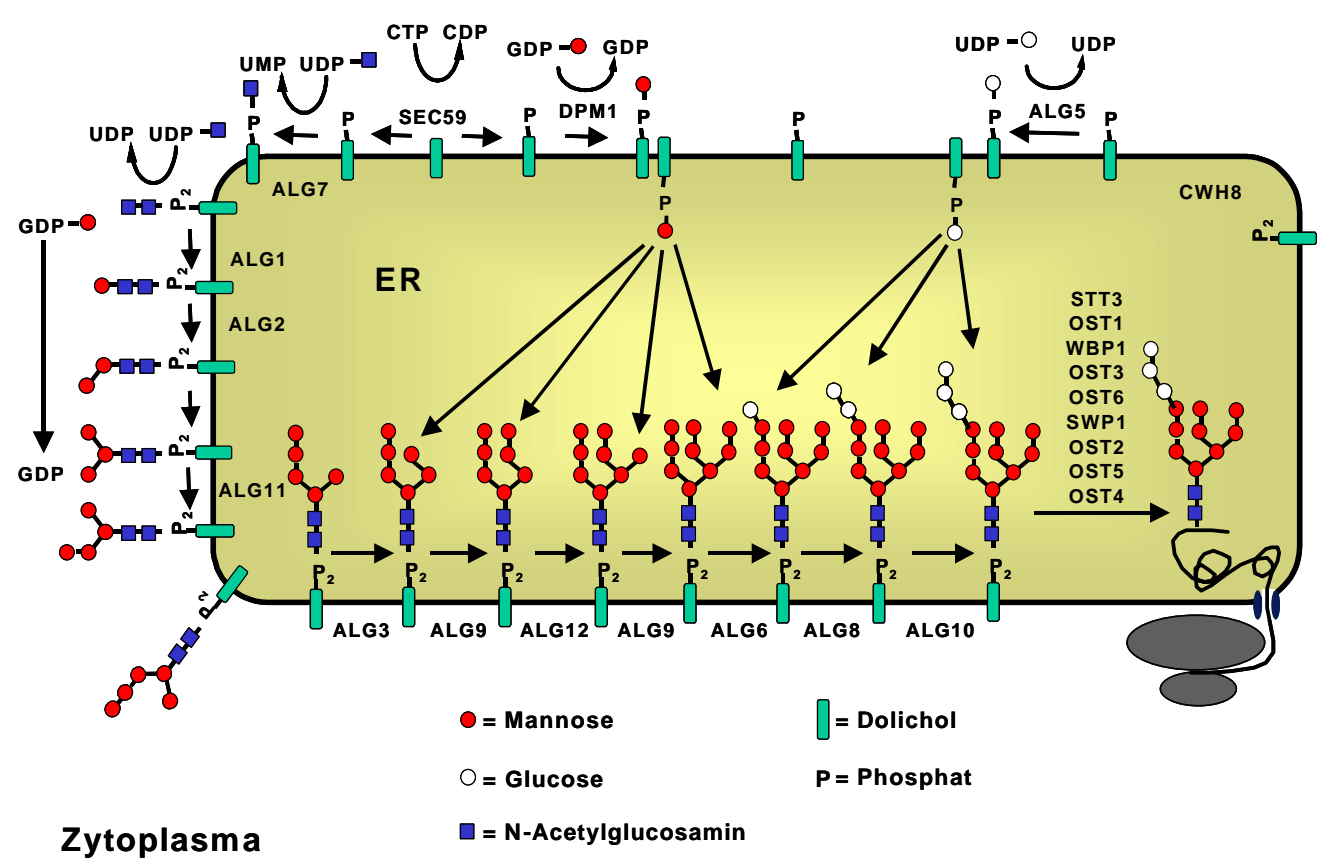

Abb. 1: N-Glykosylierungsschritte im endoplasmatischen Retikulum

Dargestellt ist die Biosynthese lipidverknüpfter Oligosaccharide sowie die Übertragung auf naszierende Proteine im ER. Die Enzymnamen entsprechen der Nomenklatur für Saccharomyces cerevisiae (ALG = Asparagine Linked Glykosylation).

Das Dolicholphosphat ist dabei so in die Membran integriert, dass sich der Phosphatrest auf der cytosolischen Seite des ER befindet. Auf den Phosphatrest wird zunächst ein N-Acetyl-glucosamin-1-phosphat-Rest von dem Donor UDP- 
GlcNAc übertragen, so dass N-Acetylglucosaminyl-pyrophosphoryl-Dolichol entsteht (Dol-PP-GlcNAc). An das N-Acetylglucosamin wird im nächsten Reaktionsschritt ein weiterer GlcNAc-Rest gebunden (Dol-PP-GlcNAc ${ }_{2}$ ). Nachfolgend werden schrittweise 5 Mannosereste von dem Donor GDP-Mannose auf den Akzeptor Dol-PP-GlcNAc 2 übertragen, wodurch das Intermediat Dol-PP-GlcNAc${ }_{2}-M^{-} n_{5}$ entsteht. Die Mannosereste sind in $\alpha-1,3-, \alpha-1,6$ und $\alpha-1,2-S t e l l u n g$ miteinander verbunden Durch die Reaktion der Flippase erfolgt eine Translokation des an DolicholPyrophosphat gebundenen Saccharids in das Lumen des ER. Hier werden nacheinander weitere 4 Mannose- sowie 3 Glucosereste durch verschiedene Mannosyltransferasen und Glucosyltransferasen übertragen. Mannosereste werden dazu im Cytoplasma von GDP-Mannose auf Dolichol-Phosphat übertragen, bevor sie an diesem Lipidcarrier in das Lumen des ER transportiert (geflippt) und von Mannosyltransferasen auf das noch unvollständige lipidverknüpfte Oligosaccharid übertragen werden (Dol-PP-GlcNAc $-\mathrm{Man}_{9}$ ). Die Glucosereste werden in einer vergleichbaren Reaktion von UDP-Glucose im Cytoplasma auf Dolichol-Phosphat übertragen, ins Lumen des ER geflippt und von spezifischen Glucosyltransferasen endständig auf das zu synthetisierende lipidverknüpfte Oligosaccharid (Dol-PP$\mathrm{GlcNAc}_{2}-\mathrm{Man}_{9} \mathrm{Glc}_{3}$ ) übertragen (Hirschberg et al., 1998). Das vollständige Oligosaccharid wird anschließend unter Freisetzung von Dolichol-Pyrophosphat durch die Oligosaccharyltransferase (OST) en bloc auf einen Asparaginrest der wachsenden Polypeptidkette übertragen, der sich innerhalb der Aminosäuresequenz aus Asp-X-Ser oder Asp-X-Threonin befindet, wobei $X$ jede Aminosäure mit Ausnahme von Prolin darstellen kann. Nur etwa ein Drittel der möglichen Asp-X-Ser/ Thr-Erkennungsstellen eines Proteins werden tatsächlich glykosyliert (Kornfeld und Kornfeld, 1985). Durch die $\alpha$-Glucosidasen I und II sowie durch die ERMannosidase I werden noch im ER die drei Glucose- und ein Mannosereste wieder abgespalten. Die korrekte Faltung der Glykoproteine wird in einer Wechselwirkung der UDP:Glucose:Glykoprotein-Transferase mit dem Chaperon Calnexin und der $\alpha$ llGlucosyltransferase sichergestellt (Tatu und Helenius, 1997). Nach dem vesikulären Transport der Glykoproteine zum Golgi erfolgt im cis-Golgi dann das weitere Trimming durch die Abspaltung von 3 Mannoseresten durch die GolgiMannosidase I. 


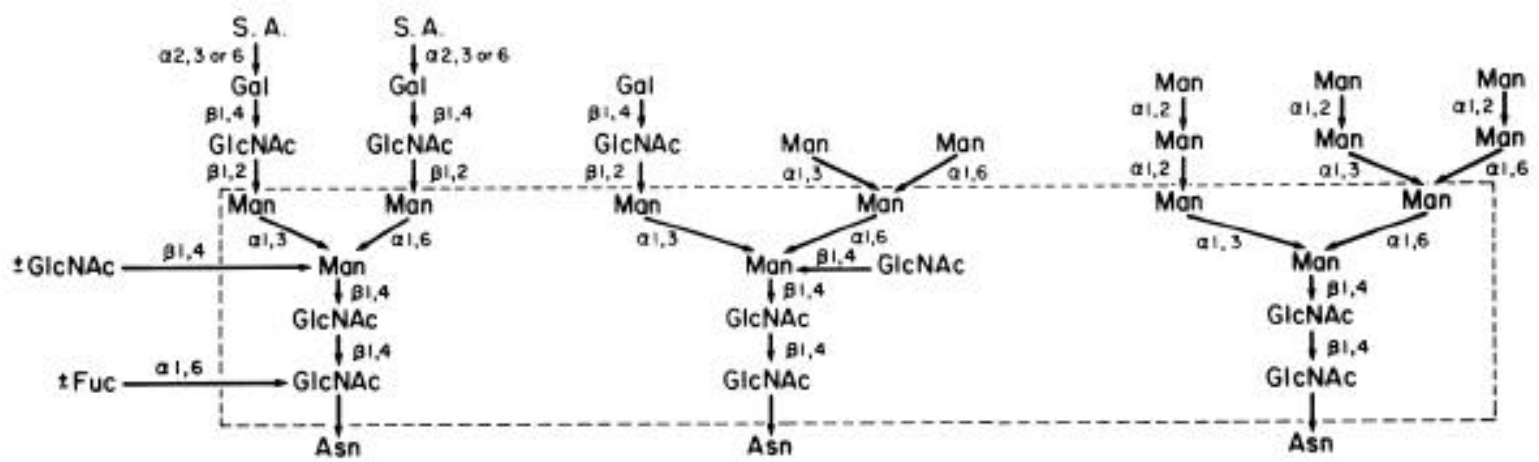

Abb. 2: Die Haupttypen der Asparagin-verknüpften Oligosaccharide

Innerhalb der gestrichelt-markierten Fläche befindet sich die Pentasaccharid Core-Struktur, die allen N-Glykanen gemeinsam ist. S.A.=Sialinsäure

Die Aminosäuresequenz des jeweiligen Glykoproteins entscheidet darüber, ob das daran gebundene $\mathrm{N}$-glykosidische Oligosaccharid in ein komplexes, ein hybrides oder ein Mannose-reiches Oligosaccharid umgewandelt wird. So wird bei der Synthese von komplexen N-glykosidischen Oligosacchariden, den bei Vertebraten am häufigsten auftretenden extrazellulären N-Glykanen, an die Kernregion aus NAcetylglucosamin und Mannose hauptsächlich im medialen und trans-Golgi-Komplex mit Hilfe spezifischer Glykosyltransferasen die für das jeweilige Glykoprotein spezifischen peripheren Saccharidreste aus drei N-Acetylglucosamin-, drei Galaktose-, einen Fucose- oder auch drei Sialinsäurereste (NANA-Reste) angeheftet. Kann dagegen die Golgi-Mannosidase I nicht mit dem an das Protein gebundenen Oligosaccharid aus $\mathrm{GlCNAc}_{2}-\mathrm{Man}_{8}$ reagieren, entsteht ein Mannosereiches Oligosaccharid. Die dabei entstehenden Oligosaccharide der verschiedenen Typen können eine unterschiedliche Anzahl von Antennen tragen (Kornfeld und Kornfeld, 1985), so dass sich in Bezug auf die Oligosaccharidstruktur an Glykoproteinen eine große Diversität ergibt.

\subsection{Defekte in der N-Glykosylierung}

Die Glykosylierung von Proteinen spielt eine wichtige Rolle bei einer Vielzahl von biologischen Prozessen. Angeborene Defekte, die die Synthese oder die Prozessierung der Glykanstrukturen von Glykoproteinen betreffen, führen beim Menschen zumeist zu multisystemischen Defekten, die mit schweren psychomotorischen und neurologischen Retardierungen einhergehen. Sie wurden bis 1999 als 'Carbohydrate Deficient Glykoprotein Syndrom (CDGS)' bezeichnet. Da 
man davon ausgehen kann, dass in Zukunft ebenfalls Defekte in der Synthese anderer Glykokonjugate wie bspw. Glykolipide oder Proteoglykane gefunden werden, erfolgte eine Umbenennung der Krankheit von CDGS in die allgemeinere Bezeichnung 'Congenital Disorders of Glykosylation' ('First International Workshop on CDGS' in Leuven/ Belgien, 1999). Die Congenital Disorders of Glykosylation werden in zwei Typen unterteilt. CDG I kennzeichnet dabei alle Defekte in der NGlykansynthese, die im Cytosol und im ER auftreten können, einschließlich des Transfers des Dolichol-verknüpften Oligosaccharids auf das neusynthetisierte Glykoprotein durch die Oligosaccharyltransferase. Unter CDG II werden alle nachfolgenden Defekte des Trimmings und der Elongation im ER oder Golgi zusammengefasst.

Tab.1: Zusammenstellung der bisher bekannten 11 CDG-Defekte

\begin{tabular}{|c|c|c|c|c|}
\hline Name & $\begin{array}{l}\text { Gen- } \\
\text { Defekt }\end{array}$ & Betroffenes Enzym & OMIM $^{*}$ & Jahr \\
\hline CDG-la & PMM2 & $\begin{array}{l}\text { Phosphomannomutase } \\
\text { (Man-6-P zu Man-1-P) }\end{array}$ & $212065 ; 601785$ & 1997 \\
\hline CDG-Ib & $P M I$ & $\begin{array}{ll}\text { Phosphomannose } & \text { Isomerase } \\
\text { (Fru-6-P- zu Man-6-P) } & \end{array}$ & $602579 ; 154550$ & 1998 \\
\hline CDG-Ic & ALG6 & alpha-1-3-Glucosyltransferase & $603147 ; 604566$ & 1998 \\
\hline CDG-Id & ALG3 & alpha-1-3-Mannosyltransferase & 601110 & 1999 \\
\hline CDG-Ie & DPM1 & $\begin{array}{l}\text { Dol-P-Man Synthase } 1 \\
\text { (GDP-Man zu Dol-P-Man) }\end{array}$ & 603503 & 1999 \\
\hline CDG-If & LEC35 & nicht bekannt & 604041 & 2001 \\
\hline CDG-Ig & ALG12 & alpha-1-6-Mannosyltransferase & --- & 2002 \\
\hline CDG-IIa & MGAT2 & $\begin{array}{l}\text { B1-2-N-Acetylglucosaminyl- } \\
\text { transferase }\end{array}$ & $212066 ; 602616$ & 1996 \\
\hline CDG-IIb & GLS1 & alpha-1-2 Glucosidase & 601336 & 2000 \\
\hline CDG-IIC & $\begin{array}{l}\text { GDP- } \\
\text { FUC-TP }\end{array}$ & $\begin{array}{l}\text { Import of GDP-Fuc in den Golgi und } \\
\text { Export von GMP }\end{array}$ & $266265 ; 605881$ & 2001 \\
\hline CDG-IId & $\begin{array}{l}\text { B-1,4- } \\
\text { GalTr }\end{array}$ & B1-4-Galaktosyltransferase I & 607091 & 2002 \\
\hline
\end{tabular}

*OMIM=online Mendelian inheritance in man (www.ncbi.nlm.nih.gov/) 
Seit der belgische Kinderarzt Jaak Jaeken 1980 die ersten Patienten mit einem Defekt in der N-Glykansynthese beschrieben hat (Jaeken et al., 1980), konnten die molekularen Ursachen von 11 verschiedenen CDG-Typen aufgeklärt werden (siehe Tabelle 1). Hierbei handelt es sich um bisher 7 CDG I-Typen (Typ la bis Ig) sowie 4 Erkrankungen, die unter CDG II zusammengefasst werden (Typ Ila bis Ild).

CDG-Verdachtspatienten werden im Allgemeinen auf eine Veränderung der Glykosylierung ihres Serum-Transferrins hin untersucht. Dieses Glykoprotein trägt normalerweise zwei biantennäre sialylierte Oligosaccharide vom komplexen Typ, die aufgrund der terminalen Sialinsäurereste negativ geladen sind (Abb. 3).

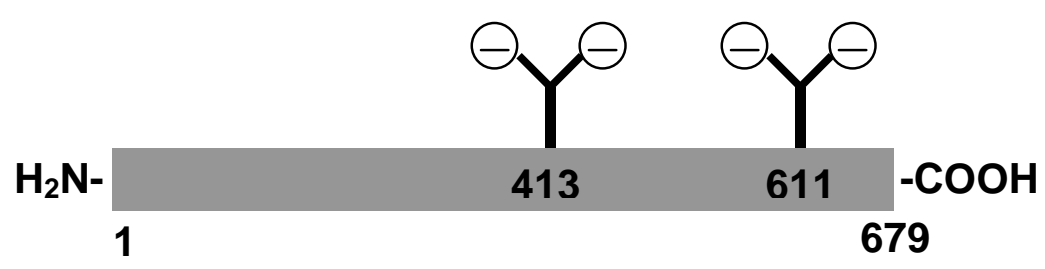

Abb. 3: Schematische Darstellung des humanen Serum-Transferrins

Das Serum-Transferrin ist an den Asparaginresten 413 und 611 jeweils mit einem biantennären $\mathrm{N}$ Glykan vom komplexen Typ verknüpft und trägt vier terminale negativ geladene Sialinsäurereste (MacGillivray et al., 1983).

Fehlen aufgrund eines Glykosylierungsdefektes des Patienten eine oder beide Ketten, kommt es zu einer Ladungsverschiebung und folglich zu einer Veränderung des isoelektrischen Punktes des Proteins. Diese Verschiebung kann mit Hilfe der isoelektrischen Fokussierung (IEF) nachgewiesen werden. Die Analyse der Transferrinbanden mit Hilfe der IEF ist zum CDG-Standardsuchtest geworden.

\section{CDG-la}

CDG-la ist der sowohl am längsten bekannte als auch der am häufigsten vorkommende Typ unter den 'Congenital Disorders of Glykosylation'. Etwa 80\% aller CDG-Patienten leiden unter diesem Typ (ca. 300 Erkrankte weltweit). CDG-la wird durch die verminderte Aktivität der Phosphomannomutase II hervorgerufen (siehe Abb. 4) (van Schaftingen und Jaeken, 1995). Das PMM2-Protein setzt im Cytosol Mannose-6-Phosphat in Mannose-1-Phosphat um, welches für die Synthese von GDP-Mannose, GDP-Fukose und Dolichol-P-Mannose benötigt wird (Kepes und Schekman, 1988; Hansen et al., 1997). Durch die verminderte Bereitstellung von GDP-Mannose und Dol-P-Mannose kommt es bei CDG-la-Patienten zu einer 
Verkürzung der Dolichol-verknüpften Oligosaccharide (Powell et al., 1994; Körner et al., 1998a), die ein schlechtes Substrat für die Oligosaccharyltransferase darstellen, was zum partiellen Verlust kompletter Zuckerketten auf reifen Glykoproteinen führt (Yamashita et al., 1993). Die verminderte Enzymaktivität der PMM2 konnte auf Mutationen im pmm2-Gen zurückgeführt werden, das beim Menschen auf Chromosom 16p13 lokalisiert ist (Matthijs et al., 1997). Bis heute wurden 69 verschiedene Mutationen im pmm2-Gen gefunden (Matthijs et al., 2000; Westphal et al., 2001). Auffällig ist, dass bei allen bisher identifizierten Mutationen eine Restaktivität von PMM2 beobachtet wurde, was Anlaß zu der Vermutung gibt, dass ein totaler Aktivitätsverlust der Phosphomannomutase unvereinbar mit dem Leben ist (Matthijs et al., 1998). Durch den PMM2-Defekt kommt es bei CDG-la-Patienten zum Verlust einer oder beider Oligosaccharidketten des Serum-Transferrins und folglich zu einer Verschiebung des isoelektrischen Punktes des Transferrins aufgrund fehlender Sialinsäurereste (Jaeken et al., 1984). Klinisch präsentieren sich die laPatienten durch geistige und körperliche Behinderung, Muskelschwäche, Ataxie, Gedeih- und Entwicklungsstörungen, invertierte Brustwarzen und Fettansammlungen an Oberarmen und Gesäß. Weiterhin kann es zu Störungen im Leberstoffwechsel, zu Blutgerinnungsproblemen und Herzfunktionsstörungen kommen (zur Übersicht siehe: de Lonlay et al., 2001). Die Sterblichkeitsrate liegt aufgrund dieser Probleme in den ersten 6 Jahren bei ca. 20\%. Mit fortschreitendem Alter findet eine Stabilisierung des Gesundheitszustandes statt (Jaeken und Carchon, 1993). Obwohl sich die NGlykosylierung von Fibroblastenzellen von CDG-la-Patienten durch Mannosezugabe ins Zellkulturmedium bzw. Reduktion der Glucosekonzentration im Medium auf ein Zehntel des normalen Wertes normalisierte (Panneerselvam et al., 1996; Körner et al., 1998b), führte eine Therapie von CDG-la-Patienten durch die orale Gabe von Mannose zu keiner Verbesserung ihres Gesundheitszustandes (Mayatepek u. Kohlmueller, 1998).

\section{CDG-Ib}

Eine der wenigen therapierbaren CDG-Erkrankungen ist der CDG-Typ Ib, der 1998 von Niehues et al. zum ersten Mal beschrieben worden ist. Biochemisch ist hier die Phosphomannose Isomerase (PMI) betroffen, ein cytosolisches Protein, das Fruktose-6-Phosphat zu Mannose-6-Phosphat umsetzt und somit der Reaktion der 
bei CDG-la betroffnenen Phosphomannomutase direkt vorgeschaltet ist (siehe Abb. 4).

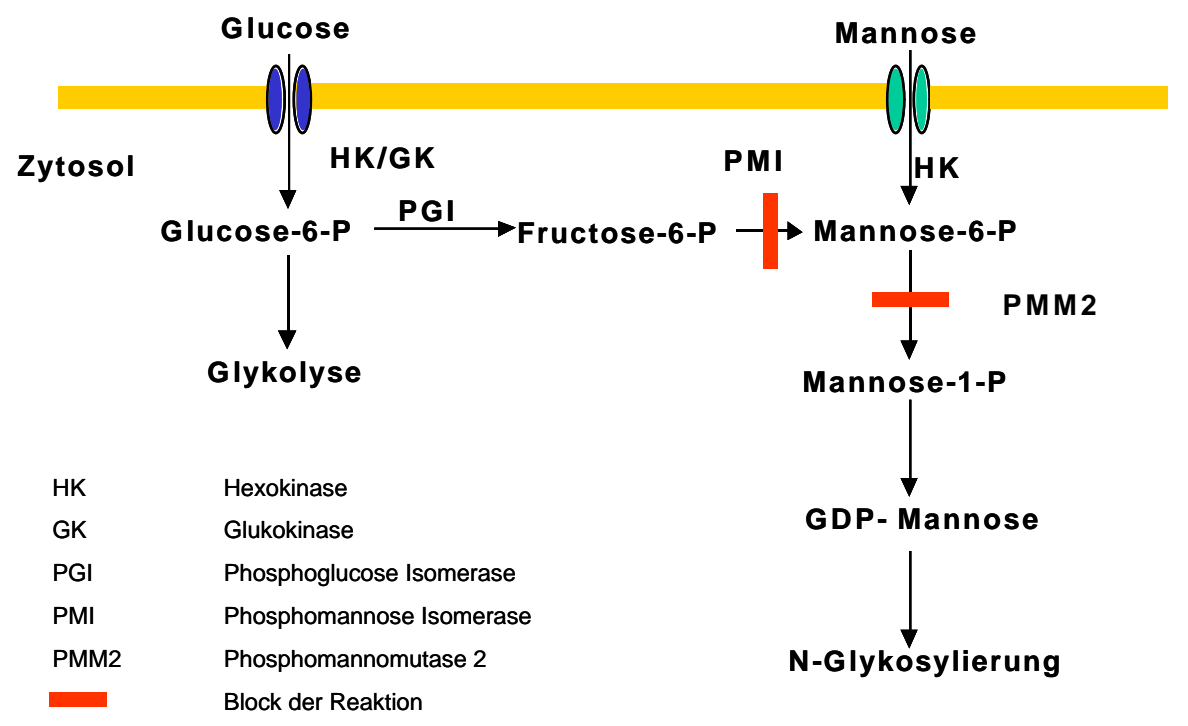

\section{Abb. 4: Schematische Darstellung der enzymatischen Defekte von CDG-la und CDG-Ib}

Glucose und Mannose können über Transportproteine ins Zytosol transportiert und durch HK und GK phosphoryliert werden. Glu-6-P kann anschließend durch PGI zu Fru-6-P umgesetzt werden. Die PMI katalysiert die Umwandlung von Fru-6-P zu Man-6-P. Diese Reaktion ist bei CDG-Ib-Patienten stark reduziert (Balken). Bei CDG-la ist die Umwandlung von Man-6-P zu Man-1-P aufgrund eines partiellen Defektes der PMM2 stark vermindert (Balken), was zu einem verminderten GDP-Man-Pool führt.

CDG-lb-Patienten leiden unter chronischer Diarrhoe mit enteropathischem Proteinverlust. Die Darmblutungen können ein lebensbedrohliches Ausmaß annehmen. Im Vergleich zu CDG-la zeigen die Patienten keine mentalen oder psychomotorischen Defekte. In der IEF gleicht CDG-Ib dem Muster von CDG-la (Niehues et al., 1998). die Therapier von CDG-lb erfolgt durch die orale Gabe von Mannose, wobei sich die Mannosekonzentration im Blut erhöht. Mannose wird in Folge verstärkt über einen mannosespezifischen Transporter in die Zellen aufgenommen und unabhängig von PMI von der Hexokinase in Mannose-6Phosphat umgewandelt (Paneerselvam et al., 1997; Niehues et al., 1998).

\section{CDG-Ic}

CDG-Ic ist der nach CDG-la bisher am häufigsten diagnostizierte CDG-Typ. CDG-Ic wird durch die verminderte Aktivität der Dol-P-Glc:Man ${ }_{9}-$ GlcNAc$_{2}-P P-D o l i c h y l$ Glucosyltransferase hervorgerufen (Körner et al., 1998c), was auf Mutationen in dem entspechenden Gen, das nach dem Ortholog in der Hefe Saccharomyces cerevisiae 
als humanes ALG6 bezeichnet wird, zurückgeführt werden konnte (Imbach et al., 1999; Hanefeld et al., 2000). Das aktive Zentrum dieses Membranproteins befindet sich im Lumen des ER, wo es den ersten Glucoserest vom Donorsubstrat Dol-P-Glc auf das Oligosaccharidintermediat Man ${ }_{9} \mathrm{GlcNAc}_{2}$-PP-Dolichyl überträgt (siehe Abb. 5). CDG-Ic Patienten zeigen eine Akkumulation dieses Intermediats (Körner et al., 1998c), das ein schlechtes Substrat für die Oligosaccharyltransferase darstellt (Turco et al., 1977). Auf neusynthetisierte Glykoproteine werden daher nur die wenigen vollständigen Oligosaccharide übertragen, die auf Grund der hALG6-Restaktivität vom Patienten synthetisiert werden, so dass nicht alle N-Glykosylierungsstellen besetzt werden können. Auch das Serum-Transferrinmuster dieses CDG-Typs ähnelt in der IEF dem des CDG-la (Körner et al., 1998c). Klinisch zeigen CDG-Ic-Patienten im Vergleich zu CDG-la-Patienten weniger stark ausgeprägte neurologische Defekte. Charakteristisch für diesen CDG-Typ sind die auftretenden Krampfanfälle während der Infektionsintervalle.

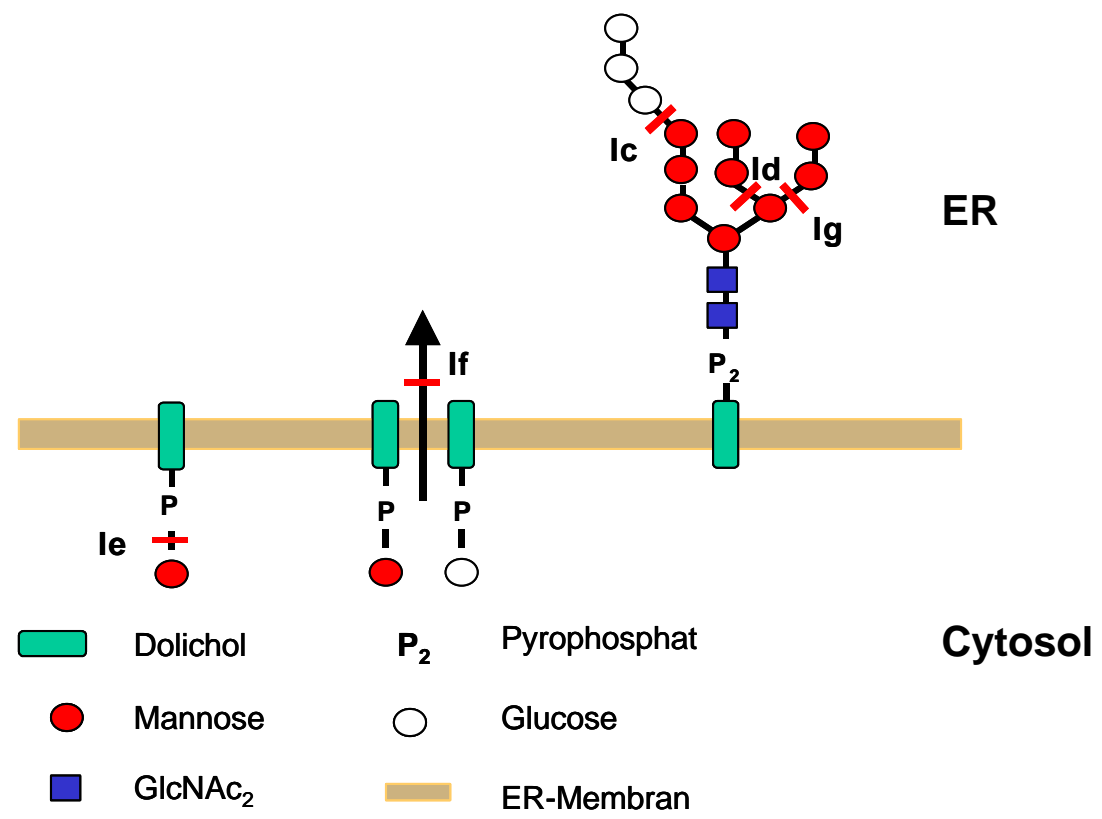

Abb. 5: Schematische Darstellung der CDG-Typen Ic bis Ig im endoplasmatischen Retikulum Die Abbildung zeigt die molekulare Ursache der CDG-Defekte Ic bis Ig, die durch Balken angezeigt werden. Die verwendeten Symbole sind in der Abbildung definiert.

\section{CDG-Id}

Durch die verminderte Aktivität der Dol-P-Man:Man 5 -GlcNAc 2 -PP-Dolichyl Mannosyltransferase aufgrund einer homozygoten Mutation im korrespondierenden Gen für dieses Protein kommt es im Lumen des ER zu einer Akkumulation des 
Intermediates $\mathrm{Man}_{5}$-GlcNAc${ }_{2}$-PP-Dol (siehe Abb. 5). Der einzige bisher bekannte Patient zeigt in der IEF des Serum-Transferrins einen teilweisen Verlust kompletter N-Glykanketten. Neusynthetisierte Glykoproteine des Patienten, die aus Fibroblasten isoliert worden waren, wiesen einen Anteil von weniger als $20 \%$ an vollständig übertragenen Oligosacchariden auf (Körner et al., 1999). Weiterhin ließen sich sowohl Man ${ }_{5}-\mathrm{GlCNAC}_{2}-$ als auch der $\mathrm{G}_{1}-\mathrm{Man}_{5}-\mathrm{GlcNAc}_{2}$-Oligosaccharide auf neusynthetisierten Glykoproteinen identifizieren, da beide Formen von der Oligosaccharyltransferase übertragen werden können (Körner et al., 1999a; Rearick et al., 1981). Der Patient zeigte schwere Krampfanfälle direkt nach der Geburt. Der inzwischen 9-jährige Junge leidet unter einer sehr eingeschränkten psychomotorischen Entwicklung, Skelettdeformationen, Sehstörungen und Mikrozephalie.

\section{CDG-le}

CDG-le-Patienten zeigen wie die CDG-Id-Patienten eine Akkumulation von $\mathrm{Man}_{5-}$ $\mathrm{GlcNAc}_{2}-\mathrm{PP}$-Dol. Die isoelektrische Fokussierung des Serumtransferrins weist eine starke disialo- aber nur eine schwache asialo-Bande auf. Verantwortlich hierfür ist ein Defekt in der cytosolischen Untereinheit der Dolichol-P-Man Synthase (DPM I), so dass zuwenig Dol-P-Mannose synthetisiert wird (siehe Abb. 5), welches für die Anheftung der 4 Dolichol-verknüpften Mannosereste im Lumen des ER notwendig ist. Die Patienten sind schwerstbehindert, zeigen kaum neurologische Entwicklung und leiden unter schweren Epilepsien (Imbach et al., 2000; Kim et al., 2000).

\section{CDG-If}

Durch Mutationen im Lec35-Gen, dessen korrespondierendes Protein für die Nutzbarmachung von Dolichol-P-Mannose und Dolichol-P-Glucose in den Zellen benötigt wird (Anand et al., 2001), kommt es in den Patientenfibroblasten zu einer Akkumulation unvollständiger Oligosaccharide im ER und zu einer Übertragung kompletter wie auch von verkürzter $\mathrm{Glc}_{3} \mathrm{Man}_{9}-\mathrm{GlCNAc}_{2}$-Oligosaccharide auf Glykoproteine (siehe Abb. 5). Klinisch zeigen die Patienten eine schwere geistige Behinderung. Sie sind nicht in der Lage zu sprechen und es wurde ein Augenleiden beobachtet, das bis zur Erblindung führen kann. Weiterhin sind sie oftmals von einer schuppenden Hauterkrankung (Ichtyosis) betroffen und können unter Zwergwuchs leiden (Schenk et al., 2001; Kranz et al., 2001). 


\section{CDG-Ig}

Die molekulare Ursache von CDG-lg konnte als Defekt des Enzyms Dol-PMan:Man ${ }_{7} \mathrm{GlcNAc}_{2}$-PP-Dolichyl-Mannosyltransferase, welches das humane Ortholog zur ALG12-Mannosyltransferase von Saccharomyces cerevisiae darstellt (hALG12), identifiziert werden. Dieses Enzym katalysiert die Übertragung von Mannoseresten vom Donorsubstrat Dol-P-Man auf Man GlcNAc $_{2}$-PP-Dolichyl im Lumen des ER (siehe Abb. 5) (Burda et al., 1999). Durch Mutationen im Gen des hALG12 kommt es bei CDG-Ig-Patienten zu einer verminderten Aktivität des Enzyms und nachfolgend zu einer Akkumulation von $\mathrm{Man}_{7} \mathrm{GlcNAc}_{2}$-PP-Dol (Thiel et al., 2002; Chantret et al., 2002; Grubenmann et al., 2002). Der Verlust kompletter N-Glykanketten führt zu einem typischen CDG-I isoelektrischen Fokussierungsmuster des SerumTransferrins. Allerdings ist die Unterglykosylierung des Transferrins bei CDG-IgPatienten weniger stark ausgeprägt als bei CDG-la-Patienten (Thiel et al., 2002).

CDG-Ig-Patienten zeigen eine verzögerte mentale und motorische Entwicklung. Sie leiden unter Mikrozephalie, muskulärer Hypotonie, verlängerter partieller Thromboplastinzeit, supraglutealen Fettpolstern und dysmorphen Gesichtsveränderungen wie verformten Ohren und verkürztem Filtrum (Nasenrinne).

\section{CDG-Ila}

CDG-Ila wurde 1991 als erster Defekt vom CDG-Typ im Golgi-Apparat lokalisiert (Ramaekers et al., 1991). 1994 konnte der genetische Defekt in dem Gen für die UDP-GlcNAc:á-6-D-Mannosid-B1,2-N-Acetylglucosaminyltransferase II (GlcNAcTII) identifiziert werden (Jaeken et al., 1994). Dieses Enzym überträgt einen NAcetylglucosaminrest auf den á 1,6-Arm der N-Glykan-Kernsequenz, so dass nachfolgend die weitere Glykosylierung des mit einem N-Acetylglucosaminrestes besetzten Arms durch Galaktosyl- und Sialyltransferasen erfolgen kann (siehe Abb.6). Die Übertragung des $\mathrm{N}$-Acetylglucosaminrestes ist notwendig für eine biantennäre Struktur der Oligosaccharide neusynthetisierter Glykoproteine. CDG-IlaPatienten können lediglich monoantennäre Oligosaccharide durch die Aktivität der NAcetylglucosaminyltransferase I bilden. Innen fehlt somit die Hälfte der negativen Ladungen auf ihrem Serum-Transferrin, so dass die IEF eine verstärkte Disialo- und keine Tetrasialotransferrinbande zeigt (Jaeken et al., 1994). Klinisch zeichnet sich dieser Defekt durch schwerste Entwicklungsstörungen, eine generelle Hypotonie und 
Gliederschwäche aus. Eine periphere Neuropathie wird im Gegensatz zu CDG-la nicht beobachtet. Auch ist das Kleinhirn normal angelegt (Ramaekers et al., 1991).

A)

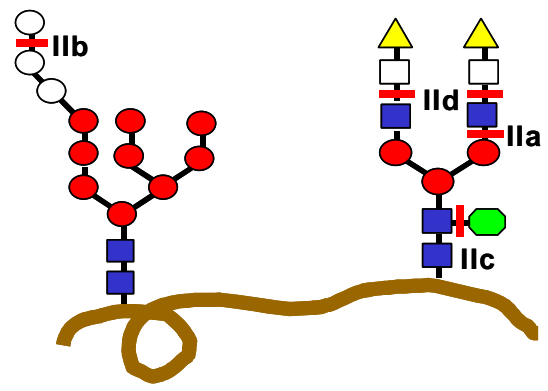

B)

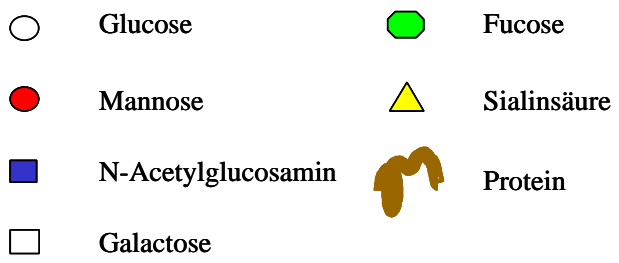

Abb. 6: Übersicht der CDG-Typen Ila, Ilb, Ilc und Ild im ER und Golgi

A) zeigt ein vollständig glykosyliertes Dolichol-verknüpftes Oligosaccharid im ER. B) zeigt ein reifes Oligosaccharid nach Trimming und Elongation im Golgi. Die CDG-Defekte Ila bis Ild sind durch Balken in den betreffenden Oligosacchariden dargestellt, die die Übertragung der weiteren Monosaccharide blockieren. Die verwendeten Symbole sind in der Abbildung erklärt.

\section{CDG-IIb}

CDG-Ilb ist durch den Defekt der ER-Glucosidase I gekennzeichnet. Die Glucosidase I katalysiert im ER, direkt nach der Übertragung des vollständigen $\mathrm{Glc}_{3} \mathrm{Man}_{9} \mathrm{GlcNAc}_{2}$ Oligosaccharids vom Dolichol-PP-Carrier auf das naszierende Polypeptid durch die Oligosaccharyltransferase, die Abspaltung des dritten Glucoserestes (siehe Abb. 6). $\mathrm{Da}$ aus bislang ungeklärten Gründen die Glykosylierung des Serum-Transferrin durch diesen Defekt nicht verändert wird, zeigt sich in der IEF keine Auffälligkeit. Der einzige bisher bekannte Patient litt unter Krampfanfällen, verminderter Nervenleitgeschwindigkeit, Muskelhypotonie, dysmorphen Veränderungen sowie Leberfunktionsstörungen (de Praeter et al., 2000).

\section{CDG-IIc}

Die molekulare Ursache für CDG-IIc konnte biochemisch auf den verminderten Import von GDP-Fucose in den Golgi-Apparat und die damit verbundene Unterfucosylierung von Glykoproteinen zurückgeführt werden (Lübke et al., 1999; siehe Abb. 6). Mit Hilfe einer retroviralen Komplementationsklonierungsstrategie konnte der genetische Defekt im Gen für den Golgi-GDP-Fucosetransporter nachgewiesen werden (Lübke et al., 2001). Im Austausch gegen GMP transportiert dieser Transporter an GDP-gebundene Fucose in den Golgi-Apparat. Patienten, 
deren Proteine aufgrund des Defektes unterfucosyliert sind, zeigen eine verzögerte geistige und körperliche Entwicklung, Mikrozephalie, kortikale Atrophie, Hypotonie sowie wiederkehrende, lebensbedrohliche Infektionen bei einer persistierenden Leukozytose. (Etzioni et al., 1992; Frydman et al., 1992; Marquardt et al., 1999).

Neben CDG-lb stellt CDG-Ilc den zweiten, zumindest partiell therapierbaren CDGTyp dar. Durch die orale Gabe von Fucose war es möglich, den erhöhten Leukozytenspiegel der behandelten Patienten auf ein normales Maß zu senken und die ständigen Infektionen zu unterbinden (Marquardt et al., 1999), allerdings zeigte sich bisher keine Normalisierung der geistigen Retardierung. In der IEF des SerumTransferrins von CDG-Ilc-Patienten läßt sich dieser Defekt nicht nachweisen, da die N-Glykane des Transferrins keine Fucosereste aufweisen.

\section{CDG-IId}

Ein Defekt des im Golgi lokalisierten Enzyms UDP-Gal:N-Acetylglucosamin-ß-1,4Galaktosyltransferase I (B1,4GalT I) ist die molekulare Ursache für CDG-Ild (Hanßke et al., 2002). Dieses Enzym katalysiert die Übertragung von Galaktose vom Donorsubstrat UDP-Galaktose auf die $\mathrm{C}_{4}$-Hydroxylgruppe von $\mathrm{N}$ Acetylglucosaminresten im Golgiapparat (siehe Abb. 6). Im einzigen bisher bekannten Patienten kommt es durch einen Baseneinschub im Gen für die B1,4GalT I zu einem vorzeitigen Translationsstop und damit zu einem verkürzten, inaktiven Protein, das nicht in den Golgi-Apparat transportiert wird, sondern im ER verbleibt. Das IEF-Muster des Serum-Transferrins des Patienten zeigte hauptsächlich asialo-, monosialo- sowie disialo-Formen aufgrund von fehlenden Sialinsäuren und Galaktoseresten. Der Patient leidet unter mentaler Retardierung, einem Hydrocephalus, Blutgerinnungsproblemen sowie einer Muskelschwäche auf Grund einer Muskeldystrophie (Peters et al., 2002). 


\section{Problemstellung}

Die 'Congenital Disorders of Glycosylation (CDG)' umfassen zur Zeit eine Gruppe von elf verschiedenen molekularen Defekten der Glykoproteinbiosynthese beim Menschen, die in Abhängigkeit der zellulären Lokalisation der Defekte in CDG-I und CDG-II untergliedert werden. Im Rahmen der CDG-Routinediagnostik wurden in den letzten Jahren in unserer Arbeitsgruppe neben bereits bekannten Typen eine Reihe von CDG-Verdachtspatientinnen/en entdeckt, bei denen die molekulare Ursache ihrer Erkrankung bisher ungeklärt ist. Eine dieser Patientinnen steht im Mittelpunkt der vorliegenden Arbeit.

Vorbefunde der Patientin M.S., die mittels isoelektrischer Fokussierung und WesternBlot erzielt wurden, weisen auf eine Erkrankung des CDG-I Typs hin, die mit dem partiellen Verlust kompletter N-Glykanseitenketten am Markerprotein SerumTransferrin einhergehen. Die bisher bekannten sieben CDG-I Typen können entweder enzymatisch (CDG-la und CDG-lb) oder mittels HPLC-Analyse verkürzter [2-- $\left.{ }^{3} \mathrm{H}\right]$ Mannose-markierter Dolichol-verknüpfter Oligosaccharide (CDG-Ic, -ld, -le, -If und -lg) identifiziert werden. Im Falle unserer Patientin konnten mit den herkömmlichen Methoden alle bekannten CDG-I Typen ausgeschlossen werden.

Auf Grund dieser Vorbefunde kommen als mögliche molekulare Ursachen für die unvollständige N-Glykosylierung des Serum-Transferrins der Patientin zum einen ein Defekt in der Übertragung kompletter Oligosaccharidketten auf das naszierende Protein durch den Enzymkomplex der Oligosaccharyltransferase in Frage. Zum anderen besteht die Möglichkeit eines Defekts in den initialen Schritten der Biosynthese Dolichol-verknüpfter Oligosaccharide, wie beispielsweise der Übertragung der ersten beiden GlcNAc-Reste auf den Carrier Dolichol-Pyrophosphat oder der ersten Mannosereste auf Dol-PP-GIcNAc 2 .

Ziel dieser Arbeit ist es, die molekulare Ursache des Glykosylierungsdefekts unserer Patientin M.S. zu beschreiben. Dabei soll der Defekt zunächst biochemisch mit Hilfe der HPLC, Dünnschichtchromatographie und Massenspektrometrie näher charakterisiert und auf einen bestimmten Bereich der N-Glykosylierung eingegrenzt werden, um anschließend die genetische Ursache identifizieren zu können. Sollte im Rahmen dieser Arbeit ein defektes Gen gefunden werden, soll nachfolgend durch Komplementationsstudien mit Hilfe eines retroviralen Expressionssystems die Funktionalität der entsprechenden Mutation in den Patientenfibroblasten überprüft werden. 


\section{Materialien und Methoden}

\subsection{Materialien}

\subsubsection{Geräte}

Analysenwaagen Typ 1602 MP und M5P

Typ Technoclav 50

Brutschrank Typ 2771

Dounce- Homogenisator

Drehrad für Eppendorfgefäße

DNA-Sequenzer Typ 310

Analysegerät für Dünnschicht-

chromatogramme

Eismaschine

Elektrophoresekammern für Agarosegele

Flüssigkeitsszintillationszähler 1900TR

Filmentwicklungsmaschine Gevamatic60

Gefrierschrank $-80^{\circ} \mathrm{C}$

Heizblock 5320

HPLC

Inkubator, wasserummantelt,

geregelte $\mathrm{CO}_{2}$-Atmosphäre

Inkubationsschüttler Modell G25

Durchlicht Mikroskop

Fluoreszenzmikroskop Axiovert 100

Magnetrührer IKA-Combimag Ret

Mikrowellenherd

Multipett, Combitips

Multiphor II-Kammer

MultiTemp

Peristaltikpumpe, P1

$\mathrm{pH}-$ Meter
Sartorius AG, Göttingen

Tecnomara, Zürich, Schweiz

Heraeus, Osterode,

Köttermann, Häningsen

Wheaton, USA

Eigenbau, Werkstatt d. Instituts

ABI, PE Biosystems

Berthold, Tracemaster 20

Ziegra, Isernhagen

Eigenbau, Werkstatt d. Instituts

Packard, Frankfurt

Agfa-Gevaert, Leverkusen

Colora Messtechnik, Lorch

Eppendorf, Hamburg

Waters, Eschborn

Forma Scientific, Marietta, USA

New Brunswick Scientific Edison, USA

Zeiss, Oberkochen

Zeiss, Oberkochen

Janke \& Kunkel, Staufen

Bosch, Stuttgart

Eppendorf, Hamburg

Amersham Pharmacia Biotech AB

Amersham Pharmacia Biotech AB

Pharmacia, Uppsala, Schweden

Beckman, München 
Photometer UV 160A

Refraktometer

Schüttelwasserbad

Semi-Dry-Blot-System

Spannungsgeräte

Spektralphotometer Modell Uvikon 810

Sterilbank, Typ A/B3

Thermoprinter, Typ P91E

Transilluminator Modell IL400M

Typ Gene Amp PCR System 2400

Ultraschall-Desintegrator Sonifier W-450

Vortex Genie

Waagen Typ 1264MP und 1265

Wärmeschrank

Wasserbad Typ HOR 7225

Wipptisch

Zentrifugen:

Biofuge Fresco

Eppendorfzentrifuge 5402 und 5415

Kühlzentrifuge J-21C und J2-MC

Kühlzentrifuge Sorvall RC-5B

Labofuge GL

Megafuge 1.0

Rotoren für die Kühlzentrifuge:

JA-10 Rotor

JA-20 Rotor

Ultrazentrifuge L80
Shimadzu, Kyoto, Japan

Schmidt, Haensch

Köttermann, Häningsen, Göttingen

cti $\mathrm{GmbH}$, Idstein/ Taunus

Hölzel, München

Kontron, Eching

Baker Company, Inc., USA

INTAS Mitsubishi, Tokio, Japan

Bachofer, Reutlingen

Perkin Elmer Cetus, Norwalk, USA

Branson Ultrasonic SA, Carouge-

Geneve, USA

Bender \& Hobein, Zürich, Schweiz

Sartorius AG, Göttingen

Memmert, Schwabach

Köttermann, Häningsen

Eigenbau, Werkstatt d. Instituts

Heraeus Sepatech, Osterode

Eppendorf, Hamburg

Beckman, München

DuPont Instruments, Bad Homburg

Heraeus Sepatech, Osterode

Heraeus Sepatech, Osterode

Beckman, München

Beckman, München

Beckman, München

National Lab, Mölln

Nunc, Wiesbaden

Neoject, Gelnhausen

Braun, Melsungen

3.1.2 Verbrauchsmaterialien

Einfrierkästen

Einfrierröhrchen

Einmalkanülen

Einmalspritzen 
4-, 6-, 24-well Zellkulturplatten

Gewebekulturschalen 35, 60, 100, 150 mm

Glaskolben 100 ml, 250 ml, 1000 ml

IEF Electrode Strip

IEF/SDS applicator strip

Immersionsöl 518C

Kanülen (steril), 26G, 20G

Linsenpapier MN 10B

Nitrocellulose Blotting Membran 0,2 $\mu \mathrm{m}$

Objektträger und Deckgläschen

Parafilm

Pasteurpipetten

Plastikröhrchen, $10 \mathrm{ml}, 50 \mathrm{ml}$

Plastikpipetten steril $(2,5,10,25 \mathrm{ml})$

Plastik-Petrischalen $(10 \mathrm{~cm})$

Reaktionsgefäße $(0,2 ; 0,5 ; 1,5 ; 2,0 \mathrm{ml})$

Röntgenfilme, XAR-5

$1 \mathrm{ml}$ Spritze, steril

Skalpelle, steril

Sterilfilter $0,2 \mu \mathrm{m}$ und $0,45 \mu \mathrm{m}$

Whatman 3 MM-Papier

Zentrifugenbecher:

JA-10 u. JA-20, Polypropylen
Greiner, Nürtingen

Greiner, Nürtingen

Schott, Mainz

Amersham Pharmacia Biotech AB

Amersham Pharmacia Biotech AB

Zeiss, Oberkochen

Braun, Melsungen

Machery-Nagel, Düren

Sartorius AG, Göttingen

Menzel Gläser

American National, Neenah, USA

Schütt, Göttingen

Greiner, Nürtingen

Greiner, Nürtingen

Sarstedt, Nürmbrecht

Sarstedt, Nürmbrecht

Kodak, Stuttgart

Sherwood, Ballymoney, Irland

Braun, Melsungen

Sartorius AG, Göttingen

Whatman Vertrieb, Göttingen

Beckman bzw. Nalgene, München

\subsubsection{Chemikalien}

Sofern nicht anders angegeben, wurden Chemikalien der Firmen Aldrich Chemical Company (Milwaukee, USA), Baker (Deventer, Niederlande), BioRad (München), Boehringer (Mannheim), Calbiochem (Frankfurt), Fluka (Buchs, Schweiz), GIBCO/ BRL (Eggenstein), Merck (Darmstadt), Pharmacia (Freiburg), Sigma (Deisenhofen), Serva (Heidelberg) und Roth (Karlsruhe) mit dem Reinheitsgrad "p.a." oder "reinst" verwendet.

Aceton

Adneosintriphosphat
Merck

Merck 
Agar

Sigma

Agarose

Sigma

Albumin aus Rinderserum

Serva

Ammoniummolybdat

Merck

Ascorbinsäure

Sigma

ATP

Sigma

Bacto-Hefe-Extrakt

Difco

Bacto-Trypton

Difco

Bromphenolblau

BioRad

5-Bromo-4-chloro-3-indolylphosphat-

Sigma

p-toluidin (BCIP)

Calciumchlorid

Merck

Chloroform

Merck

Fluorescent Mounting Medium

DAKO

Dextransulfat

Pharmacia

Dinatriumhydrogenphosphat

Merck

DMSO

Merck

EDTA- $\mathrm{Na}_{2} \times \mathrm{H}_{2} \mathrm{O}$

Merck

Essigsäure

Merck

Ethanol

Merck

Ethanolamin

Merck

Ethidiumbromid

Serva

Flüssigszintillator Rotiszint eco plus

Roth

Folin-Ciocalteus Reagenz

Merck

Formaldehyd-Lösung

Merck

Formamid

Fluka

Glucose

Merck

Glycerin

Merck

$\mathrm{H}_{2} \mathrm{O}$ (HPLC rein)

Merck

HEPES

Serva

Imidazol

Merck

Isoamylalkohol

Merck

Isopropanol

Merck

Kaliumacetat

Merck 
Kaliumchlorid

Merck

Kaliumhydrogenphosphat

Merck

Kupfersulfat

Merck

Levamisol

Sigma

Manganchlorid

Merck

Magnesiumsulfat

Merck

Methanol

Roth

MOPS

Serva

Mowiol

Calbiochem

Natriumacetat

Merck

Natriumazid

Sigma

Natriumcarbonat

Merck

Natriumchlorid

Merck

Natriumcitrat

Merck

Natriumdihydrogenphosphat

Merck

Natriumdodecylsulfat

Sigma

Natriumhydrogencarbonat

Merck

Natriumhydroxid

Merck

Natriumhydrogenphosphat

Merck

Natrium-Kalium-Tartrat

Merck

Nitroblau-tetrazolium (NBT)

Sigma

Ovalbumin

Sigma

Paraformaldehyd

Sigma

Phenol

Merck

Phospho-Wolfram-Säure

Sigma

Polybrene

Sigma

Salzsäure

Merck

Schwefelsäure

Merck

Sucrose

Merck

Trichloressigsäure

Merck

Tris-(hydroxymethyl)-aminomethan

Merck

Trypanblau

Boehringer 


\subsubsection{Detergenzien}

Triton-X-100

Sigma, Deisenhofen

\subsubsection{Enzyme, DNA- und Proteinstandards, Antibiotika}

1 kb-DNA Ladder

Ampicillin

DNAse I

Geneticin (G418)

HotStarTaq-DNA-Polymerase

Oligonukleotide (PCR)

Penicillin/ Streptomycin

Pfu-Turbo-DNA-Polymerase

Phosphatase, alkalische, CIP

Proteinase $\mathrm{K}$

Rainbow Marker

Braunschweig

Restriktionsendonukleasen

Reverse Transcriptase (Omniscript)

T4-DNA-Ligase

Taq-DNA-Polymerase

Trypsin aus Rinderpankreas

Ultrapur dNTP Set
Gibco BRL, Eggenstein

Calbiochem, Frankfurt

Boehringer, Mannheim

Gibco BRL, Eggenstein

Qiagen, Hilden

IBA-NAPS, Göttingen

Gibco BRL, Eggenstein

Stratagene, Heidelberg

Boehringer, Mannheim

Boehringer, Mannheim

Amersham Life Science,

Boehringer, Mannheim

New England Biolabs, USA

MBI Fermentas, St. Leon Roth

Qiagen, Hilden

MBI Fermentas, St. Leon Roth

MBI Fermentas, St. Leon Roth

Boehringer, Mannheim

MBI Fermentas, St. Leon Roth

\subsubsection{Kits zur Bearbeitung von DNA und RNA}

FuGENE6 Transfektionsreagenz

RediPrime II DNA Labelling Kit

QIAquick DNA Purification Kit

QiaPlasmid Mini Kit

QiaPlasmid Midi Kit

QiaPCR-Purification-Kit

Quick-Change in-vitro-Mutagenese Kit

QIAquick Nucleotide Removal Kits
Roche, Mannheim

Amersham Pharmacia, Braunschweig

Qiagen, Hilden

Qiagen, Hilden

Qiagen, Hilden

Qiagen, Hilden

Stratagene, Heidelberg

Qiagen, Hilden 
RNeasy Mini Kit

HotStarTaq-Polymerase Kit

TA-Vektor-Cloning Kit

ABI PRISM Dye Terminator
Qiagen, Hilden

Qiagen, Hilden

Promega, Madison, USA

Perkin Elmer Cetus, Norwalk, USA

\subsubsection{EDV}

Hardware

Apple Macintosh LCII

Apple Computer

Apple LaserWriter 16/600 PS

Apple Computer

CanoScan D660U Scanner

Canon

Lexmark Optra SC 1275

Lexmark

Gericom Notebook P4

Gericom Computer

Software

Adobe Photoshop 5.5

Adobe Systems Inc.

DNA Star

DNASTAR Inc.

Windows

Microsoft

Windows Office 98

Microsoft

Image Reader

Fuji

Image Gauge 3.0

Fuji

Kaleidagraph Grafikprogramm

Synergy Software

\subsubsection{Antikörper}

Rabbit-Anti-Human-Transferrin (Primärantikörper)

Goat-Anti-Rabbit, HRP-gekoppelt (Sekundärantikörper)

\subsubsection{Radioaktive Substanzen}

$\alpha-\left[{ }^{32} \mathrm{P}\right]-\mathrm{dCTP}$, Redivue (3000 Ci/mmol)

Amersham-Buchler, Braunschweig

[2- $\left.{ }^{3} \mathrm{H}(\mathrm{N})\right]-\mathrm{D}-M a n n o s e(15-30 \mathrm{Ci} / \mathrm{mmol})$

NEN Life Science Prod. Incorp.,

Zaventem, Belgien

\subsubsection{Vektoren}

pBluescript SK II (-)

Stratagene, Heidelberg

pGEM-T-Easy

Promega, Madison, USA

pLNCXII

Clontech, Heidelberg 


\subsubsection{Bakterienstämme}

Folgende Bakterienstämme wurden routinemäßig zur Transformation von PlasmidDNA eingesetzt.

E. coli XL1-Blue (Genotyp: $\mathrm{F}^{-}:: \operatorname{Tn} 10 \operatorname{proA}^{+} \mathrm{B}^{+}$lacl $^{\mathrm{p}} \Delta$ (lacZ)M15/recAl endAI gyrA96(Nal) thi hsdR17 $\left(\mathrm{r}_{\mathrm{K}}^{-} \mathrm{m}_{\mathrm{K}}{ }^{+}\right)$supE44 relAl lac)

E. coli DH5-Alpha (Genotyp: $\mathrm{F}^{-}$deoR recAl endAI hsdR1 $\left(\mathrm{r}_{\mathrm{k}}{ }^{-} \mathrm{m}_{\mathrm{k}}{ }^{+}\right)$supE44 1-thi gyrA96 relAl

Genotypbezeichnung: siehe Bachmann (1987)

\subsubsection{Zelllinien}

primäre Fibroblasten

\begin{tabular}{|l|l|l|}
\hline \multicolumn{1}{|c|}{ Zelllinie } & \multicolumn{1}{|c|}{ Beschreibung } & \multicolumn{1}{c|}{ Referenz } \\
\hline Patientin M.S. & $\begin{array}{l}\text { Primäre Fibroblasten aus einer Oberarm- } \\
\text { Hautbiopsie der Patientin M.S. }\end{array}$ & diese Arbeit \\
\hline Vater K.S. & $\begin{array}{l}\text { Primäre Fibroblasten aus einer Oberarm- } \\
\text { Hautbiopsie des Vater K.S. }\end{array}$ & diese Arbeit \\
\hline $\begin{array}{l}\text { 6 Kontroll- } \\
\text { Fibroblastenzell- } \\
\text { linien }\end{array}$ & $\begin{array}{l}\text { Primäre Fibroblasten aus Oberarm- } \\
\text { Hautbiopsien der verschiedenen } \\
\text { Kontrollpersonen. }\end{array}$ & $\begin{array}{l}\text { Körner et al., } \\
1999-2001\end{array}$ \\
\hline
\end{tabular}

Retrovirale Verpackungszelllinien

\begin{tabular}{|l|l|l|}
\hline \multicolumn{1}{|c|}{ Zelllinie } & \multicolumn{1}{|c|}{ Beschreibung } & \multicolumn{1}{|c|}{ Referenz } \\
\hline FNX-Eco (ATTC, & Retrovirale, ecotrope Verpackungszellinie & Nolan et al., \\
durch Prof. G. & (293T, primäre, humane & Stanford \\
Nolan, Stanford, & Nierenepithelzellen). Stabil transfiziert mit \\
USA, lizensiert) & a) Moloney GagPol-IRES-Lyt2 (Hygro- & University \\
Selektion) und b) ecotrope Moloney & \\
Hüllprotein (Diptheria-Selektion) & \\
(Clontech) & $\begin{array}{l}\text { Dualtrope, retrovirale Verpackungszelllinie } \\
\text { (NIH 3T3-Derivate); Expression des } \\
\text { dualtropischen Hüllproteins 10A1 (DHFR- } \\
\text { Selektion); Moloney GagPol (TK-Selektion) }\end{array}$ & Miller und Miller, \\
\hline
\end{tabular}


Stabil transfizierte humane, primäre Fibroblasten

\begin{tabular}{|l|l|l|}
\hline \multicolumn{1}{|c|}{ Zelllinie } & \multicolumn{1}{|c|}{ Beschreibung } & \multicolumn{1}{c|}{ Referenz } \\
\hline Patientin M.S. & $\begin{array}{l}\text { Primäre Fibroblasten der Patientin M.S. } \\
\text { stabil transfiziert mit mock (LNCXII-Vektor), } \\
\text { mutierter-alg2-cDNA und WT-alg2-cDNA }\end{array}$ & diese Arbeit \\
\hline $\begin{array}{l}\text { Kontrollfibro- } \\
\text { blastenzelllinie }\end{array}$ & $\begin{array}{l}\text { Primäre Fibroblasten einer Kontrolle stabil } \\
\text { transfiziert mit mock (LNCXII-Vektor) }\end{array}$ & $\begin{array}{l}\text { Körner et al., } \\
1999-2001\end{array}$ \\
\hline
\end{tabular}

\subsubsection{Standardpuffer und -lösungen}

10xPBS

TBS

Hanks

$50 \times T A E$

$10 \%$ SDS
$80 \mathrm{~g} \mathrm{NaCl}$

$1,6 \mathrm{~g} \mathrm{Na}_{2} \mathrm{HPO}_{4}$

ad $800 \mathrm{ml} \mathrm{H}_{2} \mathrm{O}_{\text {bidest, }} \mathrm{pH} 7,4$

ad $1000 \mathrm{ml} \mathrm{H}_{2} \mathrm{O}_{\text {bidest }}$

10mM Tris/ HCl, $\mathrm{pH} 7,4$

$150 \mathrm{mM} \mathrm{NaCl}$

$8 \mathrm{~g} \mathrm{NaCl}$

$0,4 \mathrm{~g} \mathrm{KCl}$

$0,06 \mathrm{~g} \mathrm{KH}_{2} \mathrm{PO}_{4}$

$0,35 \mathrm{~g} \mathrm{NaHCO}_{3}$

1g Glucose

ad $1000 \mathrm{ml} \mathrm{H}_{2} \mathrm{O}_{\text {bidest }}$

$\mathrm{pH} \mathrm{7,4}$

2M Tris-Base

100mM EDTA

$\mathrm{pH}$ 8,0 mit Eisessig

$10 \mathrm{~g}$ Natriumdodecylsulfat/ $100 \mathrm{ml} \mathrm{H}_{2} \mathrm{O}_{\text {bidest }}$ 
$20 \times$ SSC

$175,3 \mathrm{~g} \mathrm{NaCl}$

$88,2 \mathrm{~g} \mathrm{Na}-\mathrm{Citrat}$

ad $1000 \mathrm{ml} \mathrm{H}_{2} \mathrm{O}_{\text {bidest }}$

$\mathrm{pH} 7,0$

10x TE

100mM Tris/ HCl

10mM EDTA

$\mathrm{pH} 7,6$

50xDenhardts

$$
\begin{aligned}
& 1 \% \text { Ficoll } \\
& 1 \% \text { Polyvinylpyrrolidon } \\
& 1 \% \text { BSA }
\end{aligned}
$$

DEPC- $\mathrm{H}_{2} \mathrm{O}$

$0,1 \%$ Diethylpyrocarbonat (DEPC) in $\mathrm{H}_{2} \mathrm{O}_{\text {bidest }}$

Rühren über Nacht bei RT und autoklavieren

\subsubsection{Medien zur Anzucht von Escherichia coli}

Die im Anschluß aufgeführten Komplexnährmedien wurden für 20 Minuten bei $121^{\circ} \mathrm{C}$ autoklaviert. Für feste Medien wurde 1,5 \% (w/ v) Agar zugesetzt.

Nutrient Broth (NB)

Nutrient Broth

$8 \mathrm{~g}$

$\mathrm{H}_{2} \mathrm{O}_{\text {bidest }}$ ad $1000 \mathrm{ml}$

Luria-Bertani-Medium (LB) nach SAMBROOK et al. (1989)

Trypton $10 \mathrm{~g}$

Hefeextrakt

$\mathrm{NaCl}$

$\mathrm{H}_{2} \mathrm{O}_{\text {bidest }}$ ad $1000 \mathrm{ml}$

$\mathrm{pH} 7,5(\mathrm{NaOH})$

$\underline{\text { X-gal-Medium }}$

X-gal-Medium bestand aus LB-Medium mit den folgenden Zusätzen:

X-gal (2\% [w/v] in N,N'-Dimethylformamid)

Ampicillin

$2 \mathrm{ml} / 1000 \mathrm{ml}$

IPTG (0,2M Lösung) 


\subsubsection{Antibiotikum}

Die Ampicillin-Stammlösung wurde nach SAMBROOK et al. (1989) angesetzt, sterilfiltriert und aliquotiert in autoklavierten Eppendorf-Cups bei $-20^{\circ} \mathrm{C}$ gelagert. Der Zusatz der Ampicillin-Stammlösung zu den autoklavierten Nährlösungen erfolgte erst nach deren Abkühlung auf unter $50^{\circ} \mathrm{C}$, wobei eine Endkonzentration von $50 \mu \mathrm{g} / \mathrm{ml}$ eingestellt wurde.

Ampicillin-Stammlösung (Na-Salz) $\quad 100 \mathrm{mg} / \mathrm{ml}$ in $\mathrm{H}_{2} \mathrm{O}_{\text {bidest }}$ gelöst

\subsubsection{Zellkulturmedien und Lösungen zur Arbeit mit eukaryontischen Zellen}

\section{Gekaufte Medien und Lösungen}

Modified Eagle Medium (MEM)

Gibco BRL, Eggenstein

Dulbecco's Modified Eagle Medium (DMEM)

Gibco BRL, Eggenstein

Fötales Kälberserum (FKS)

Gibco BRL, Eggenstein

L-Glutamin (200mM)

Gibco BRL, Eggenstein

Trypsin-EDTA-Lösung

Gibco BRL, Eggenstein

$$
\begin{aligned}
& 0,05 \%(w / v) \text { Trypsin } \\
& 0,02 \%(w / v) \text { EDTA in } \\
& \text { modifizierter Puck's Salzlösung }
\end{aligned}
$$

Penicillin/ Streptomycin $(10.000 \mathrm{U} / \mathrm{ml}) \quad$ Gibco BRL, Eggenstein

\section{Selbst angesetzte Medien und Lösungen}

PBS für die Zellkultur $150 \mathrm{mM} \mathrm{NaCl}$

$$
\begin{aligned}
& 120 \mathrm{mM} \mathrm{KCl} \\
& 10 \mathrm{mM} \mathrm{Na}_{2} \mathrm{HPO}_{4} / \mathrm{KH}_{2} \mathrm{PO}_{4}, \mathrm{pH} 7,4 \\
& 0,002 \%(\mathrm{w} / \mathrm{v}) \text { Phenolrot }
\end{aligned}
$$

\section{Medien für die Kultivierung von FNX-Eco und AmphoPack PT67-Zellen}

DMEM (Gibco BRL, Eggenstein)

10\% (v/v) hitzeinaktiviertes FKS

2 mM L-Glutamin (Gibco BRL, Eggenstein)

$100 \mathrm{U} / \mathrm{ml}$ Penicillin/ Streptomycin 
Die Hitzeinaktivierung des FKS (Inaktivierung des Komplementsystems) erfolgte bei $56^{\circ} \mathrm{C}$ für $45 \mathrm{~min}$.

\subsection{Methoden}

\subsubsection{Methoden zur Arbeit mit bakteriellen Kulturen}

\subsubsection{Flüssigkulturen}

Die Zellanzucht von Bakterienstämmen im Komplexmedium erfolgte in Erlenmeyerkolben, deren Volumen dem 4- bis 10-fachen Kulturvolumen entsprachen, indem von einer bewachsenen Agarplatte eine Einzelkolonie mit der ausgeglühten Impföse abgenommen und in der jeweiligen Kulturflüssigkeit geschwenkt wurde. Die Kultivierung erfolgte bei $30^{\circ} \mathrm{C}$ oder $37^{\circ} \mathrm{C}$ in einem Schüttelinkubator oder Schüttelwasserbad.

\subsubsection{Plattenkulturen}

Die verwendeten Escherichia coli-Stämme wurden zur kurzfristigen Aufbewahrung auf geeigneten Agarplatten ausgestrichen und über Nacht bei $30^{\circ} \mathrm{C} \mathrm{bzw} .37^{\circ} \mathrm{C}$ inkubiert. Bei $4^{\circ} \mathrm{C}$ konnten die mit Parafilm umwickelten Plattenkulturen bis zu 4 Wochen aufbewahrt werden.

\subsubsection{Stammkonservierung und Reaktivierung}

Längerfristige Konservierungen von Stämmen erfolgten durch Anlegen von GlycerinStammkulturen. Von einer ausgewachsenen LB-Flüssigkultur mit Antibiotika wurden $830 \mu \mathrm{l}$ abgenommen und in sterile Schraubröhrchen, die mit $170 \mu \mathrm{l} 87 \%(\mathrm{v} / \mathrm{v})$ autoklaviertem Glycerin gefüllt waren, überführt. Nach der vollständigen Durchmischung erfolgte die Lagerung bei $-80^{\circ} \mathrm{C}$. Eine Reaktivierung von konservierten Stämmen wurde durch Ausstreichen auf Komplexagarplatten vorgenommen. Nach der Inkubation über Nacht bei $37^{\circ} \mathrm{C}$ erfolgte zur Reinheitskontrolle ein erneuter Ausstrich auf eine weitere Komplexagarplatte. Routinemäßig fand nach dem Anlegen einer Stammkultur einmal eine Reaktivierung statt, um sicherzustellen, daß sich die Kultur revitalisieren ließ. 


\subsubsection{Reinheitskontrollen}

Nach der Revitalisierung von Glycerin-Stammkulturen und vor dem Anlegen von Flüssigkulturen wurden Reinheitskontrollen durchgeführt. Hierbei erfolgte ein Ausstrich auf Agarplatten, wobei sich nach der Inkubation über Nacht bei $37^{\circ} \mathrm{C}$ im Brutschrank die Einheitlichkeit der Koloniebildung erkennen ließ. Flüssigkulturen wurden auf ihre Einheitlichkeit hin unter dem Mikroskop untersucht.

\subsubsection{Zelldichtebestimmungen}

Die Zelldichte einer Bakterienkultur wurde mit Hilfe eines Photometers bestimmt. Die Messung der optischen Dichte (OD) erfolgte bei einer Wellenlänge von $600 \mathrm{~nm}$.

\subsubsection{Zellernte}

Die Zellernte von Bakterienkulturen erfolgte in Abhängigkeit der Größe der Kulturvolumina. Kulturvolumina von 1,5 bis $2 \mathrm{ml}$ wurden in Eppendorf-Cups in einer Tischzentrifuge für $3 \mathrm{~min}$ bei $13000 \mathrm{U} / \mathrm{min}$ pelletiert. Zellkulturen mit einem Volumen von 10 bis $50 \mathrm{ml}$ konnten in sterilen Plastikröhrchen oder in JA-20Zentrifugenbechern durch Zentrifugation für $20 \mathrm{~min}$ bei $4000 \mathrm{U} / \mathrm{min}$ pelletiert werden. Noch größere Kulturvolumina wurden für $10 \mathrm{~min}$ bei $12000 \mathrm{U} / \mathrm{min}$ in JA-10Zentrifugenbechern pelletiert.

\subsubsection{Zellbiologische Methoden zur Arbeit mit eukaryontischen Kulturen}

\subsubsection{Kultivierung von eukaryontischen Zellen}

Die Zellen wurden in wassergesättigter Atmosphäre unter $5 \% \mathrm{CO}_{2}$ bei $37^{\circ} \mathrm{C}$ kultiviert. Medien und Lösungen wurden auf $37^{\circ} \mathrm{C}$ vorgewärmt, wenn nicht anders angegeben. Im allgemeinen erfolgte die Kultivierung der Zellen mit folgendem Medium:

DMEM +10\% FKS + 1x Penicillin/ Streptomycin + 1x L-Glutamin

Die viralen Verpackungszellen (FNX-Exo und AmphoPack PT67) wurden in DMEM + 10\% hitzeinaktiviertem FKS + 1x Pen/ Strep + 1x L-Glutamin gehalten . 


\subsubsection{Trypsinieren und Ernten von Zellen}

Das Passagieren der Zellen erfolgte routinemäßig nach Erreichen der Konfluenz des Zellrasens. Dazu wurde das Medium abgesaugt und die Zellen einmal mit PBS gewaschen. Nach Entfernen des PBS wurden die Zellen ca. 5min mit Trypsin/ EDTA bei $37^{\circ} \mathrm{C}$ bis zum Ablösen der Zellen (Mikroskop) inkubiert. Die Trypsin-Reaktion wurde durch Zugabe von serumhaltigem Medium gestoppt und die Zellen durch mehrfaches Pipettieren vereinzelt. Die Zellzahl pro Milliliter wurde mit der NeubauerZählkammer bestimmt. Die Zellen wurden in der gewünschten Dichte ausgesät oder zur weiteren Verarbeitung durch Zentrifugation (5min, 1000U/min in der Labofuge) pelletiert.

Trypsin-EDTA-Lösung

$$
\begin{aligned}
& \text { 0,05\% (w/v) Trypsin } \\
& 0,02 \%(w / v) \text { EDTA in modifizierter Puck's Salzlösung }
\end{aligned}
$$

\subsubsection{Kryokonservierung von Zellen}

Die einzufrierenden Zellen wurden trypsiniert, in Medium aufgenommen und in der Labofuge pelletiert ( $5 \mathrm{~min}$ bei $1000 \mathrm{U} / \mathrm{min}$ ). Der Überstand wurde entfernt und die Zellen in $1 \mathrm{ml}$ kaltem Einfriermedium aufgenommen und in beschriftete Kryoröhrchen überführt. Die Zellen wurden zunächst bei $-80^{\circ} \mathrm{C}$ für einen Tag eingefroren und anschließend in flüssigem Stickstoff gelagert.

Einfriermedium: $\quad 10 \%(v / v)$ DMSO in jeweiligem Zellkulturmedium.

\subsubsection{Auftauen und Revitalisieren von Zellen}

Nach der Entnahme des Kryoröhrchens aus dem Stickstofftank wurde es etwa 1min bei RT erwärmt und anschließend in $70 \%$ Ethanol bei $37^{\circ} \mathrm{C}$ aufgetaut bis nur noch ein kleiner Eiskern zu sehen war. Die Zellsuspension wurde mit einer gestopften Pasteurpipette vorsichtig entnommen, in $5 \mathrm{ml}$ kaltes Medium überführt und in der Labofuge für $5 \mathrm{~min}$ bei $1000 \mathrm{U} / \mathrm{min}$ sedimientiert. Der Überstand wurde abgezogen, das Zellpellet in $5 \mathrm{ml}$ kaltem Medium resuspendiert und in eine Zellkulturflasche überführt. Am nächsten Tag wurde das Medium gewechselt, um restliches DMSO, tote Zellen und Zelltrümmer zu entfernen. 


\subsubsection{Proteinbiochemische Methoden}

\subsubsection{Serumpräparation aus venösem Blut}

Zur Gewinnung von humanem Serum erfolgte die Blutentnahme aus einer Ellenbeugenvene. Das erhaltene Blut wurde $2 \mathrm{~h}$ bei RT zur Gerinnung inkubiert. Durch Zentrifugation bei $5000 \mathrm{~g}$ und RT für $10 \mathrm{~min}$ ließ sich das Serum als Überstand abpipettieren.

\subsubsection{Eisensättigung der Serumproben}

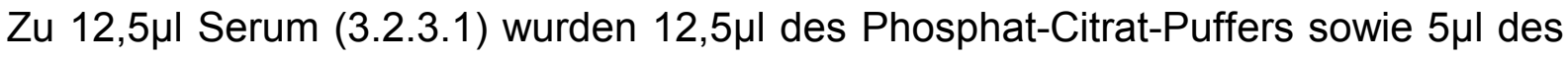
Eisenchloridpuffers hinzupipettiert. Dieser Ansatz wurde für $1,5 \mathrm{~h}$ bei $37^{\circ} \mathrm{C}$ im Heizblock inkubiert. Die eisengesättigten Proben wurden 1:50 mit $\mathrm{H}_{2} \mathrm{O}$ verdünnt.

Phosphat-Citrat-Puffer:

$0,05 \mathrm{M} \mathrm{NaH}_{2} \mathrm{PO}_{4} \times 2 \mathrm{H}_{2} \mathrm{O}$

0,02 M Natriumcitrat

$\mathrm{pH} 7,4$

Eisenchlorid-Puffer:

$2,4 \mathrm{mM} \mathrm{FeCl}_{3} \times 6 \mathrm{H}_{2} \mathrm{O}$

\subsubsection{Proteinbestimmung nach BRADFORD (1976), modifiziert}

Die Proteinbestimmung nach Bradford beruht auf der Bindung von Coomassie Brilliant Blue G-250 an Protein, wodurch ein Komplex entsteht und sich das Absorptionsmaximum proportional zum gebildeten Komplex von 465nm zu 595nm hin verschiebt. Zur Bestimmung der Proteinkonzentration wurde eine Eichgerade mit 0-20 $\mu \mathrm{g}$ Rinderserumalbumin aufgenommen. Die 20-40 $\mu$ l Proben wurden mit $1 \mathrm{ml}$ Bradford-Reagenz versetzt und 15 min bei RT inkubiert bevor die Extinktionsmessung bei $595 \mathrm{~nm}$ im Zeiss Photometer PM 4 (Firma Zeiss, Oberkochen) erfolgte.

Bradford-Reagenz: 100mg Brilliant Blue G-250 ad $50 \mathrm{ml} 96 \%(\mathrm{v} / \mathrm{v})$ Ethanol $100 \mathrm{ml} 85 \%(\mathrm{v} / \mathrm{v}) \mathrm{H}_{3} \mathrm{PO}_{4}$ 
Direkt vor dem Versuch werden 15\% (v/v) der Stammlösung werden. mit $85 \%$ (v/v) $\mathrm{H}_{2} \mathrm{O}_{\text {bidest }}$ versetzt.

\subsubsection{Isoelektrische Fokussierung von Serum-Transferrin}

Die isoelektrische Fokussierung (IEF) für humanes Serumtransferrin wurde nach Westermeier (1996, modifiziert) durchgeführt. Bei diesem Verfahren werden die Proteine gemäß ihres isoelektrischen Punktes aufgetrennt. Das humane Serumtransferrin verfügt über zwei N-Glykane des komplexen, biantennären Typs, mit 4 terminalen negativ geladenen Sialinsäuren. Diese Tetrasialo-Form stellt die Hauptform des Transferrins bei gesunden Menschen dar. Liegt aufgrund eines $\mathrm{N}$ Glykosylierungsdefekts ein Unterschied im Glykosylierungsmuster des Transferrins vor, wodurch die terminalen Sialinsäuren betroffen sind, so ist ein von der Norm abweichendes Laufverhalten in der IEF zu erkennen.

\section{Vorbereiten des Gels}

Ein GelBond Film mit einer Größe von 124mm x 258mm wurde mit der hydrophoben Seite nach unten auf eine angefeuchtete Glasplatte mit entsprechender Größe gedrückt und die Gelkammer anschließend mit einer zweiten Glasplatte komplett zusammengebaut und bei $60^{\circ} \mathrm{C}$ inkubiert. In einem Erlenmeyerkolben wurden $2 \mathrm{~g}$ Sorbitol mit $19 \mathrm{ml} \mathrm{H}_{2} \mathrm{O}$ und $0,16 \mathrm{~g}$ Agarose vermischt und der Ansatz samt Kolben ausgewogen. In der Mikrowelle wurde der Ansatz solange aufgekocht, bis sich die Agarose und das Sorbitol vollständig gelöst hatten. Das verdampfte $\mathrm{H}_{2} \mathrm{O}$ wurde aufgefüllt, der Ansatz mit einer Wasserstrahlpumpe entgast und auf $70^{\circ} \mathrm{C}$ abgekühlt. Unter Rühren wurden 1,3ml Ampholine ( $\mathrm{pH}$ 5-7) in den Erlenmeyerkolben hinzupipettiert. Der Ansatz wurde zwischen die Glasplatten pipettiert, anschließend erfolgte das Auspolymerisieren für $2 \mathrm{~h}$ bei RT. Vor Durchführung der IEF wurde das Gel in vier gleichgroße Teile zurechtgeschnitten (jeweils in der Größe von 6,4mm x $12,4 \mathrm{~mm})$. Als Laufkammer wurde die Multiphor II verwendet, die durch die MultiTemp konstant auf $10^{\circ} \mathrm{C}$ gehalten wurde. Nach Applikation von ein paar Tropfen $\mathrm{H}_{2} \mathrm{O}$ wurde das Gel symmetrisch auf die Multiphor II-Kammer platziert. Ein 6,4mm langer, in 0,25M NaOH Lösung getränkter Kathodenstreifen (IEF Electrode Strip) sowie ein 6,4mm langer, in 0,25M Essigsäure getränkter Anodenstreifen (IEF Electrode Strip) wurden nach Abtropfen an die Enden des Gels aufgelegt. Anschließend wurde die Glasplatte mit den Elektroden genau auf den jeweiligen Elektrodenstreifen gelegt. 
Bei 350V und 30mA erfolgte die Vorfokussierung des IEF-Geles für 45min, wodurch sich die Ampholine entsprechend ihres pH-Wertes in dem Gel verteilten. Nach der Vorfokussierung wurde der IEF/SDS applicator strip medial an den Kathodenstreifen angelegt, und in jede zweite Tasche wurden die Proben in einem Volumen von 20 $\mathrm{\mu l}$ (entspricht ca. $11 \mu \mathrm{g}$ Protein) aufgetragen. Die Einfokussierung der Proben in das Gel erfolgte bei $100 \mathrm{~V}$ und $30 \mathrm{~mA}$ für $30 \mathrm{~min}$ bevor die Fokussierung bei $380 \mathrm{~V}$ und $30 \mathrm{~mA}$ über 2,5h ablief. Im Anschluß an die IEF wurden 180 $\mu$ l einer 1:2 verdünnten Lösung des Antikörpers 'Kaninchen-Anti-Human-Transferrin’ (Dako) auf das Gel aufgetragen und mit einer gebogenen Pasteurpipette gleichmäßig auf dem Gel verteilt. Nach 15 min wurde das Gel in 0,9\%ige NaCl-Lösung überführt und 3-12h inkubiert bevor es einmal mit $\mathrm{H}_{2} \mathrm{O}$ gespült und weitere 30min in $\mathrm{H}_{2} \mathrm{O}$ auf einer Wippe gewaschen wurde. Zum Trocknen des Gels wurden zwei dünne sowie zwei dicke Filterpapiere in Gelgröße zurechtgeschnitten und nach leichtem Anfeuchten mit $\mathrm{H}_{2} \mathrm{O}$ auf das $\mathrm{Gel}$ gelegt. Direkt auf das Gel wurden die dünnen Filterpapiere gelegt, darüber die zwei Lagen Filterpapier und ein Gewicht von etwa $1 \mathrm{~kg}$, das dazu diente, einen gleichmäßigen Druck auszuüben. Nach 30min wurde das Filterpapier entfernt und das Gel mit einem Fön getrocknet. Zur Färbung wurde das Gel für 10min in Coomassie-Lösung überführt und zum Entfärben in Entfärbelösung gelegt. Anschließend wurde das Gel durch Fönen getrocknet.

Coomassie-Lösung:

$300 \mathrm{ml}$ Entfärbelösung

$1,5 \mathrm{~g}$ Coomassie R 250

Entfärbelösung:

$350 \mathrm{ml}$ Ethanol

$100 \mathrm{ml}$ Essigsäure

$650 \mathrm{ml} \mathrm{H}{ }_{2} \mathrm{O}$

\subsubsection{SDS-Polyacrylamidgelelektrophorsese (SDS-PAGE) zur Auftrennung von Proteinen}

Bei der SDS-PAGE werden denaturierte und durch SDS negativ geladene Proteine im elektrischen Feld aufgrund ihrer unterschiedlichen Molekulargewichte voneinander getrennt. Es wurde nach der Methode von Laemmli et al. (1970) vorgegangen. 


\section{Trenngel}

Ansatz für 1 großes Gel

7,5\% Trenngel

$7,35 \mathrm{ml}$

$10 \%$ Trenngel

Rotiphorese Gel 30 (30\% Acrylamid, 0,8\%

Bisacrylamid)

4x Puffer 1,5M Tris/HCl; pH 8,8; 0,4\% SDS

$10 \%$ APS

TEMED

$\mathrm{H}_{2} \mathrm{O}$

$5 \%$ Sammelgel

Ansatz für 1 großes Gel

Rotiphorese Gel 30 (30\% Acrylamid, 0,8\%

$1,3 \mathrm{ml}$

Bisacrylamid)

4x Puffer 0,5M Tris/HCl; pH 6,8; 0,4\% SDS

$10 \%$ APS

TEMED

$\mathrm{H}_{2} \mathrm{O}$

\section{6-fach Probenpuffer}

2 M Tris- $\mathrm{HCl} ; \mathrm{pH}$ 6,8

SDS

Glycerol 100\%

Bromphenolblau

$\mathrm{H}_{2} \mathrm{O}$

$\beta$-Mercaptoethanol

Anodenpuffer

$50 \mathrm{mM}$ Tris

380 mM Glycine

ad $5 \mathrm{I} \mathrm{H}_{2} \mathrm{O}$
$24 \mathrm{ml}$

$12 \mathrm{~g}$

$45 \mathrm{ml}$

$60 \mathrm{mg}$

ad $88 \mathrm{ml}$

$12 \mathrm{ml}$

Zur Herstellung des Trenngels wurde die entsprechende Lösung frisch angesetzt, sofort zwischen die Glasplatten der Elektrophoreseeinheit gegossen und mit 1Butanol überschichtet. Nach dem Auspolymerisieren des Gels (ca. 1h) wurde das 
Sammelgel auf das mit $\mathrm{H}_{2} \mathrm{O}$ gespülte Trenngel gegossen und ein Kamm für 10 Taschen von oben zwischen die Glasplatten eingebracht. Das Sammelgel benötigte ca. 30min bis zum vollständigen Auspolymerisieren. Anschließend wurde der Kamm entfernt und die Taschen mit $\mathrm{H}_{2} \mathrm{O}$ gespült. Die zu untersuchenden Proben $(50 \mu \mathrm{g}$ Protein) wurden mit $\mathrm{H}_{2} \mathrm{O}$ und Probenpuffer auf ein Volumen von $70 \mu$ l für die großen Gele beziehungsweise $18 \mu \mathrm{l}$ für die Mini-Gele gebracht. Die Ansätze wurden $5 \mathrm{~min}$ bei $95^{\circ} \mathrm{C}$ im Heizblock denaturiert und vor dem Aufbringen in die Geltaschen kurz anzentrifugiert. Die Elektrophorese des Mini-Gelsystems erfolgte durchgehend mit einer konstanten Spannung von 200V bei Raumtemperatur. Die Elektrophorese der großen Gele erfolgte mit einer konstanten Stromstärke von 50mA bei einer Temperatur von $4^{\circ} \mathrm{C}$.

\subsubsection{Coomassie-Färbung von SDS-Polyacrylamid-Gelen}

Die Coomassie-Färbung dient der schnellen, unspezifischen Färbung von Proteinbanden im SDS-Polyacrylamid-Gel.

\section{Färbelösung}

Coomassie Blue R

Methanol $250 \mathrm{ml}$

Essigsäure $50 \mathrm{ml}$

$\mathrm{H}_{2} \mathrm{O}$ ad $500 \mathrm{ml}$

\section{Entfärbelösung}

Methanol

$200 \mathrm{ml}$

Essigsäure

$50 \mathrm{ml}$

$\mathrm{H}_{2} \mathrm{O}$

$250 \mathrm{ml}$

Zum Färben wurde das SDS-Polyacrylamidgel für $1 \mathrm{~h}$ bei RT in die Färbelösung überführt. Anschließend wurde der nichtgebundene Farbstoff durch die Entfärbelösung aus dem Gel herausgewaschen, so dass nur der proteingebundene Farbstoff sichtbar wurde. Anschließend wurde das Gel gewässert und getrocknet. 


\subsubsection{Transfer von Proteinen auf Nitrozellulose-Membranen ("Western blotting")}

Für den immunologischen Nachweis wurde gelelektrophoretisch aufgetrenntes Protein durch Elektrotransfer auf Nitrozellulosemembranen transferiert. Hierzu wurde das Trenngel nach erfolgter SDS-PAGE (3.2.3.5) 10-15min in Kathodenpuffer äquilibiriert. Drei Lagen 3MM-Whatman-Papier (GB 003) sowie die Nitrozellulosemembranen wurden auf Gelgröße zugeschnitten und ebenfalls in Kathodenpuffer eingelegt. Drei weitere Lagen Whatman-Papiere wurden in Anodenpuffer eingelegt. Für den Transfer wurden Trenngel und Nitrozellulosemembran luftblasenfrei zwischen die drei jeweils in Anoden- oder Kathodenpuffer getränkten Whatman-Papiere gelegt. Da der Transfer der Proteine von der Kathode in Richtung Anode erfolgte, mußte die Membran beim Aufbau des Semi-Dry-Blots der Anode zugewandt sein. Der Transfer erfolgte für $65 \mathrm{~min}$ bei $1 \mathrm{~mA} / \mathrm{cm}^{2}$. Anschließend wurde durch Anfärben des Gels mit Coomassie-Blau überprüft, ob die Proteine vollständig auf die Membran übertragen worden waren.

Kathodenpuffer:

$$
\begin{aligned}
& \text { 40mM ع-Aminocapronsäure, pH 9,0 } \\
& 25 \mathrm{mM} \text { Tris/ HCl, pH 9,0 } \\
& 20 \%(\mathrm{v} / \mathrm{v}) \text { Methanol (p.A.) }
\end{aligned}
$$

Anodenpuffer

$$
75 \text { mM Tris/ HCl, pH 7,4 }
$$$$
20 \%(v / v) \text { Methanol (p.A.) }
$$

\subsubsection{Detektion von Proteinen auf Nitrozellulosemembranen}

Auf Nitrozellulosefilter immobilisierte Proteine (3.2.3.7) können mit spezifischen Antikörpern detektiert werden. Die Nitrozellulose-Membran wurde zur Immunodetektion von Transferrin wie folgt unter kontinuierlicher Bewegung auf einer Wippe inkubiert. Die Membran wurde dreimal für $5 \mathrm{~min}$ in PBST gewaschen und anschließend zur Absättigung unspezifischer Bindungsstellen $1 \mathrm{~h}$ in $5 \%$ Blotto bei $37^{\circ} \mathrm{C}$ inkubiert, zweimal 5 min mit PBST gewaschen und für $1 \mathrm{~h}$ bei RT mit dem ersten Antikörper 'Kaninchen-anti-HTF' (1:500 in 0,1\% PBST) versetzt. Die Membran wurde dreimal für jeweils 20min mit PBST gewaschen. Mit dem Sekundärantikörper 'Ziegeanti-Kaninchen' (HRP-gekoppelt; 1:10.000 in PBST) wurde die Membran 1h bei RT 
inkubiert und anschließend dreimal mit PBST und einmal mit $\mathrm{H}_{2} \mathrm{O}_{\text {bidest }}$ gewaschen, bevor der Chemilumineszenz-Nachweis (3.2.3.9) geführt wurde.

PBST

PBS/ 0,1\% Tween-20

$5 \%$ Blotto

$5 \%(w / v)$ Magermilchpulver in PBS

\subsubsection{Chemilumineszenz-Nachweis}

Die Immunodetektion erfolgte mit Hilfe des Pierce Supersignal Detection Systems, indem die beiden Lösungen des Systems 1:1 gemischt und die Membran damit 5min inkubiert wurde. Anschließend wurde die Membran in Folie eingeschlagen und ein Kodak-XAR-Röntgenfilm für wenige Minuten aufgelegt.

\subsubsection{Herstellung von Fibroblastenextrakten}

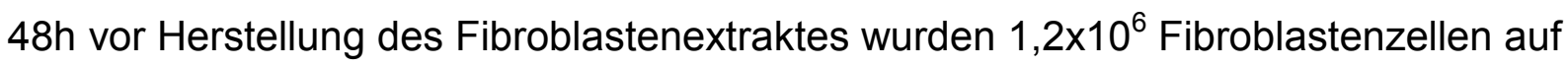
$6 \mathrm{~cm}-$ Gewebekulturschalen ausplattiert. Die Zellen wurden mit PBS gewaschen und in $1 \mathrm{ml}$ PBS abgeschabt. Der Zellaufschluß erfolgte durch 10maliges Passieren durch eine 22g-Kanüle. Anschließend wurde die Proteinkonzentration nach Bradford (siehe 3.2.3.3) bestimmt.

\subsubsection{Bestimmung der Aktivität der Phosphomannomutase 2 in Patienten- und Kontrollfibroblasten}

Für die PMM2-Aktivitätsbestimmung wurden jeweils $9 \mu \mathrm{g}$ des Gesamtproteins von Kontrollen und der Patientin eingesetzt. Die Aktivität des Enzyms wurde anhand des Umsatzes von Mannose-6-Phosphat zu Mannose-1,6-bisphosphat in Anwesenheit von Glucose-1,6-bisphosphat bestimmt. Der Reaktionsansatz $(25 \mu l)$ enthielt neben

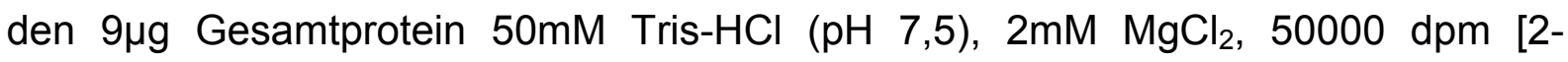
${ }^{3} \mathrm{H}$ ]Mannose-6-Phosphat und 1mM Glucose-1,6-Bisphosphat. Nach einer Inkubation bei $37^{\circ} \mathrm{C}$ für $30 \mathrm{~min}$ wurden die Ansätze abzentrifugiert. Aus den Überständen wurde das [2- $\left.{ }^{3} \mathrm{H}\right]-$ Mannose-6-Phosphat vom [2- $\left.{ }^{3} \mathrm{H}\right]-$ Mannose-1,6-Bisphosphat durch Hochspannungselektrophorese bei $65 \mathrm{~V} / \mathrm{cm}$ für 50min auf Whatman 3MM Papier in 80mM Pyridinpuffer ( $\mathrm{pH} \mathrm{5,5} \mathrm{mit} \mathrm{Eisessig} \mathrm{eingestellt)} \mathrm{getrennt.} \mathrm{Nach} \mathrm{Trocknung} \mathrm{des}$ Papiers erfolgte die Auswertung im Flachbettscanner Tracemaster 20 (Fa. Berthold). 
3.2.3.12 Bestimmung der Aktivität der Phosphomannose Isomerase (PMI) in Patienten- und Kontrollfibroblasten

Die PMI-Aktivität in Patienten- und Kontrollfibroblasten wurde im gekoppelten

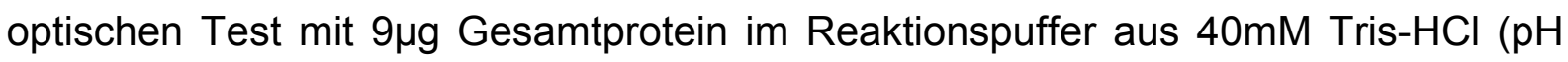
7,4), $6 \mathrm{mM} \mathrm{MgCl} 2,5 \mathrm{mM} \mathrm{Na} \mathrm{HPO}_{4} / \mathrm{KH}_{2} \mathrm{PO}_{4}, 1 \mathrm{mM}$ NADP, 100mU Phosphoglucose Isomerase und 500mU Glucose-6-Phosphat gemessen. Der Start der enzymatischen Reaktion erfolgte durch Zugabe von Mannose-6-Phosphat (1mM Endkonzentration). Die Proben wurden bei RT für $2 \mathrm{~h}$ inkubiert und die Reaktion bei einer OD von 340nm verfolgt.

\subsubsection{Metabolische Markierung von Fibroblasten mit [2- $\left.{ }^{3} \mathrm{H}\right]-M a n n o s e$}

Um die lipidverknüpften und die proteinverknüpften Oligosaccharide der Patientin M.S. zu analysieren, wurden Fibroblastenzellen der Patientin sowie von Kontrollen metabolisch markiert. Hierzu wurden 48h vor der Markierung 1,2 Mio Fibroblastenzellen auf $6 \mathrm{~cm}$-Zellkulturschalen ausplattiert. Die Inkubation der Zellen erfolgte für 30min in MEM-Medium, das 0,5mM Glucose und $125 \mu \mathrm{Ci}\left[2-{ }^{3} \mathrm{H}\right]$ Mannose enthielt. Anschließend wurden die Fibroblasten 3x mit eiskaltem PBS gewaschen und in eiskalten Methanol abgeschabt. Der Zellaufschluss erfolgte durch Ultraschall (3x10sec). Nach Lyse wurden $4 \mathrm{ml}$ Chloroform hinzupipettiert und das Material anschließend erneut mit Ultraschall behandelt. Nach Zentrifugation für 10min bei $5000 \mathrm{U} / \mathrm{min}$ und $4^{\circ} \mathrm{C}$ wurde der Überstand abgenommen und das Pellet zwei weitere Male mit Chloroform-Methanol (3:2) extrahiert. Die verbleibenden Pellets enthielten die langkettigen LLOs und die Proteinfraktion. Die vereinigten Überstände, die Dol-PMan und kurzkettige LLOs enthielten, wurden unter Stickstoff getrocknet. Anschließend wurden das eingedampfte Dol-P-Man und die kurzkettigen LLOs in 3ml Chloroform-Methanol (3:2) resuspendiert, gewaschen und anschließend mit Hilfe der Dünnschichtchromatographie auf Silica Gel 60-Platten in Chloroform/ Methanol/ $\mathrm{H}_{2} \mathrm{O}$ (65:25:4) analysiert. Die Auswertung erfolgte im Flachbettscanner Tracemaster 20 (Körner et al., 1998b)

\subsubsection{Milde Säurebehandlung und HPLC-Analyse langkettiger, lipidverknüpfter Oligosaccharide}

Die unter 3.2.3.13 nach der Chloroform-Methanol-Extraktion erhaltenen Pellets enthielten die langkettigen LLOs. Die Pellets wurden gewaschen und mit Chloroform/

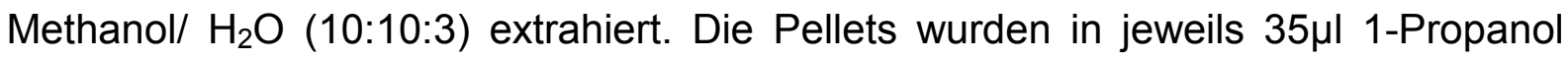


resuspendiert und die Oligosaccharide durch milde Säurebehandlung mit $500 \mu l$ $0,02 \mathrm{~N} \mathrm{HCl}$ für $30 \mathrm{~min}$ bei $100^{\circ} \mathrm{C}$ vom Lipidcarrier abgespalten. Nach Trocknung des Reaktionsansatzes unter Stickstoff wurde das Pellet mit $200 \mu \mathrm{H}_{2} \mathrm{O}$ versetzt und zum Resuspendieren mit Ultraschall behandelt. Nach Zentrifugation des Ansatzes für $5 \mathrm{~min}$ bei $14000 \mathrm{U} / \mathrm{min}$ wurde der Überstand für die HPLC-Analyse verwendet. Die HPLC Analyse von aufgereinigten N-Glykanen wurde mit Hilfe einer Supelcosil LC$\mathrm{NH}_{2}$-Säule $(25 \mathrm{~cm} \times 4,6 \mathrm{~cm} \times 5 \mu \mathrm{m}$; Fa. Supelco) durchgeführt, die als funktionelle Gruppe $\mathrm{NH}_{2}$-Reste trägt und Zuckerketten nach ihrer Größe auftrennen kann. Für die HPLC wurde ein linearer Gradient von $70 \%$ auf $50 \%$ Acetonitril in Wasser bei einer Flußgeschwindigkeit von $1 \mathrm{ml} / \mathrm{min}$ gefahren. Die gesammelten Fraktionen wurden mit $2 \mathrm{ml}$ Szintillationsflüssigkeit (Rothiszint) versetzt und anschließend durch Messung im Flüssigkeitszintillationszähler (Packard) analysiert (Körner et al., 1998b).

\subsubsection{Enzymatische Deglykosylierung proteinverknüpfter Oligosaccharide durch PNGase F}

Die Isolierung N-glykosidisch-verknüpfter Kohlenhydratketten von neusynthetisierten Glykoproteinen erfolgte durch enzymatische Deglykosylierung mit PNGase F. 75$100 \mu g$ Protein wurden mit 0,1M $\beta$-Mercaptoethanol/ 0,5\% SDS-Lösung auf ein Volumen von $90 \mu \mathrm{l}$ gebracht und $5 \mathrm{~min}$ bei $95^{\circ} \mathrm{C}$ im Heizblock inkubiert, um die

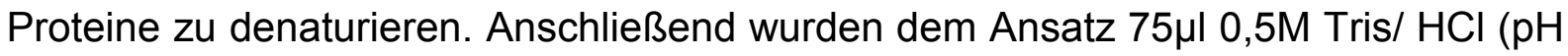

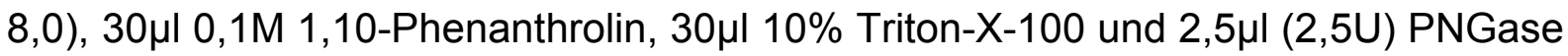
$\mathrm{F}$ hinzugefügt und über Nacht im Schüttelinkubator bei $37^{\circ} \mathrm{C}$ unter leichtem Schütteln (300U/min) inkubiert. Die Reaktion wurde durch Inkubation für $5 \mathrm{~min}$ bei $95^{\circ} \mathrm{C}$ beendet. Die freigesetzten Oligosaccharide wurden mit Hilfe von C18-Sep-Pak Säulen (Waters) von Proteinen abgetrennt, unter Vakuum getrocknet, in 100 $\mathrm{l}$ $\mathrm{H}_{2} \mathrm{O}_{\mathrm{HPLC}}$ aufgenommen und mittels HPLC (siehe 3.2.3.14) analysiert (Körner et al., 1998b).

\subsubsection{Milde Säurebehandlung und HPLC-Analyse kurzkettiger, lipidverknüpfter Oligosaccharide}

Die unter 3.2.3.13 erhaltenen Überstände enthielten Dol-P-Man sowie die kurzkettigen LLOs. Diese wurden unter Stickstoffatmosphäre getrocknet, nach 3.2.3.14 einer milden Säurebehandlung unterzogen und anschließend mittels HPLC analysiert. 


\subsubsection{Markierung von Oligosacchariden mit PMP}

Gesammelte HPLC-Fraktionen (siehe 3.2.3.16) wurden mittels Speedvac eingeengt

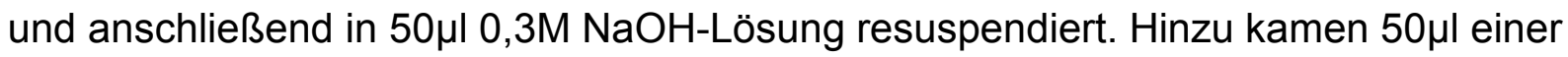
Lösung aus 0,5M 1-Phenyl-3-Methyl-Pyrazolinon (PMP) in Methanol, 0,3M NaOHund $0,1 \mathrm{M} \mathrm{HCl}$-Lösung. Nach Inkubation bei $70^{\circ} \mathrm{C}$ für $30 \mathrm{~min}$ wurde der Ansatz auf RT gekühlt und $150 \mu \mathrm{l}$ einer $0,1 \mathrm{M} \mathrm{HCl}$-Lösung hinzugegeben. Es folgte eine erneute Einengung mittels Speedvac. Nach Resuspendierung in $50 \mu \mathrm{l} \mathrm{H}_{2} \mathrm{O}$ folgte ein

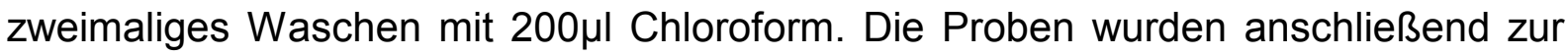
massenspektrometrischen Analyse eingesetzt.

\subsubsection{Massenspektrometrische Untersuchungen von abgespaltenen Zuckerketten}

Massenspektrometrische Untersuchungen wurden auf einem MALDI-TOF Gerät des Types Bruker REFLEX III der Firma Bruker durchgeführt. Das Prinzip eines linearen Flugzeitmassenspektrometers besteht darin, daß die durch einen Laserimpuls erzeugten Ionen mit gleicher Ladung aber unterschiedlichen $\mathrm{m} / \mathrm{z}$-Werten (Masse/Ladungsverhältnis) nach Durchlaufen der gleichen Potentialdifferenz unterschiedliche Geschwindigkeiten besitzen. Schwere lonen mit hohem $\mathrm{m} / \mathrm{z}-$ Wert erreichen den Detektor später als leichte Ionen. Ionen gleicher Masse starten mit einer gewissen Verteilungsbreite der Energie. Dies trägt zur Peakbreite der Ionensignale bei. Die Flugstrecke des Gerätes betrug $145 \mathrm{~cm}$. Die zu untersuchenden Proben (3.2.3.17) wurden mit einem Stickstofflaser der Wellenlänge $337,1 \mathrm{~nm}$ ionisiert. Geladene Oligosaccharide wurden im linearen, negativen Modus analysiert, ungeladene Oligosaccharide wurden im linearen, positiven Modus untersucht. Als Matrix wurde Dihydrobenzoesäure (DHB) verwendet. Zwei verschiedene Lösungen

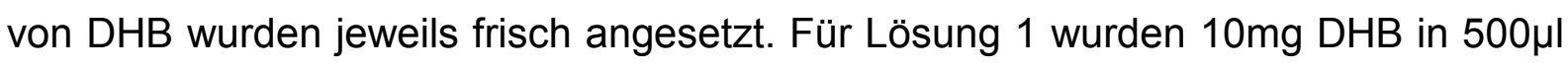
Aceton gelöst, für Lösung 2 wurden 10mg DHB in $333 \mu \mathrm{l}$ Acetonitril, $167 \mu \mathrm{l} \mathrm{H}_{2} \mathrm{O}, 10 \mu \mathrm{l}$

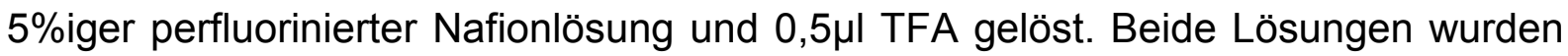
vor ihrer Verwendung $20 \mathrm{~min}$ bei $13000 \mathrm{U} / \mathrm{min}$ zentrifugiert. Lösung 1 wurde als dünne Schicht auf das Probenfeld aufgetragen, so dass sich eine leicht milchige Oberfläche bildete. Auf die jeweiligen Probenfelder wurden anschließend 0,5-1,0 $\mu$ l der in Wasser gelösten und mit PMP markierten Probe aufgetragen und im Dunklen durch einen leichten Luftstrom getrocknet. 0,5 $\mu$ lösung 2 wurden auf die Proben aufgetragen und ebenfalls im Dunklen durch einen leichten Luftstrom getrocknet. 


\subsubsection{Methoden zur molekularbiologischen Arbeit mit DNA und RNA}

\subsubsection{Leukozytenpräparation}

Die Leukozyten der Patientin und deren Eltern wurden aus EDTA-Blut präpariert. Hierzu wurden $10 \mathrm{ml}$ EDTA-Blut mit 1,5ml der Lösung 1, 5ml der Lösung 2 sowie $3,5 \mathrm{ml}$ der Lösung 3 vorsichtig vermischt und für $1 \mathrm{~h}$ bei RT inkubiert. Der Überstand wurde abgenommen und für $15 \mathrm{~min}$ bei $1250 \mathrm{U} / \mathrm{min}$ zentrifugiert. Das Pellet wurde mit 2,4 $\mathrm{ml} \mathrm{H}_{2} \mathrm{O}$ und $0,8 \mathrm{ml}$ der Lösung 5 versetzt, anschließend vorsichtig resuspendiert und für 1,5min bei RT inkubiert. Nach Zugabe von $0,8 \mathrm{ml}$ der Lösung 4 erfolgte eine weitere Zentrifugation bei 1250U/min für 15 min. Dieser Hämolyseschritt wurde ein weiteres Mal wiederholt, bevor die im Pellet vorliegenden Leukozyten zur Präparation von total-RNA oder genomischer DNA verwendet oder für eine spätere Verwendung bei $-80^{\circ} \mathrm{C}$ eingefroren wurden.

\begin{tabular}{|c|c|c|}
\hline Lösung 1: & $\begin{array}{l}\text { D-Glucose } \\
\text { Na-Citrat } \\
\text { Zitronensäure } \\
\mathrm{NaCl} \\
\mathrm{H}_{2} \mathrm{O}\end{array}$ & $\begin{array}{l}2,69 \mathrm{~g} \\
2,2 \mathrm{~g} \\
0,73 \mathrm{~g} \\
0,9 \mathrm{~g} \\
\text { ad } 100 \mathrm{ml}\end{array}$ \\
\hline Lösung 2: & \multicolumn{2}{|c|}{$6 \%$ Dextran in $0,9 \% \mathrm{NaCl}$} \\
\hline Lösung 3: & \multicolumn{2}{|c|}{$5 \%$ D-Glucose in $0,9 \% \mathrm{NaCl}$} \\
\hline Lösung 4: & \multicolumn{2}{|l|}{$3,6 \% \mathrm{NaCl}$} \\
\hline Lösung & $0,9 \% \mathrm{NaCl}$ & \\
\hline
\end{tabular}

3.2.4.2 Isolierung genomischer DNA aus Leukozyten und primären, humanen Fibroblasten (nach Hogan et al., 1986)

Leukozyten aus $10 \mathrm{ml}$ Blut bzw. Fibroblastenzellen einer $100 \mathrm{~mm}$ Gewebekulturschale

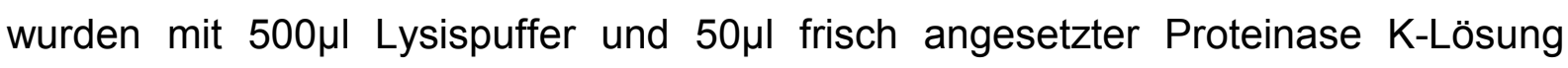
versetzt und durch Vortexen gemischt. Der Ansatz wurde über Nacht bei $56^{\circ} \mathrm{C}$ im Schüttelinkubator inkubiert. Nach einer Phenol-/Chloroform-Extraktion und Ethanolfällung konnte die genomische DNA auf eine abgeflammte Pasteurpipette aufgerollt werden. Nach Waschen der DNA mit $70 \%$ (v/v) Ethanol und Trocknung bei $\mathrm{RT}$ wurde die DNA in $300 \mu \mathrm{l} \mathrm{H}_{2} \mathrm{O}_{\text {bidest }}$ resuspendiert. Die Aufbewahrung genomischer DNA erfolgte bei $4^{\circ} \mathrm{C}$. 
Verwendete Lösungen:

$\begin{array}{lll}\text { Lysis-Puffer: } & 50 \mathrm{mM} & \text { Tris/ HCl; pH 8,0 } \\ & 100 \mathrm{mM} & \text { EDTA } \\ & 100 \mathrm{mM} & \mathrm{NaCl} \\ 1 \%(\mathrm{w} / \mathrm{v}) & \mathrm{SDS}\end{array}$

Proteinase K: $\quad$ 10mg in $1 \mathrm{ml}$ Lysis-Puffer

Phenol (wassergesättigt)

\subsubsection{Isolierung von Gesamt-RNA}

Gesamt-RNA wurde aus primären, humanen Fibroblasten sowie aus Leukozyten mit Hilfe des RNeasy-Kits der Firma Qiagen isoliert. Es wurde nach dem Protokoll des

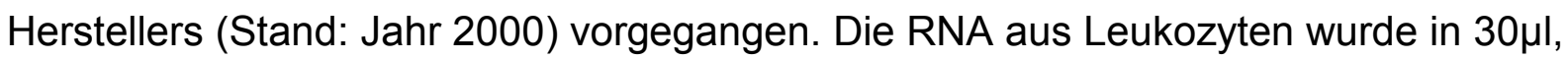

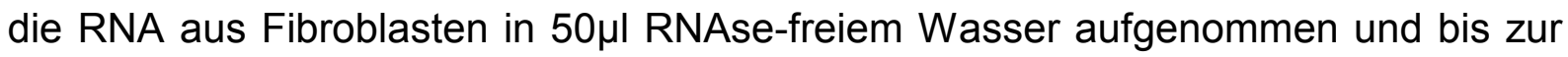
Verwendung bei $-80^{\circ} \mathrm{C}$ gelagert.

\subsubsection{Isolierung von Plasmid-DNA aus Escherichia coli}

Plasmid-DNA aus Escherichia coli wurde mit Hilfe der Qiagen-Kits für Mini- bzw. Midi-Präparationen nach Angaben des Herstellers isoliert.

\subsection{Mini-Präparation von Plasmid-DNA}

Die Anzucht des jeweiligen E. coli-Stammes fand in $5 \mathrm{ml}$ LB-Flüssigkultur mit Ampicillin im Schüttelinkubator bei $37{ }^{\circ} \mathrm{C}$ über Nacht statt. Zwei $\mathrm{ml}$ der Übernachtkultur wurden in der Eppendorftischzentrifuge für $1 \mathrm{~min}$ bei $13.000 \mathrm{U} / \mathrm{min}$ abzentrifugiert. Das Pellet wurde mit kaltem Puffer P1 versetzt und zum Lösen gevortext. 250 $\mu$ l Puffer P2 wurden hinzupipettiert und die Zelllösung für 5min bei RT inkubiert. Nach Zugabe von 350 $\mu$ l Puffer N3 erfolgte eine 15-minütige Zentrifugation bei $13.000 \mathrm{U} / \mathrm{min}$ in der Eppendorftischzentrifuge zur Abtrennung der chromosomalen DNA und der Proteine. Der klare Überstand mit der Plasmid-DNA wurde in QiaPrep-Minisäulen pipettiert. Nach einer 1-minütigen Zentrifugation bei $13.000 \mathrm{U} / \mathrm{min}$ wurde der Durchfluß verworfen und die Säulenmembran mit 750 $\mathrm{l}$ Puffer PE gespült. Der Durchfluß konnte erneut verworfen werden. Zum Trocknen der Membran erfolgte eine erneute Zentrifugation bei $13.000 \mathrm{U} / \mathrm{min}$ für $1 \mathrm{~min}$. Zur 
Elution der Plasmid-DNA wurden 50-100 $\mu$ Puffer EB auf die Säule pipettiert, 1min bei RT inkubiert und anschließend für $1 \mathrm{~min}$ bei $13.000 \mathrm{U} / \mathrm{min}$ zentrifugiert.

\subsubsection{Midi-Präparation von Plasmid-DNA}

$200 \mathrm{ml}$ einer E.coli Übernachtkultur wurden im JA-10 Rotor bei $8500 \mathrm{~g}$ für 10min abzentrifugiert. Der Überstand wurde verworfen und das Pellet in $4 \mathrm{ml}$ Puffer P1 aufgenommen. Nach Zugabe von $4 \mathrm{ml}$ Puffer P2 erfolgte eine 5-minütige Inkubation bei RT, die durch Zugabe von $4 \mathrm{ml}$ eiskaltem Puffer P3 beendet wurde. Einer 20minütigen Inkubation auf Eis folgte eine Zentrifugation im JA-20 Rotor für $45 \mathrm{~min}$ bei $4^{\circ} \mathrm{C}$ und $18.000 \mathrm{U} / \mathrm{min}$. Der klare Überstand wurde vorsichtig abgenommen und erneut zum Abtrennen der letzten Protein- und chromosomalen DNA-Reste für 15min zentrifugiert. Der so erhaltene Überstand wurde auf eine mit 4ml Puffer QBT äquilibrierte Qiagen-100-Säule pipetiert und nachfolgend zweimal mit Puffer QC gewaschen. Die Plasmid-DNA konnte dann mit 5ml Puffer QF eluiert werden. Mit 0,7 Vol Isopropanol erfolgte eine Fällung der DNA im 50ml Plastikröhrchen in der Labofuge für $1 \mathrm{~h}$ bei $5000 \mathrm{U} / \mathrm{min}$ und $10^{\circ} \mathrm{C}$. Das Pellet wurde dann zweimal mit $70^{\circ} \mathrm{C}$ Ethanol gewaschen und anschließend an der Luft getrocknet. Die Aufnahme der DNA erfolgte in Puffer EB.

$\begin{array}{lll}\text { Pufferzusammensetzung } & \\ \text { P1: } & 50 \mathrm{mM} & \text { Tris/ HCl; } \mathrm{pH} 8,0 \\ & 10 \mathrm{mM} & \text { EDTA } \\ & 100 \mu \mathrm{g} / \mathrm{ml} & \text { RNAse A } \\ \text { P2: } & 0,2 \mathrm{M} & \mathrm{NaOH} \\ & 1 \%(\mathrm{w} / \mathrm{v}) & \text { SDS } \\ \text { P3: } & 3 \mathrm{M} & \text { Kaliumacetat; } \mathrm{pH} 5,5 \\ \text { QBT: } & 750 \mathrm{mM} & \mathrm{NaCl} \\ & 50 \mathrm{mM} & \text { MOPS; } \mathrm{pH} 7,0 \\ & 15 \%(\mathrm{v} / \mathrm{v}) & \text { Ethanol } \\ & 0,15 \%(\mathrm{v} / \mathrm{v}) & \text { Triton-X-100 } \\ & 1,0 \mathrm{M} & \text { NaCl } \\ \text { QC-Puffer: } & 50 \mathrm{mM} & \text { MOPS; pH 7,0 } \\ & 15 \%(\mathrm{v} / \mathrm{v}) & \text { Ethanol } \\ & 1,25 \mathrm{M} & \text { NaCl } \\ \text { QF-Puffer: } & 50 \mathrm{mM} & \text { Tris/ HCl; } \mathrm{pH} 8,5 \\ & 15 \%(\mathrm{v} / \mathrm{v}) & \text { Ethanol }\end{array}$




\subsubsection{Phenol-Chloroform-Extraktion}

Dem hier verwendeten äquilibrierten basischen Phenol wurde nach dem Auftauen Chloroform-Isoamylalkohol (24:1) im Verhältnis 1:1 zugesetzt. Zur Trennung der Phasen wurde die Lösung für 3-4h bei RT inkubiert. Die Aufbewahrung erfolgte bei $4^{\circ} \mathrm{C}$ im Dunklen.

Um Proteine aus DNA-haltigen Lösungen zu extrahieren, wurden diese Lösungen einer Phenol-Chloroform-Extraktion unterzogen. Dabei wurden der zu behandelnden DNA-Lösung 2 Volumen Phenol-Chloroform zugesetzt, die entstehenden Phasen durch mehrmaliges Schwenken gut durchmischt und anschließend für 4 min bei $10.000 \mathrm{U} / \mathrm{min}$ und Raumtemperatur zur Trennung der Phasen abzentrifugiert. Die wässrige obere Phase mit der DNA wurde so abgenommen und in ein neues E-Cup überführt, daß von dem Protein, welches sich in der Interphase angesammelt hatte, nichts mit in das neue E-Cup überführt wurde. Es folgte die Zugabe von einem Volumen Chloroform-Isoamylalkohol (24:1) zur Entfernung von verbliebenen Phenolresten in der Probe. Nach einer erneuten Zentrifugation für 4 min bei 10.000 $\mathrm{U} / \mathrm{min}$ konnte die obere Phase abgenommen, in sterile E-Cups überführt und einer Alkoholpräzipitation (3.2.4.6) unterzogen werden.

\subsubsection{Alkoholpräzipitation}

Um DNA-Lösungen zu konzentrieren, wurden Fällungen mit Ethanol (3.2.4.6.1) oder Isopropanol (3.2.4.6.2) durchgeführt. Beachtet werden mußte hierbei, daß für eine gute Ausfällung die Kalium- bzw. Natriumionenendkonzentration der DNA-Lösung 250-500mM betragen mußte. Um dies zu gewährleisten, wurde $5 \mathrm{M} \mathrm{NaCl-Lösung}$ bzw. 3M Na-Acetat- oder 3M K-Acetat-Lösung zugesetzt. Eine Alkoholpräzipitation konnte auf zwei Wegen erfolgen. Routinemäßig wurde die Präzipitation mit Ethanol durchgeführt. Um dagegen besonders reine Plasmid-DNA zu erhalten, beispielsweise für Sequenzierungsansätze, wurde die DNA mit Isopropanol gefällt.

\subsection{Alkoholpräzipitation von DNA mit Ethanol}

Zu der wässrigen DNA-Lösung, die nach der Chloroform-Isoamylalkohol-Behandlung (3.2.4.5) erhalten wurde, wurden 2,5 Volumen Ethanol ( $99 \%$ [v/v]) zugesetzt, so daß eine Endkonzentration von ca. $70 \%$ eingestellt wurde. Zu beachten war hierbei, daß der Alkohol Raumtemperatur hatte, um ein Ausfällen von störenden Salzen bei der sich anschließenden Zentrifugation zu verhindern (13000U/min, Raumtemperatur, 
30-60min). Eine längere Zentrifugationsdauer als 30min erhöhte die DNA-Ausbeute. Der Überstand wurde dekantiert und das umgedrehte E-Cup nach kurzer Wartezeit noch einmal kräftig ausgeschlagen, um letzte Ethanolreste zu entfernen. Das DNAPellet wurde durch Zugabe von $1 \mathrm{ml} 70 \%$ Ethanol (v/v) gewaschen und erneut kurz abzentrifugiert (13000U/min, 5min). Der Alkohol wurde anschließend vorsichtig entfernt, das Pellet getrocknet und in TE-Puffer aufgenommen.

TE-Puffer:

Tris/ $\mathrm{HCl}$

$\mathrm{Na}_{2}$-EDTA

$\mathrm{pH} 8,0$
$10 \mathrm{mM}$

$1 \mathrm{mM}$

\subsection{Alkoholpräzipitation von DNA mit Isopropanol}

Der zu fällenden DNA-Lösung, die nach der Chloroform-Isoamylalkohol-Extraktion (3.2.4.5) erhalten worden war, wurde 0,7 Volumen Isopropanol (RT) zugesetzt und der Ansatz durch mehrmaliges Schwenken durchmischt. Durch Zentrifugation für 3060min bei 13000U/min und RT erfolgte die Fällung der DNA. Nach Waschen des erhaltenen Pellets mit $70 \%$ (v/v) Ethanol wurde die DNA getrocknet und anschließend in TE-Puffer resuspendiert.

\subsubsection{Lagerung von DNA und RNA}

Die Aufbewahrung von isolierter Plasmid-DNA erfolgte in der Regel bei $-20^{\circ} \mathrm{C}$. Längerfristige Lagerungen fanden bei $-80^{\circ} \mathrm{C}$ statt. Genomische DNA wurde bei $4^{\circ} \mathrm{C}$ aufbewahrt. Isolierte RNA wurde routinemäßig bei $-80^{\circ} \mathrm{C}$ aufbewahrt.

\subsubsection{Restriktionsverdau von DNA}

Für Restriktionsverdaue von DNA wurden pro $\mu \mathrm{g}$ DNA 2-10 U Enzym eingesetzt, wobei $1 \mathrm{U}$ der Enzymmenge entspricht, durch die $1 \mu \mathrm{g} \lambda$-DNA/h unter Standardbedingungen gespalten wird. Weiterhin kamen 0,1 Volumen des zum Restriktionsenzym mitgelieferten spezifischen 10-fach konzentrierten Puffers hinzu. Beachtet werden mußte, daß die Glycerinendkonzentration im Verdauansatz nicht über $5 \%(\mathrm{v} / \mathrm{v})$ lag, da dies zu einem negativen Effekt auf die spezifische Aktivität des Enzyms hätte führen können. Bei einem gleichzeitigen Verdau von DNA mit zwei verschiedenen Restriktionsenzymen (Doppelverdau), die unterschiedliche Salzkonzentrationen benötigten, wurde entweder ein Puffer gewählt, in dem beide Enzyme noch eine zufriedenstellende Teilaktivität aufwiesen, oder aber es wurden 
zwei aufeinanderfolgende Verdaue mit dem jeweils optimalen Puffersystem für das jeweilige Enzym durchgeführt, wobei nach dem ersten Verdau eine PhenolChloroform-Extraktion sowie eine Ethanolpräzipitation stattfanden. Die Restriktionsverdauansätze wurden bei der vom Hersteller empfohlenen Temperatur für wenigstens $2 \mathrm{~h}$ inkubiert. Beendet wurden die Reaktionen durch Inaktivierung der Enzyme mit Proben-Puffer, Inkubation für $10-20$ min bei $65^{\circ} \mathrm{C}$ (nach Angaben des Herstellers) oder durch Einfrieren bei $-20^{\circ} \mathrm{C}$. Kontrolliert wurde der korrekte Ablauf der Restriktionsverdaue durch eine Agarosegelelektrophorese.

\subsubsection{Dephosphorylierung von DNA-Fragmenten}

Um die Re-Ligation der gespaltenen Vektor-DNA zu verhindern, wurde nach erfolgter Spaltung des Vektors mit Restriktionsendonukleasen eine Dephosphorylierung mit alkalischer Phosphatase (CIP) durchgeführt. Hierdurch wurden die endständigen 5'Phosphatgruppen entfernt. Auf $1 \mu \mathrm{g}$ Vektor-DNA wurde $1 \mathrm{U}$ CIP in 1xCIP-Puffer eingesetzt und der Ansatz für $1 \mathrm{~h}$ bei $37^{\circ} \mathrm{C}$ inkubiert. Die Inaktivierung der alkalischen Phosphatase erfolgte für $20 \mathrm{~min}$ bei $75^{\circ} \mathrm{C}$. Anschließend wurde die DNA mit Phenol und Phenol/ Chloroform extrahiert und mit Ethanol gefällt.

\subsubsection{Agarose-Gelelektrophorese}

Um DNA-Fragmente aufzutrennen, wurde eine Agarose-Gelelektrophorese durchgeführt. Die Agarose wurde mit TBE-Laufpuffer angesetzt und 5min autoklaviert bzw. in einer Mikrowelle mehrmals aufgekocht. Die Agarose konnte dann für maximal 2 Wochen bei $60^{\circ} \mathrm{C}$ aufbewahrt werden. Dabei wurde je nach DNA-Größe 0,8-

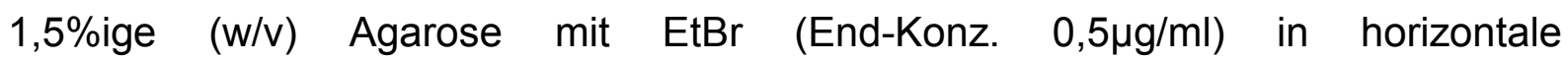
Flachbettapparaturen gegossen. Nach dem Einfüllen der Agarose in die Apparatur wurde der Kamm eingesetzt. Nach Erstarren der Agarose (ca. 15min) wurde das Gel mit TBE-Laufpuffer überschichtet. Die zu untersuchenden DNA-Proben wurden mit 10\% (v/v) Proben-Puffer vermischt und in die Taschen pipettiert. Die Elektrophorese erfolgte bei einer Spannung von $4 \mathrm{~V} / \mathrm{cm}$. Die durch das $\mathrm{EtBr}$ fluoreszierende DNA konnte bei einer Wellenlänge von 254nm auf dem UV-Transilluminator sichtbar gemacht und das Gel analysiert werden. 
verwendete Lösungen:

TBE-Laufpuffer:

$50 \mathrm{mM}$ Tris/ $\mathrm{HCl}$

$50 \mathrm{mM}$ Borsäure

2,5 $\mathrm{mM} \mathrm{Na}_{2}$-EDTA

$\mathrm{pH} 8,5$

Proben-Puffer

$50 \%(w / v)$ Saccharose

$0,1 \%(w / v)$ Bromphenolblau

$7 \mathrm{M}$ Harnstoff

$1 \mathrm{mM} \mathrm{Na}_{2}$-EDTA

$\mathrm{pH} 7,0$

Ethidiumbromid-Lösung:

$0,5 \mu \mathrm{g} / \mathrm{ml}$

\subsubsection{Größenbestimmung von DNA-Fragmenten durch Agarosegel- Elektrophorese nach SOUTHERN (1979)}

Um die Größe von DNA-Fragmenten bspw. nach Restriktionsverdau (3.2.4.8) oder PCR (3.2.4.18) zu bestimmen, wurde eine Agarosegel-Elektrophorese durchgeführt. Dazu wurde neben die zu überprüfende linearisierte Proben-DNA ein Standard aufgetragen, von dem die einzelnen Größen der DNA-Banden, die sich hinterher unter UV-Licht zeigten, bekannt waren.

\subsubsection{Isolierung von DNA-Fragmenten aus Agarosegelen}

Um nach einem Restriktionsverdau (3.2.4.8) oder einer PCR (3.2.4.18) spezifische DNA-Fragmente von anderen Fragmenten zu trennen, wurde der jeweilige Ansatz mit 10\% (v/v) Volumen Proben-Puffer versehen und auf ein Agarosegel aufgetragen. Nach Beendigung des Gellaufs wurde das entsprechende DNA-Fragment unter dem UV-Licht einer UV-Handlampe ausgeschnitten und gewogen. Die Extraktion der DNA aus dem Agaorsegelblock erfolgte mit dem QIAquick Gel Extraktion Kit der Firma Qiagen, wobei nach der Hersteller-Vorschrift vorgegangen wurde. Das Verfahren beruht auf dem Auflösen der Agarose durch den mitgelieferten QX1-Puffer und einer nachfolgenden Abtrennung durch den ebenfalls zum Kit gehörenden Puffer PE über eine Säule, in der die DNA haften bleibt und anschließend mit Puffer EB (10mM Tris/ $\mathrm{HCl}, \mathrm{pH} 8,5)$ eluiert werden kann. Die Aufnahme der DNA erfolgte routinemäßig in

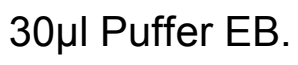




\subsubsection{Konzentrationsbestimmungen von DNA und RNA}

Zur Konzentrationsbestimmung von DNA und RNA fand eine Bestimmung der Absorption bei 260nm statt. Bei dieser Wellenlänge entspricht eine Absorption von 1,0 bei $1 \mathrm{~cm}$ Schichtdicke der verwendeten Quarzküvette einer Konzentration von etwa $50 \mu \mathrm{g} / \mathrm{ml}$ dsDNA bzw. $40 \mu \mathrm{g} / \mathrm{ml}$ ssDNA oder RNA (SAMBROOK et al., 1989).

Zur Überprüfung des Reinheitsgrades von isolierter DNA wurde routinemäßig zusätzlich die Absorption bei $280 \mathrm{~nm}$ bestimmt. Dabei sollte das Verhältnis von $\mathrm{OD}_{260 \mathrm{~nm}} / \mathrm{OD}_{280 \mathrm{~nm}}$ für reine $\mathrm{DNA}$ bei 1,8 liegen (SAMBROOK et al., 1989). Proteinverunreinigungen senken diesen Wert.

\subsubsection{Ligation}

Um DNA-Fragmente in einen Vektor zu klonieren, wurden der pGEM-T-Easy-Kit der Firma Promega bzw. der T4-DNA-Ligations-Kit der Firma MBI-Fermentas verwendet. Ausgehend von der DUGAICZYK-Formel (DUGAICZYK et al., 1975; s.u.) wurde das zu klonierende DNA-Fragment mit einem 2-bis 4-fachen molaren Überschuß zur Vektor-DNA zugegeben. Hinzu kamen 0,1 Volumen 10-fach konzentrierter LigasePuffer des Herstellers und 0,1 Volumen T4-DNA-Ligase. Die Inkubation erfolgte für mindestens $1 \mathrm{~h}$ bei $4^{\circ} \mathrm{C}$ im Falle des pGEM-T-Easy-Kits bzw. bei RT, wenn der T4DNA-Ligations-Kit verwendet wurde. Die Beendigung der Reaktion erfolgte durch eine 10 minütige Inkubation bei $65^{\circ} \mathrm{C}$. Um die Transformationsrate zu steigern, wurde der Ligationsansatz 1:5 mit $\mathrm{H}_{2} \mathrm{O}_{\text {bidest }}$ verdünnt (JESSE, 1984).

\subsubsection{Herstellung kompetenter $E$. coli-Zellen (nach INOUE et al., 1990) und Transformation von kompetenten Zellen}

Herstellung kompetenter Zellen

Für die durchgeführten Transformationen wurden kompetente E. coli XL1-Blue-Zellen verwendet, die nach der Methode von INOUE et al. (1990) hergestellt worden waren. Von einer LB-Übernachtkultur (ohne Antibiotikum) von E. coli XL1-Blue wurden 8ml abgenommen und damit 250ml SOB-Medium beimpft. Das Wachstum dieser Kultur erfolgte bei $18^{\circ} \mathrm{C}$ bis zu einer $\mathrm{OD}_{600 \mathrm{~nm}}$ von 0,6 . Anschließend kamen die Zellen für $10 \mathrm{~min}$ auf Eis, bevor sie für $10 \mathrm{~min}$ bei $5000 \mathrm{U} / \mathrm{min}$ und $4^{\circ} \mathrm{C}$ pelletiert wurden. Der Überstand wurde verworfen und das Zellpellet vorsichtig in $80 \mathrm{ml}$ eiskaltem TB resuspendiert. Nach einer erneuten Inkubation für 10 min auf Eis erfolgte ein weiterer Zentrifugationsschritt $\left(5000 \mathrm{U} / \mathrm{min}, 4^{\circ} \mathrm{C}, 10 \mathrm{~min}\right)$. Das erhaltene Zellpellet wurde 
vorsichtig in $20 \mathrm{ml}$ eiskaltem TB aufgenommen und mit DMSO versetzt $(7 \%$ [v/v] Endkonzentration). Nach $10 \mathrm{~min}$ auf Eis wurden die Zellen aliquotiert $(0,1-0,2 \mathrm{ml}$ Aliquots) und sofort in bereitstehendem flüssigen Stickstoff eingefroren. Die Lagerung der kompetenten Zellen erfolgte bei $-80^{\circ} \mathrm{C}$.

Nach Herstellung von neuen kompetenten Zellen wurden sie einer "KontrollTransformation" mit reiner Vektor-DNA unter Selektionsbedingungen unterzogen. Nach Ausplattieren auf Agarplatten mit dem entsprechenden Antibiotikum wurde die Transformationsrate der kompetenten Zellen überprüft.

SOB:

$2 \%(w / v)$ Bacto Tryptone

$0,5 \%(w / v)$ Hefeextrakt

$10 \mathrm{mM} \mathrm{NaCl}$

$2,5 \mathrm{mM} \mathrm{KCl}$

$10 \mathrm{mM} \mathrm{MgCl}_{2}$

$10 \mathrm{mM} \mathrm{MgSO}_{4}$

$\mathrm{pH} \mathrm{6,7} \mathrm{-} \mathrm{7,0}$

TB: $\quad 10 \mathrm{mM}$ Pipes

$15 \mathrm{mM} \mathrm{CaCl}_{2}$

$250 \mathrm{mM} \mathrm{KCl}$

$55 \mathrm{mM} \mathrm{MnCl} 2$

$\mathrm{pH} 6,7$

( $\mathrm{pH}$ vor Zugabe von $\mathrm{MnCl}_{2}$ mit $5 \mathrm{~N} \mathrm{KOH}$ einstellen)

\section{Transformation von kompetenten Zellen}

$50 \mu \mathrm{l}$ der langsam auf Eis aufgetauten kompetenten Zellen wurden mit dem Ligationsansatz versetzt und nach vorsichtiger Durchmischung für 20min zur Adsorbtion der DNA auf Eis inkubiert. Anschließend erfolgte ein 1-minütiger Hitzeschock bei $42^{\circ} \mathrm{C}$, der der Aufnahme der DNA in die Zellen diente. Nach Inkubation der Zellen für $2 \mathrm{~min}$ auf Eis wurden $500 \mu$ L LB-Medium ohne Antibiotika zupipettiert. Nach einer Inkubation der Transformationsansätze für $30 \mathrm{~min}$ bei $37^{\circ} \mathrm{C}$ zur Ausprägung der plasmidkodierten Eigenschaften (z.B. Antibiotikaresistenz) wurden 50-200 $\mu$ l des Transformationsansatzes auf Komplexmediumagarplatten mit Antibiotikum (und z.T. mit IPTG und X-Gal) mit einem Drigalsky-Spatel ausplattiert und über Nacht bei 30 oder $37^{\circ} \mathrm{C}$ inkubiert. 


\subsubsection{DNase I-Verdau}

Zur Verhinderung von unspezifischen Reaktionen aufgrund von verunreinigender DNA in RNA-haltigen Lösungen während der reversen Transkription erfolgte ein DNAse I-Verdau.

Ansatz:

$1 \mu \mathrm{g}$ total RNA

$1 \mu$ Omniscript RT-Puffer

$0,5 \mu \mathrm{l}$ DNAse I $(10 \mathrm{U} / \mu \mathrm{l})$

ad $10 \mu \mathrm{l}$ RNAse-freies $\mathrm{H}_{2} \mathrm{O}$

Der Ansatz wurde für $15 \mathrm{~min}$ bei $37^{\circ} \mathrm{C}$ inkubiert, anschließend mit $1 \mu \mathrm{l} 25 \mathrm{mM}$ EDTA versetzt und für $10 \mathrm{~min}$ bei $65^{\circ} \mathrm{C}$ inkubiert, um die DNase I zu inaktivieren.

\subsubsection{Reverse Transkription von mRNA in cDNA}

Während der reversen Transkription wird mRNA in cDNA umgeschrieben. Für diese Reaktion wurde die Qiagen Omniscript Reverse Transcriptase eingesetzt, wobei nach den Vorschriften des Herstellers vorgegangen worden ist. Pro RT-Reaktion wurden jeweils 500ng total-RNA aus humanen Fibroblasten bzw. Leukozyten als Template verwendet, die zuvor DNAse I (3.2.4.16) behandelt worden war. Ein Standard-RT-Ansatz sah folgendermaßen aus:

\section{Standard-RT-Reaktion}

$2 \mu \mathrm{l}$ 10xRT-Puffer

$2 \mu \mathrm{l} 5 \mathrm{mM}$ dNTP

$1 \mu$ I Omniscript Reverse Transcriptase

$2 \mu \mathrm{l}$ spezifischer Primer (10pmol/ $\mu \mathrm{l})$

500ng total-RNA aus (DNAse I-Verdau)

ad $20 \mu \mathrm{l} \mathrm{H}_{2} \mathrm{O}_{\mathrm{RNAse}-\text { frei }}$

Inkubation für $1 \mathrm{~h}$ bei $37^{\circ} \mathrm{C}$.

Im Anschluß an die reverse Transkription erfolgten zwei unabhängige PCRReaktionen mit der HotStarTaq-DNA-Polymerase, um die synthetisierten cDNAEinzelstränge zu amplifizieren (siehe 3.2.4.18). 


\subsubsection{Polymerase-Chain-Reaction (PCR) nach SAIKI et al. (1985), modifiziert}

Die PCR ist eine in vitro-Technik, mit der man gezielt DNA-Abschnitte, die von zwei bekannten Sequenzen (Primern) eingerahmt werden, vervielfältigen kann. Die Amplifikationen wurden in einem Perkin Elmer Cycler durchgeführt. Als Template wurde cDNA aus den RT-Ansätzen, genomische DNA, PCR-Produkte oder Plasmide eingesetzt.

Eine Standard-Reaktion mit dem HotStar-Taq-DNA-Polymerase Kit der Firma Qiagen wurde in einem Volumen von $50 \mu l$ durchgeführt und enthielt die folgenden Komponenten.

\section{Standard-PCR-Ansatz}

template-DNA

Primer $A$ und $B$

10xReaktionspuffer

Q-solution

dNTP-Mix (10mM)

HotStarTaq-DNA-Polymerase.

$\mathrm{H}_{2} \mathrm{O}_{\text {bidest }}$
$30-125 n g$

$1,25 \mu \mathrm{l}(10 \mathrm{pmol} / \mu \mathrm{l})$

$5 \mu l$

$10 \mu l$

$1 \mu \mathrm{l}$

$0,5 \mu \mathrm{l}(2,5 \mathrm{U})$

ad $50 \mu \mathrm{l}$

PCR-Reaktionen mit anderen DNA-Polymerasen (bspw. von MBI-Fermentas) wurden entsprechend ohne Q-Solution angesetzt. Weiterhin entfiel die Aktivierung der DNA-Polymerase (s.u.). Alle für die PCR verwendeten Primer sind am Ende des Materialien und Methodenteils aufgeführt.

\section{Berechnung der Annealing-Temperatur der Primer}

Zur Bestimmung der Annealing-Temperatur beim PCR-Lauf mußte die Schmelztemperatur der Primer $\left(\mathrm{T}_{\mathrm{M}}\right)$ berechnet werden. Die Berechnung erfolgte mit Hilfe der folgenden Gleichung:

$\mathrm{T}_{\mathrm{M}}=\left((\right.$ Anzahl der Basen $\left.\mathrm{A}+\mathrm{T}) \times 2^{\circ} \mathrm{C}\right)+\left((\right.$ Anzahl der Basen $\left.\mathrm{G}+\mathrm{C}) \times 4^{\circ} \mathrm{C}\right)$

Von der berechneten durchschnittlichen Schmelztemperatur der Primer wurden 8$10^{\circ} \mathrm{C}$ abgezogen, um auf eine geeignete Annealingtemperatur zu kommen.

\section{PCR-Amplifizierungsprogramm}

Ein routinemäßig durchgeführtes PCR-Programm mit dem verwendeten Perkin Elmer Cycler läßt sich aus der hier aufgeführten Tabelle 2 entnehmen. 
Tab. 2: Routinemäßig durchgeführtes PCR-Programm

\begin{tabular}{|l|c|c|}
\hline \multicolumn{1}{|c|}{ Programmschritt } & Temperatur & Dauer [min] \\
\hline 1. Denaturierung der DNA & $95^{\circ} \mathrm{C}$ & $1-15^{*}$ \\
\hline 2. Denaturierung der DNA & $94^{\circ} \mathrm{C}$ & 0,5 \\
\hline 3. Annealing der Primer & $55^{\circ} \mathrm{C}$ & 0,5 \\
\hline 4. Verlängerung der DNA & $72^{\circ} \mathrm{C}$ & 3 \\
\hline 5. Verlängerung der DNA & $72^{\circ} \mathrm{C}$ & 6 \\
\hline 6. Pause & $4{ }^{\circ} \mathrm{C}$ & \\
\hline \multicolumn{2}{|l|}{ Die Schritte 2-5 wurden 30 mal wiederholt } \\
\hline
\end{tabular}

${ }^{*}$ in Abhängigkeit von der eingesetzten DNA-Polymerase: 15min bei der HotStarTaq-DNA-Polymerase (Qiagen); 1min bei der Taq-DNA-Polymerase (MBI-Fermentas) sowie bei der Pfu-DNA-Polymerase (Stratagene).

Zur Entfernung von Reaktionsrückständen wurden die PCR-Ansätze nach abgelaufenem Programm entweder einer Phenol-Chloroform-Extraktion und EthanolPräzipitation unterzogen oder mit dem PCR-Purification-Kit nach der Herstellervorschrift aufgereinigt.

\subsubsection{9 in vitro-Mutagenese}

Mit Hilfe der in vitro-Mutagenese lassen sich Mutationen in Vektoren oder Plasmide einbringen, um bspw. neue Restriktionsschnittstellen oder Aminosäureaustausche in einer klonierten cDNA zu erzeugen. Synthetische Oligonukleotide von etwa 30bpLänge, die die gewünschte Mutation in ihrer Mitte tragen und jeweils komplementär zum jeweiligen Strang der DNA-Matrize sind, wurden für die Mutagenese eingesetzt. Durch Verwendung der Pfu-Turbo-Polymerase (Firma Stratagene) mit 'proofreading' Aktivität wurden DNA-Stränge synthetisiert, die die gewünschte Mutation trugen und zudem über keine DNA-Methylierung verfügten. Nach Ablauf der Reaktion wurde der $50 \mu l-A n s a t z$ mit dem Restriktionsenzym Dpnl (10 U) versetzt und $1 \mathrm{~h}$ bei $37^{\circ} \mathrm{C}$ inkubiert. Dpnl erkennt die parentale, methylierte DNA und baut diese ab. Durch Transformation in E.coli-XL1-Blue-Zellen wurden Vektoren bzw. Plasmide erhalten, die über die eingebrachte Mutation verfügten.

Verwendet wurde das Protokoll für die QuickChange in vitro-Mutagenese der Firma Stratagene, wobei nach Angaben des Herstellers vorgegangen wurde (siehe auch Tab. 3). 
Mutagenese-Ansatz:

$\begin{array}{ll}\text { 10xPCR-Puffer } & 5 \mu \mathrm{l} \\ \text { dNTP }(10 \mathrm{mM}) & 1 \mu \mathrm{l} \\ \text { Primer } 1 \text { und } 2 & \text { jeweils } 125 \mathrm{ng} \\ \text { Template } & 30 \mathrm{ng} \\ \text { Pfu-Turbo-PM } & 1 \mu \mathrm{l}(2,5 \mathrm{U} / \mu \mathrm{l}) \\ \mathrm{H}_{2} \mathrm{O}_{\text {bidest }} & \text { ad } 50 \mu \mathrm{l}\end{array}$

Tabelle 3: verwendetes PCR-Mutagenese-Programm

\begin{tabular}{|l|c|c|}
\hline \multicolumn{1}{|c|}{ Programmschritt } & Temperatur & Dauer [min] \\
\hline 1. Denaturierung der DNA & $94^{\circ} \mathrm{C}$ & 0,5 \\
\hline 2. Denaturierung der DNA & $94^{\circ} \mathrm{C}$ & 0,5 \\
\hline 3. Annealing der Primer & $55^{\circ} \mathrm{C}$ & 1 \\
\hline 4. Verlängerung der DNA & $68^{\circ} \mathrm{C}$ & $1 / \mathrm{kbp}$ \\
\hline 5. Pause & $4^{\circ} \mathrm{C}$ & \\
\hline \multicolumn{2}{|l|}{ Die Schritte 2-4 wurden 16 mal wiederholt } \\
\hline
\end{tabular}

\subsubsection{DNA-Sequenzierung}

Die durchgeführten Sequenzierungen von PCR-Produkten und Plasmiden nach der Methode der Dye-Labeled Terminator Sequencing DNA-Sequenzierungsmethode (ROSENBLUM et al., 1997) mit dem DNA-Sequenzer Typ 310. Bei dieser DNASequenzierungsmethode wird eine Markierung kovalent an die dNTPs angehängt, und zwar jeweils eine anders gefärbte Markierung für den jeweiligen Kettenabbruch. Aus der Sequenz der Farben ergibt sich direkt die Basensequenz.

\section{Ein Sequenzierungsansatz sah folgendermaßen aus:}

$\begin{array}{ll}\text { dsDNA } & 10 \mathrm{ng} \text { (PCR-Produkt); } 250 \mathrm{ng} \text { (Plasmid-DNA) } \\ \text { Primer } & 5 \mathrm{pmol} \\ \text { Premix } & 2 \mu \mathrm{l} \\ \text { ad } \mathrm{H}_{2} \mathrm{O}_{\text {bidest }} & 10 \mu \mathrm{l}\end{array}$

In dem Premix befanden sich neben dem Puffer für die PCR noch die Polymerase (AmpliTaq-Gold-DNA-Polymerase) und die markierten dNTPs. Der Sequenzierungsansatz wurde in einem Perkin Elmer Cycler unter Verwendung des hier aufgeführten Programms inkubiert. Die verwendeten Primer sind am Ende des Materialien und Methodenteils aufgeführt. 
1. Eingangs-Denaturierung der DNA für $30 \mathrm{sec}$ bei $94^{\circ} \mathrm{C}$

2. Denaturierung der DNA für $15 \mathrm{sec}$ bei $94^{\circ} \mathrm{C}$

3. Primer-Annealing für $15 \mathrm{sec}$ bei $50^{\circ} \mathrm{C}$

4. Extension für $4 \mathrm{~min}$ bei $60^{\circ} \mathrm{C}$

5. Pause bei $4{ }^{\circ} \mathrm{C}$.

Die Schritte 2-4 wurden 25 mal wiederholt.

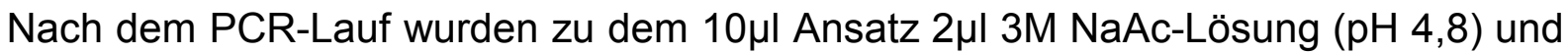
$50 \mu \mathrm{l} 100 \% \quad(\mathrm{v} / \mathrm{v})$ Ethanol zugegeben und vermischt. Durch 15-minütiges Zentrifugieren bei $13000 \mathrm{U} /$ bei RT wurde die DNA pelletiert. Der Alkohol wurde abpipettiert und das Pellet mit $250 \mu \mathrm{l} 70 \%$ (v/v) Ethanol gewaschen (5 min, 13000U/min, RT). Nach vorsichtigem Entfernen des Ethanols wurde die DNA 10min bei RT getrocknet. Das getrocknete Pellet konnte bei $-20^{\circ} \mathrm{C}$ bis zum Sequenzlauf aufbewahrt werden. Vor dem Start der Sequenzierungsreaktion wurde das DNAPellet mit $25 \mu \mathrm{H}_{2} \mathrm{O}_{\text {bidest }}$ versetzt und darin resuspendiert. Anschließend erfolgte die Denaturierung der DNA-Proben für $2 \mathrm{~min}$ bei $90^{\circ} \mathrm{C}$ und der Lauf im DNA-Sequenzer. Für die Auswertung der Sequenzen standen die Programme EDIT VIEW 1.0 ABI PRISM und DNA-Star zur Verfügung.

\subsubsection{Northern Blot von Gesamt-RNA der Patientin und Kontrollen}

Zur Trennung von RNA wurden Agarose-Formaldehyd-Gele mit einem speziellen Lauf- und Probenpuffer verwendet.

10x Laufpuffer:

$$
\begin{aligned}
& \text { 200mM MOPS } \\
& 50 \mathrm{mM} \mathrm{NaAc} \\
& 10 \mathrm{mM} \text { EDTA } \\
& \mathrm{pH} 7,0 \text { mit } 5 \mathrm{~N} \mathrm{NaOH} \text { einstellen }
\end{aligned}
$$

$\begin{array}{ll}\text { Probenpuffer: } & 4 \text { Teile } \mathrm{H}_{2} \mathrm{O} \\ & 4 \text { Teile Formamid } \\ & 2 \text { Teile Formaldehyd }(37 \%) \\ & 2 \text { Teile } 10 x \text { Laufpuffer } \\ & 1 \text { Teil Bromphenol-Blau-Lösung }\end{array}$


RNA-Gele wurden in einer speziell nur für diesen Zweck benutzten Gelkammer gefahren, die zuvor $2 \mathrm{~h}$ in $5 \mathrm{~N} \mathrm{NaOH}-L o ̈ s u n g ~ i n k u b i e r t$ worden war. Die Agarose $(1 \%)$ wurde in 1xLaufpuffer gelöst, auf $55^{\circ} \mathrm{C}$ abgekühlt, mit Ethidiumbromid (Endkonzentration 0,5mg/ ml) und Formaldehyd (Endkonzentration 0,65\%) versetzt und in eine RNAse-freie Form gegossen. Die RNA-Proben ( $5 \mu$ total-RNA) wurden gefällt und das Pellet in $25 \mu$ l Probenpuffer gelöst. Vor dem Auftrag wurden die RNAProben $5 \mathrm{~min}$ auf $65^{\circ} \mathrm{C}$ erhitzt. Nach dem Lauf wurde das Gel 10min in 20x SSC äquilibriert. Der Transfer erfolgte über Nacht mit 20x SSC als Transferpuffer. Der Filter wurde bei RT getrocknet und für 11sec auf dem UV-Transilluminator mit UVLicht (254nm) bestrahlt, um die RNA kovalent an den Filter zu binden.

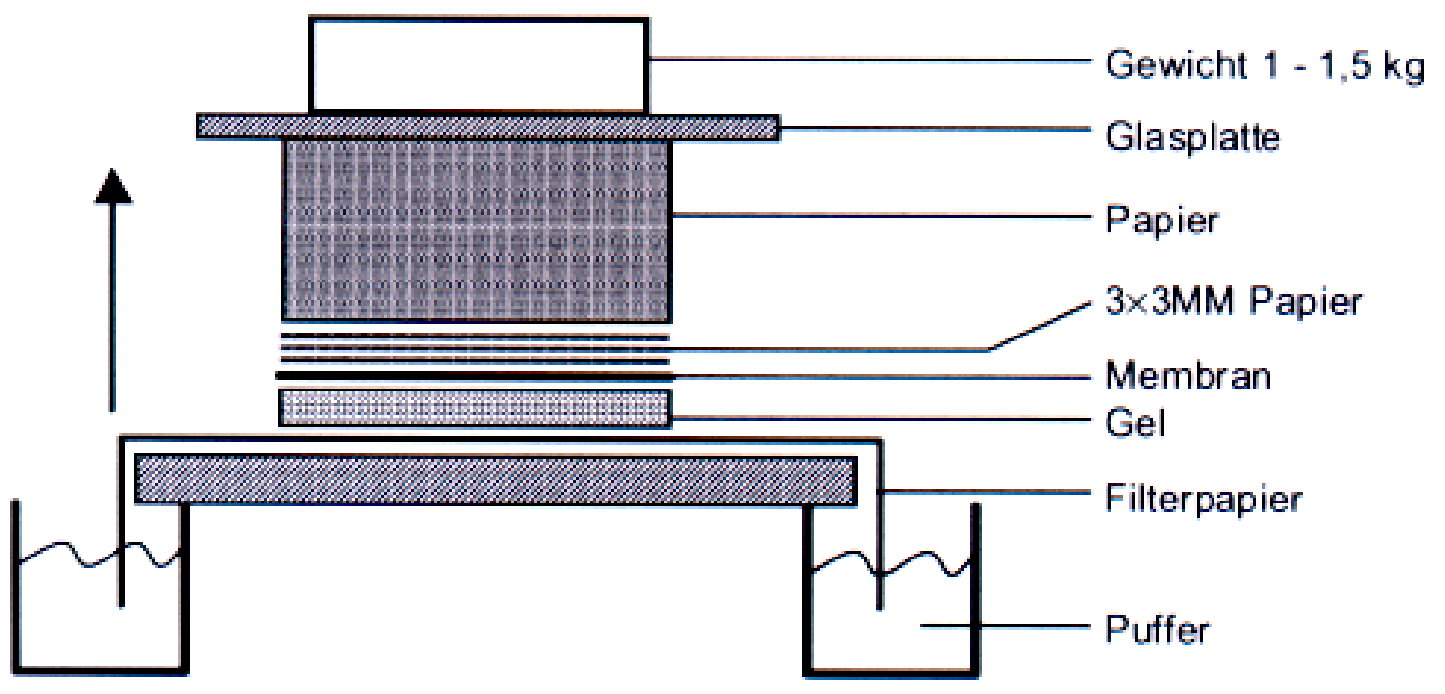

Abb. 7: Northern Blot

Die Abbildung zeigt die Technik des Transfers der Nukleinsäure aus dem Agarosegel auf HybondNylon-Filter. Der Pfeil zeigt die Richtung des Flüssigkeitsstroms an, durch den die RNA aus dem Agarosegel auf einen darüberliegenden Filter übertragen wird.

\subsubsection{DNA-Markierung mit $\alpha-^{32} \mathrm{P}-\mathrm{dCTP}$}

Spezifische DNA-Sonden wurden zur Detektion von spezifischer humaner mRNA in einem Northern Blot eingesetzt. Hierzu verwendet wurden für die interessierende mRNA spezifische PCR-Fragmente mit einer Länge zwischen 500bp und 800bp. Die radioaktive Markierung der DNA-Sonde (denaturierte DNA) erfolgte nach dem Random Priming-Verfahren. Hierzu wurde das RediPrime II DNA Labelling Kit der Firma Amersham Pharmacia verwendet. 30ng des PCR-Fragments wurden in $45 \mu \mathrm{l}$ 
$\mathrm{H}_{2} \mathrm{O}_{\text {bidest }}$ aufgenommen, $5 \mathrm{~min}$ bei $95^{\circ} \mathrm{C}$ denaturiert und nach Anzentrifugieren sofort auf Eis gestellt. Die $45 \mu \mathrm{l}$ mit der denaturierten DNA wurden zusammen mit $5 \mu \mathrm{l} \alpha-{ }^{32} \mathrm{P}-$ dCTP $(50 \mu \mathrm{Ci})$ auf den pelletierten Markierungs-Mix gegeben und gemischt. Der Ansatz wurde $15 \mathrm{~min}$ bei $37^{\circ} \mathrm{C}$ inkubiert und die radioaktiv markierten DNAFragmente wurden anschließend von den nicht inkorporierten Nukleotiden mittels des QIAquick Nucleotide Removal Kits der Firma Qiagen getrennt. Hierbei wurde nach der Hersteller-Vorschrift für die Aufreinigung radioaktiver DNA-Fragmente verfahren. Eluiert wurde die DNA in $200 \mu$ l Puffer EB. Die eingebaute Radioaktivität im Cerenkov-Verfahren (Berger, 1984) bestimmt. Die spezifische Aktivität der ${ }^{32} \mathrm{P}$ markierten DNA-Fragmente lag in der Regel bei ca. $10^{6} \mathrm{cpm} / \mu \mathrm{g}$ DNA.

\subsubsection{Hybridisierung der Hybond-N-Filter mit radioaktiv markierten DNA-} Sonden

Zur Hybridisierung wurde die getrocknete Nylonmembran mit dem Hybridisierungsmix $\left(1 \mathrm{ml} / \mathrm{cm}^{2}\right)$ in einem $50 \mathrm{ml}$ Plastikröhrchen $10-15 \mathrm{~min}$ bei $42^{\circ} \mathrm{C}$ vorinkubiert. Die radioaktiv markierte DNA-Sonde (Endkonz.: 2x10 $\mathrm{cpm} / \mathrm{ml}$ Mix) und ca. $20 \mu \mathrm{l}$ Lachsspermien-DNA (Endkonz.: 100 $\mu \mathrm{g} / \mathrm{ml}$ Hybridisierungsmix) wurden 5 min bei $95^{\circ} \mathrm{C}$ denaturiert und dem Hybridisierungsmix mit dem Filter zugesetzt. Dieser Hybridisierungsansatz wurde über Nacht bei $42^{\circ} \mathrm{C}$ auf einem Drehrad inkubiert. Danach wurde der radioaktive Hybridisierungsmix dekantiert und der Filter zweimal für 10min in Waschlösung 1 bei RT, danach solange mit Waschlösung 2 bei $68^{\circ} \mathrm{C}$ stringent gewaschen bis eine meßbare Radioaktivität (Handmonitor) auf dem Filter von etwa 30cpm detektiert wurde. Der Filter wurde in Folie eingeschweißt und auf einem Röntgenfilm (Kodak XAR-5) zwischen Verstärkerfolien (Cronix Dupont) bei $-80^{\circ} \mathrm{C}$ über Nacht inkubiert.

\section{Lachsspermien-DNA}

Die Lachsspermien-DNA wurde mit einer sterilen Schere zerkleinert und in $\mathrm{H}_{2} \mathrm{O}_{\text {bidest }}$ gelöst (Endkonz.: 10mg/ml). Nach 10min Ultraschall und Aufkochen in der Mikrowelle wurde erneut beschallt. Die so homogenisierte DNA wurde aliquotiert und bei $-20^{\circ} \mathrm{C}$ gelagert. 
$\underline{\text { Hybridisierungsmix }}$

$72 \mathrm{ml}$ Formamid

$36 \mathrm{ml} 20 x$ SSC

1,5ml $1 \mathrm{M}$ Tris/ $\mathrm{HCl}, \mathrm{pH} 7,5$

$1,5 \mathrm{~g}$ SDS

3ml 50x Denhardts-Lösung

$15 \mathrm{~g}$ Dextransulfat

Das Dextransulfat wurde in $30 \mathrm{ml} \mathrm{H}_{2} \mathrm{O}_{\text {bidest }}$ aufgenommen und bei $80^{\circ} \mathrm{C}$ gelöst. Anschließend wurden die restlichen Substanzen zugesetzt und das Volumen auf $150 \mathrm{ml}$ mit $\mathrm{H}_{2} \mathrm{O}_{\text {bidest }}$ aufgefüllt.

Waschlösung 1:

$2 \times \operatorname{SSC}$

$5 \%$ (w/v) SDS in $\mathrm{H}_{2} \mathrm{O}_{\text {bidest }}$

Waschlösung 2:

$0,2 \times$ SSC

$0,1 \%$ (w/v) SDS in $\mathrm{H}_{2} \mathrm{O}_{\text {bidest }}$

\subsubsection{Transfektion von FNX-Eco-Zellen mit FuGENE6-Transfektionsreagenz}

Zur stabilen Expression der komplementierenden Patienten- bzw. WT-cDNA wurden die primären, humanen Fibroblasten nach der Klonierung der jeweiligen cDNA in den retroviralen, selektierbaren pLNCXII-Vektor transduziert. Unter der Kontrolle des CMV-Promotors integriert dieser Vektor neben der cDNA auch das NeomycinResistenzgen in das Genom der Fibroblasten, so daß durch G418-Selektion stabile Zelllinien erzeugt werden können. Am Tag vor der Transfektion wurden $5 \times 10^{5} \mathrm{der}$ adhärenten FNX-Eco-Zellen mit 4ml Medium in $60 \mathrm{~mm}$ Zellkulturschalen ausplattiert. Die Transfektion mit dem FuGENE6-Transfektionsreagenz erfolgte nach der Vorschrift des Herstellers. Hierzu wurden drei Teile Transfektionsreagenz mit 94 Teilen serumfreien DMEM in einem sterilen Eppendorfgefäß vorsichtig gemischt und bei RT für 5min inkubiert. 3ug Plasmid (pLNCXII mit der mutierten bzw. WT-cDNA für die lange alg2-Isoform) bzw. nur pLNCXII-Vektor-DNA (mock), jeweils gelöst in $3 \mu l$ sterilem $\mathrm{H}_{2} \mathrm{O}_{\text {bidest, }}$ wurden in ein weiteres Eppendorfgefäß pipettiert und mit dem DMEM-Transfektionsreagenzgemisch vermischt. Nach einer Inkubation von 20min bei RT wurde das Transfektionsgemisch tröpfchenweise auf die Zellen gegeben. 


\subsubsection{Produktion retroviraler Partikel zur Transduktion primärer, humaner} Fibroblasten

Die transiente Transfektion von FNX-Eco-Zellen wurde wie unter 3.2.4.24 beschrieben durchgeführt. Die Zellen wurden anschließend für $24 \mathrm{~h}$ bei $37^{\circ} \mathrm{C}$ inkubiert. Zur Stabilitätserhaltung retroviraler Partikel erfolgte dann ein Temperaturshift der Zellen auf $33^{\circ} \mathrm{C}$ und eine weitere Inkubation für $24 \mathrm{~h}$. Der die ecotropen Viruspartikel enthaltende Überstand der FNX-Eco-Zellen wurde durch

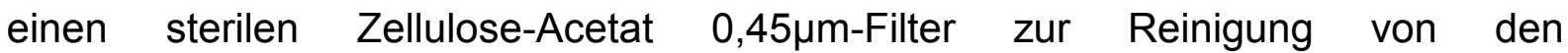
Verpackungszellen gegeben und mit $6 \mu \mathrm{g}$ Polybrene pro $\mathrm{ml}$ Zellüberstand zur Herabsetzung der ladungsbedingten Abstoßung zwischen dem Viruspartikel und der Zellmembran versetzt. Der so behandelte Überstand wurde dann zur Infektion von $5 \times 10^{5}$ PT67-Verpackungszellen eingesetzt, die am Tag vor der Infektion auf 60mm Gewebekulturschalen ausplattiert worden waren. Nach einer Inkubation von $8 \mathrm{~h}$ bei $37^{\circ} \mathrm{C}$ erfolgte der Temperaturshift der Zellen auf $33^{\circ} \mathrm{C}$ für $16 \mathrm{~h}$. Die Ernte der amphotrophen Überstände erfolgte auf gleiche Weise wie bei den ecotrophen Überständen. Die amphotrophen Verpackungszellen erhielten $4 \mathrm{ml}$ frisches Medium und wurden für weitere $24 \mathrm{~h}$ bei $33^{\circ} \mathrm{C}$ zur Produktion eines zweiten amphotropen Virusüberstandes inkubiert. Mit dem geernteten ersten amphotropen Überstand wurden die $48 \mathrm{~h}$ zuvor ausplattierten primären, humanen Fibroblasten $\left(2 \times 10^{5}\right.$ Zellen/ $60 \mathrm{~mm}$ Gewebekulturschale) ein erstes Mal infiziert und die Zellen für $16 \mathrm{~h}$ bei $37^{\circ} \mathrm{C}$ inkubiert. Das Medium wurde abgezogen, durch neues Medium ersetzt und die Zellen für weitere $8 \mathrm{~h}$ kultiviert. 24h nach Abnahme des ersten amphotropen Überstandes wurde ein zweiter Überstand von den PT67-Zellen geerntet, um die humanen Fibroblasten ein zweites Mal zu infizieren. Dieser Vorgang wiederholte sich noch ein weiteres Mal. Die Fibroblastenzellen, die am Ende 3x mit amphotropen Überständen behandelt worden waren, wurden für weitere $48 \mathrm{~h}$ in selektionsfreiem Medium kultiviert. Dann erfolgte der Wechsel auf Medium mit G418 (0,4mg/ml Geneticin) und eine Selektion über 10 Tagen, um stabile Zellinien zu erhalten. 


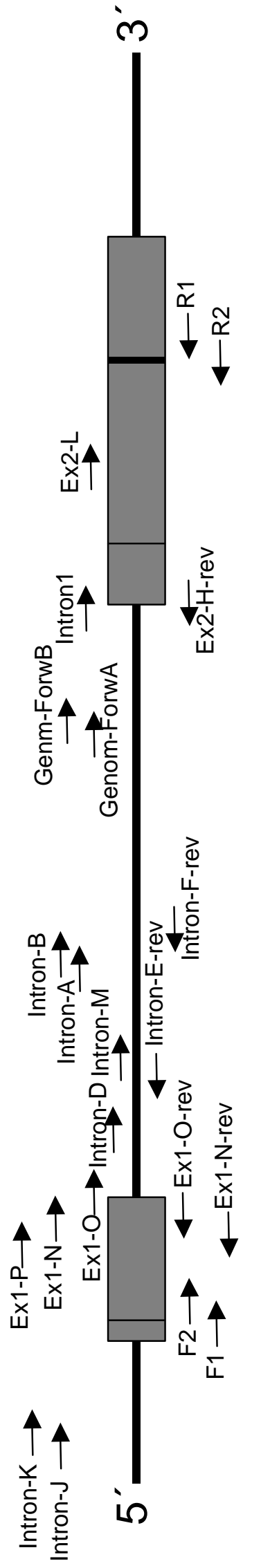

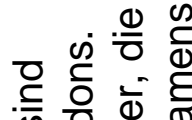

क

कृ

ய究苍至

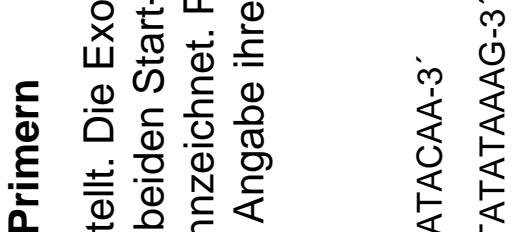

ब

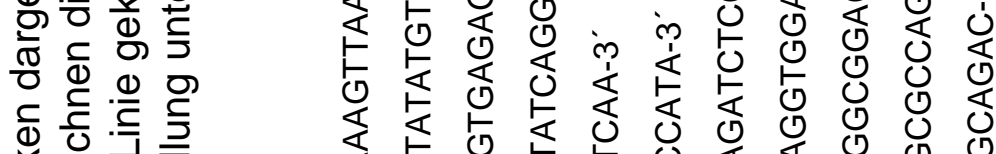

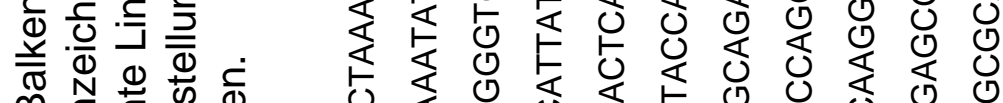

ब

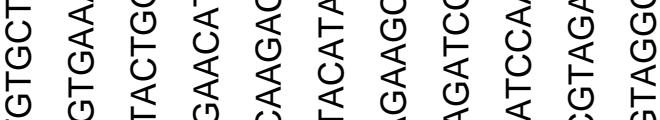

ब

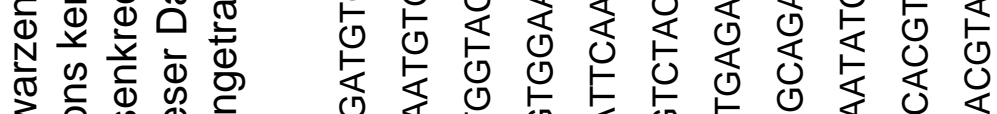

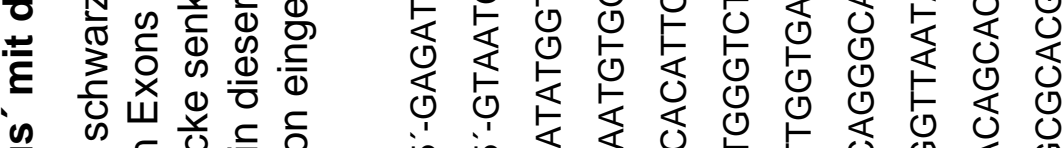

象

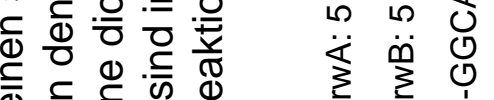

过

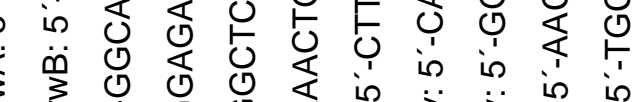

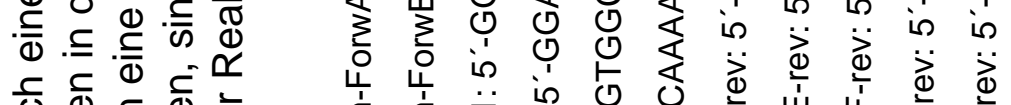

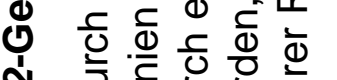

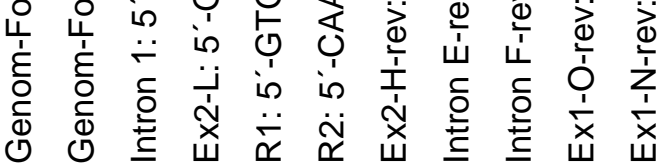

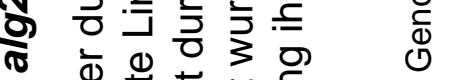

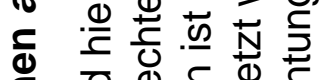

ब

蛋

$\&$ 을 空

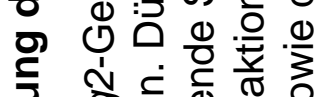

ภิธ

응

\&

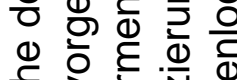

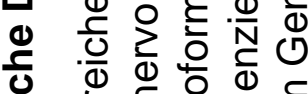

Ф

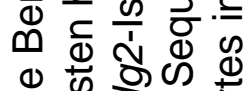

赵

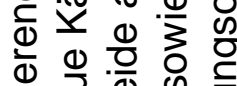

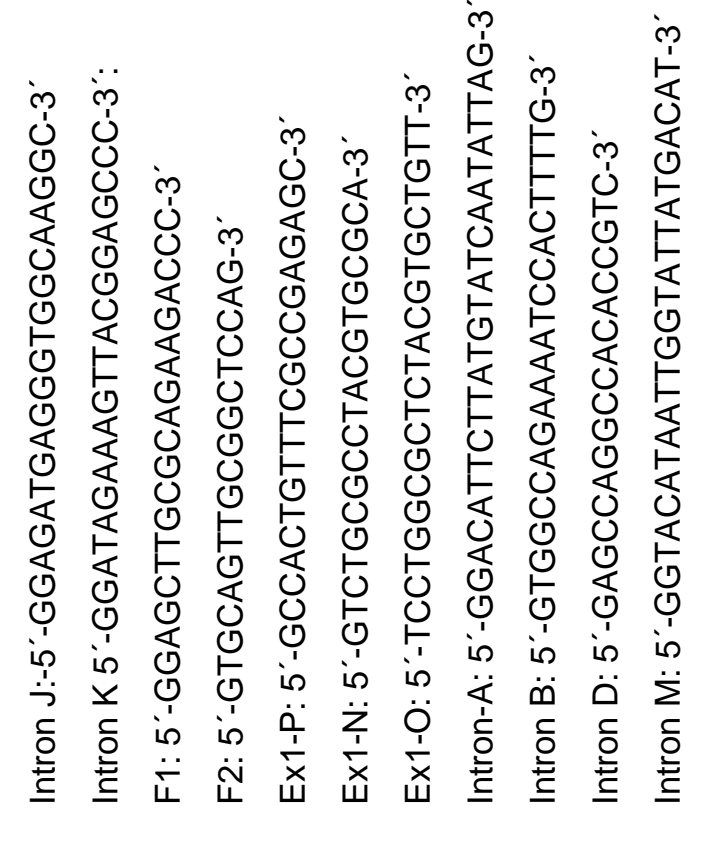




\section{Ergebnisse}

\subsection{Patientenanamnese}

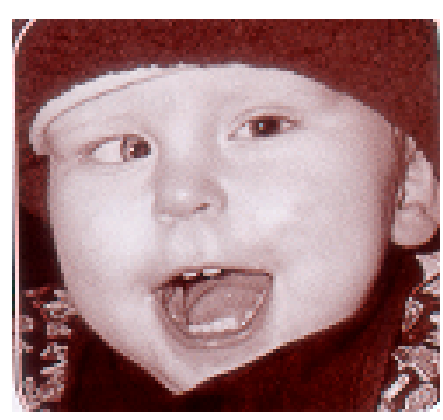

Die Patientin M.S. wurde am 05.08.1999 als erstes Kind gesunder Eltern geboren. In der Familie mütterlicherseits wurden bei der Großmutter sowie bei einem Onkel eine Anfallsbereitschaft diagnostiziert. Darüber hinaus traten mehrere ungeklärte Todesfälle im frühen Säuglingsalter, Verhaltensauffälligkeiten und motorische Gangstörungen auf.

In der Familie des Vaters sind keine Auffälligkeiten bekannt. Die Schwangerschaft verlief unauffällig. In der 36 . Schwangerschaftswoche mußte die Geburt wegen eines vorzeitigen Blasensprungs eingeleitet werden. Das Geburtsgewicht des Kindes betrug $3230 \mathrm{~g}$, der APGAR-Test (Klassifizierungstest für Adaptationsstörungen) zeigte normale Werte von 9/10/10. Es traten keine postnatalen Komplikationen auf, und das Kind zeigte bis zum 3. Lebensmonat eine unauffällige frühkindliche Entwicklung. Danach wurde auf beiden Augen eine Irismissbildung sowie ein Katarakt auf dem linken Auge festgestellt, welches operativ behandelt wurde. Darüber hinaus wurde eine Haltungsasymmetrie nach rechts sowie eine allgemein verzögerte Entwicklung und eine geringere Reaktion auf Umweltreize jeder Art festgestellt. Im Alter von 4 Monaten wurde die Diagnose eines BNS-Leidens (BlitzNick-Salaam-Krämpfe: kurze Propulsivbewegungen mit tonischer Versteifung) gesichert und eine antikonvulsive Behandlung eingeleitet. Bei der Vorsorgeuntersuchung U5 im Alter von 6 Monaten fiel bei dem Kind das fehlende Abstützen mit geöffneten Händen in Bauchlage auf. Die Werte für Körperlänge (69,5 $\mathrm{cm})$ und Kopfumfang $(43 \mathrm{~cm}$ ) lagen im Normbereich. Das Körpergewicht von $8150 \mathrm{~g}$ lag im oberen Normbereich. Die Bewegungen des Kopfes und der Hände waren ungerichtet. Ein nahezu vollständiger Stillstand der Myelinisierung, ein stark vermindertes Erlernen der Blickfixation, eine einmalig festgestellte Hepatomegalie und eine längere Phase von Erbrechen waren Anlaß für eine Stoffwechseldiagnostik. Dabei wurden bei der Patientin verlängerte Blutgerinnungszeiten (PTT) und eine starke Erniedrigung des Blutgerinnungsfaktors XI festgestellt, wie sie unter anderem in Fällen von CDG beobachtet wurden. Daher wurde im Alter von 9 Monaten eine 
CDG-Diagnostik mit Hilfe der isoelektrischen Fokussierung und des Western-Blots des Serumtransferrins eingeleitet.

\subsection{Proteinbiochemische Untersuchungen}

\subsubsection{Isoelektrische Fokussierung und Western Blot Analyse des Serum- Transferrins}

Im Rahmen der CDG-Diagnostik wurde zunächst eine isoelektrische Fokussierung des Serum-Transferrins unserer Patientin M.S., eines CDG-la-Patienten sowie einer Kontrolle durchgeführt (siehe Abb. 8 oben).

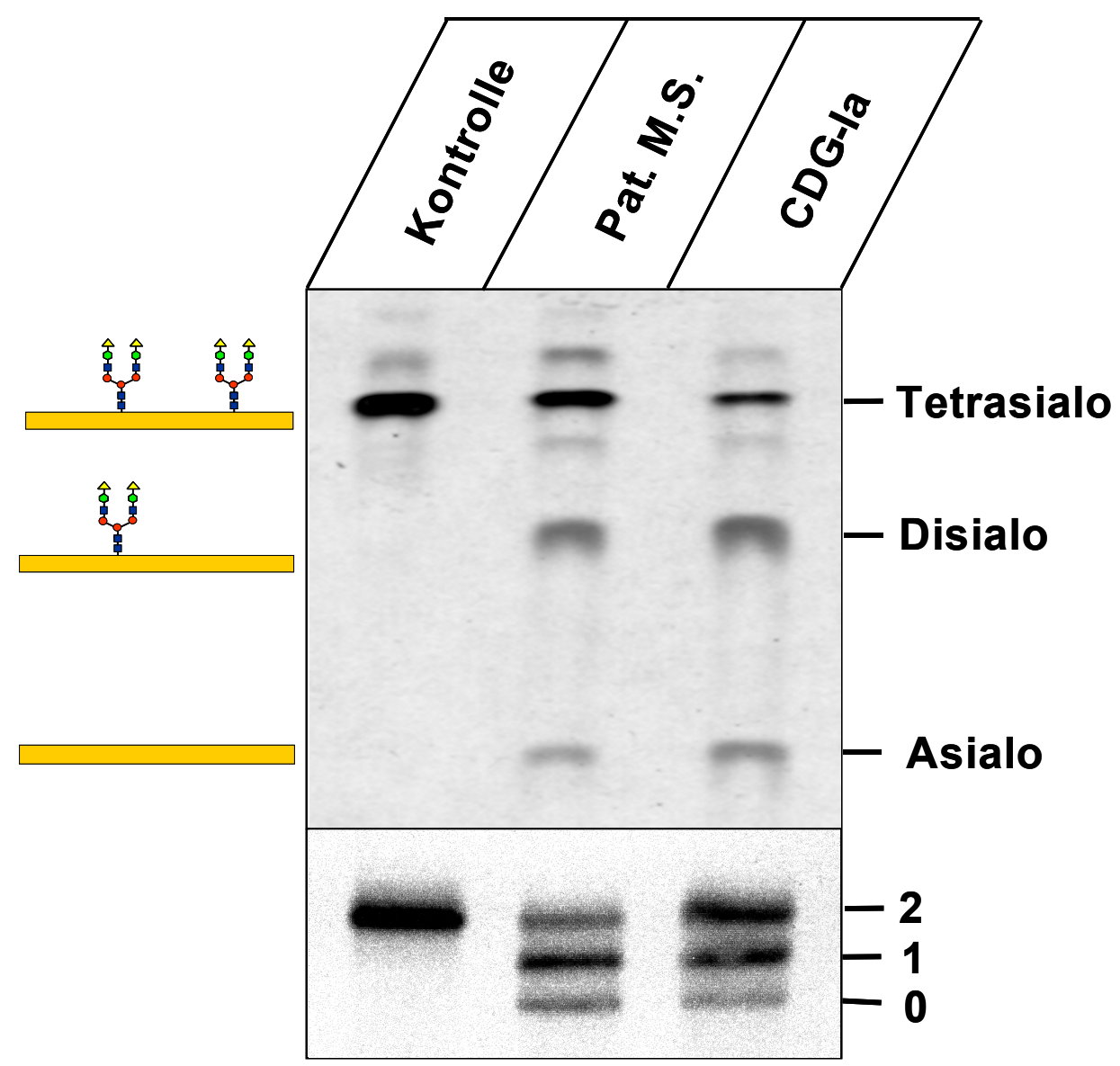

Abb. 8: Isoelektrische Fokussierung und SDS-PAGE des Serum-Transferrins.

Die obere Abbildung zeigt die isoelektrische Fokussierung von Kontroll- und PatientenSerumtransferrin. Die gelben Balken stellen das Transferrinmolekül dar. Das N-glykosidisch verknüpfte Oligosaccharid setzt sich aus den Zuckern N-Acetylglucosamin ( $\mathbf{a})$, Mannose (O), Galaktose $(O)$ und Sialinsäure $(\triangle)$ zusammen. Die untere Abbildung zeigt die Analyse des Serumtransferrins mittels SDS-PAGE. Die Zahlen geben die Anzahl der Transferrin-gebundenen NGlykane wieder. 
Dabei wies das Serum-Transferrin der Kontrollperson eine homogene Bande auf, die der typischen Tetrasialoform von vollständig glykosyliertem und sialyliertem Transferrin entspricht (siehe Einleitung). Bei der Patientin M.S. sowie bei der CDGla-Positivkontrolle erscheinen neben dieser Tetrasialoform des Transferrins zudem gleichstarke Banden für die Disialo- sowie Asialoform des Proteins, was den partiellen Verlust von zwei bzw. vier Sialinsäureresten anzeigt. Dieses IEF-Muster kann u.a. durch den Verlust vollständiger Oligosaccharidketten auf dem TransferrinMolekül erklärt werden, wie es beispielsweise auch bei CDG-la-Patienten gefunden wurde (Jaeken et al., 1984). Mit dem Fehlen kompletter N-Glykane geht auch der Verlust der terminalen Sialinsäurereste einher, wodurch sich die Ladung des Proteins und damit auch das Laufverhalten des Transferrins in der IEF ändert. Um nachzuweisen, daß bei der Patientin tatsächlich komplette Zuckerketten auf dem Transferrin fehlen, wurde eine Western-Blot Analyse des Serum-Transferrins durchgeführt (siehe Abb. 8 unten). Die Glykosylierungsstellen des SerumTransferrins der Negativkontrolle sind vollständig mit Zuckerketten besetzt, was im Western Blot durch eine homogene Bande, der vollständig glykosylierten Transferrinform, zu erkennen ist. Bei der Patientin zeigen sich, wie bei der CDG-laKontrolle, neben dem vollglykosylierten Transferrin zwei zusätzliche Banden, was auf den Verlust einer bzw. beider N-Glykan Moleküle auf dem Serum-Transferrin hinweist.

Durch die Ergebnisse der IEF sowie des Western Blots konnte gezeigt werden, daß auf dem Serum-Transferrin der Patientin M.S. nicht alle Zuckerketten vorhanden sind und damit auch die terminalen Sialinsäurereste fehlen. Das Fehlen ganzer Zuckerketten auf dem Serum-Transferrin deutet auf einen frühen Defekt in der NGlykosylierung und damit auf einen Typ I der CDG hin.

\subsubsection{Bestimmung der Aktivität der Phosphomannomutase 2 (PMM2)}

Etwa $80 \%$ aller CDG-Erkrankten leiden unter CDG-la, einem Defekt des Enzyms PMM2, daß im Cytosol die Umsetzung von Mannose-6-Phosphat zu Mannose-1Phosphat katalysiert (Kepes und Schekman, 1988; Hansen et al., 1997). Bei einem Aktivitätsverlust dieses Enzyms kommt es zum partiellen Verlust kompletter NGlykanketten auf dem Serumprotein Transferrin. Um zu überprüfen, ob es sich bei der Erkrankung der Patientin M.S. ebenfalls um CDG-la handelt, wurde eine Aktivitätsbestimmung der PMM2 sowohl für die Patientin M.S. als auch für Kontrollen 
durchgeführt. Zu diesem Zweck wurden Fibroblastenextrakte mit $\left[2-{ }^{3} \mathrm{H}\right]$ Mannose-6Phosphat inkubiert und die Entstehung von $\left[2-{ }^{3} \mathrm{H}\right]$ Mannose-1,6-Bisphosphat mit Hilfe der Hochspannungspapierelektrophorese bestimmt.

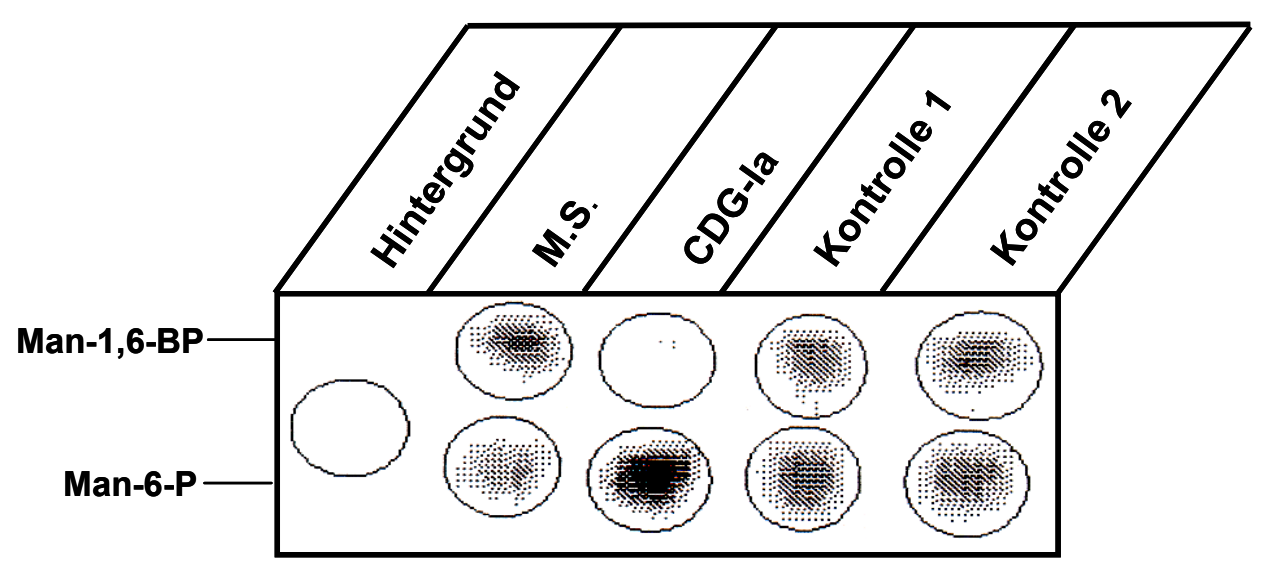

Abb.9: Aktivitätsbestimmung der PMM2 durch Hochspannungspapierelektrophorese

Der Umsatz von [2- $\left.{ }^{3} \mathrm{H}\right]$ Man-6-P (unten) zu $\left[2-{ }^{3} \mathrm{H}\right]$ Man-1,6-BP (oben) in Gegenwart von Fibroblastenextrakten der Patientin bzw. Kontrollen wurde mit Hilfe der Hochspannungspapierelektrophorese und anschließender Auswertung des Trägerpapiers im Flachbettscanner Tracemaster 20 bestimmt. Anschließend wurden das Verhältnis von $\left[2-{ }^{3} \mathrm{H}\right] \mathrm{Man}-1,6-$ $\mathrm{BP} /\left[2-{ }^{3} \mathrm{H}\right] \mathrm{Man}-6-\mathrm{P}$ errechnet und darüber die Enzymaktivität bestimmt. Die Versuchsbedingungen sind so gewählt, daß PMM2 aus Kontrollen etwa $50 \%$ des angebotenen $\left[2-{ }^{3} \mathrm{H}\right]$ Man-6-P zu $\left[2-{ }^{3} \mathrm{H}\right] \mathrm{Man}-1,6-$ BP umsetzt.

Parallel zur Aktivitätbestimmung der PMM2 der Patientin wurden zwei Negativ- und eine CDG-la-Positivkontrolle mitgeführt. Bei den Negativ-Kontrollen zeigten sich bei der Hochspannungspapierelektrophorese zwei gleichstarke Signale für $\left[2-{ }^{3} \mathrm{H}\right] \mathrm{Man}-6-$ $\mathrm{P}$ und $\left[2-{ }^{3} \mathrm{H}\right] \mathrm{Man}-1,6-\mathrm{BP}$. Die CDG-la Positiv-Kontrolle zeigt aufgrund eines PMM2Aktivitätsdefizits einen stark verminderten Umsatz zu Man-1,6-BP. Die Patientin hingegen weist einen ähnlichen Umsatz wie die Kontrollen auf. In Tabelle 4 sind die gemessenen cpm-Werte von $\left[2-{ }^{3} \mathrm{H}\right]$ Man-6-P und $\left[2-{ }^{3} \mathrm{H}\right]$ Man-1,6-BP der Kontrollen und der Patientin sowie die ermittelte jeweilige PMM2-Aktivität dargestellt.

Die Kontrollen 1 und 2 zeigen eine gemittelte PMM2-Aktivität von $0,885 \mathrm{mU} / \mathrm{mg}$, wogegen die CDG-la-Positivkontrolle eine Aktivität von lediglich $0,09 \mathrm{mU} / \mathrm{mg}$ Protein aufweist, was in etwa $1 / 10$ der Enzymaktivität der gesunden Kontrollpersonen entspricht. Für die Patientin wurde eine PMM2-Aktivität von 1,53U/ mg Protein ermittelt, die im Vergleich zu den Kontrollen damit sogar im oberen Normbereich liegt. Ein Defekt in dem PMM2-Enzym konnte als Ursache für die Unterglykosylierung des Transferrins bei der Patientin somit ausgeschlossen werden. 
Tabelle 4: Ermittlung der PMM2-Aktivität

\begin{tabular}{|c|c|c|c|c|}
\hline & $\begin{array}{c}\text { Net } \\
{[\mathrm{cpm}]}\end{array}$ & $\begin{array}{c}\text { Net [cpm] ohne } \\
\text { Hintergrund }\end{array}$ & $\begin{array}{c}\text { Man-1,6-BP/ } \\
\text { Man-6-P }\end{array}$ & $\begin{array}{l}\text { PMM2-Aktivität } \\
\text { [mU/ mg Protein] }\end{array}$ \\
\hline Kontrolle 1 (M-6-P) & 452,61 & 382,50 & \multirow[t]{2}{*}{0,90} & \multirow[t]{2}{*}{1,0} \\
\hline Kontrolle 1 (M-1,6-BP) & 414,60 & 344,50 & & \\
\hline Kontrolle 2 (M-6-P) & 462,68 & 392,60 & \multirow[t]{2}{*}{0,69} & \multirow[t]{2}{*}{0,77} \\
\hline Kontrolle 2 (M-1,6-BP) & 342,73 & 272,60 & & \\
\hline CDG-la (M-6-P) & 715,35 & 645,20 & \multirow[t]{2}{*}{0,08} & \multirow[t]{2}{*}{0,09} \\
\hline CDG-la (M-1,6-BP) & 121,95 & 51,80 & & \\
\hline M.S. (M-6-P) & 286,68 & 216,60 & \multirow[t]{2}{*}{1,39} & \multirow[t]{2}{*}{1,53} \\
\hline M.S. (M-1,6-BP) & 369,91 & 299,80 & & \\
\hline Hintergrund & 70,11 & & & \\
\hline
\end{tabular}

\subsubsection{Bestimmung der Aktivität der Phosphomannose Isomerase}

Ein weiterer früher CDG-Defekt, der sich ebenfalls mit den Ergebnissen der IEF und des Western Blots für die Patientin decken würde, ist der Typ CDG-lb. Die Bestimmung der Aktivität des hierbei betroffenen Enzyms Phosphomannose Isomerase erfolgte durch einen gekoppelten optischen Test, bei dem der Umsatz von Mannose-6-Phosphat über Fructose-6-Phosphat und Glucose-6-Phosphat zu 6Phosphogluconolacton bestimmt wird. Die im letzten Schritt erfolgende Umsetzung von $\mathrm{NADPH}+\mathrm{H}^{+}$zu NADP ${ }^{+}$durch die Glucose-6-Phosphat Dehydrogenase dient dabei zur photometrischen Quantifizierung (van Schaftingen und Jaeken, 1995). Bestimmt wurde die Aktivität der PMI aus Fibroblastenextrakten der Patientin sowie von drei Kontrollen. Die PMI-Aktivität der Patientin lag mit 11,32 $\mathrm{mU} / \mathrm{mg}$ Protein im Vergleich zu den drei mitgeführten Kontrollen, die über eine gemittelte Aktivität von 9,57mU/mg Protein verfügten, im Normbereich. Ein CDG-lb-Defekt aufgrund einer verminderten Aktivität der PMI konnte damit neben CDG-la ausgeschlossen werden.

\subsubsection{HPLC-Analyse Dolichol-verknüpfter Oligosaccharide der Patientin M.S. zum Ausschluss der CDG-Typen Ic, Id, le, If und Ig}

Nachdem die Erkrankungen vom Typ CDG-la und lb im Fall der Patientin M.S. ausgeschlossen werden konnten, wurden weitere bekannte CDG-I Typen mit Hilfe der HPLC-Analyse von metabolisch mit $\left[2{ }^{3} \mathrm{H}\right]$ Mannose markierten Dolichol- 
verknüpften Oligosacchariden aus Kontroll- und Patientenfibroblasten untersucht (Körner et al., 1998b). Nach der Abspaltung der Oligosaccharide durch milde saure Hydrolyse erfolgte eine Auftrennung mittels HPLC über einen Acetonitrilgradienten

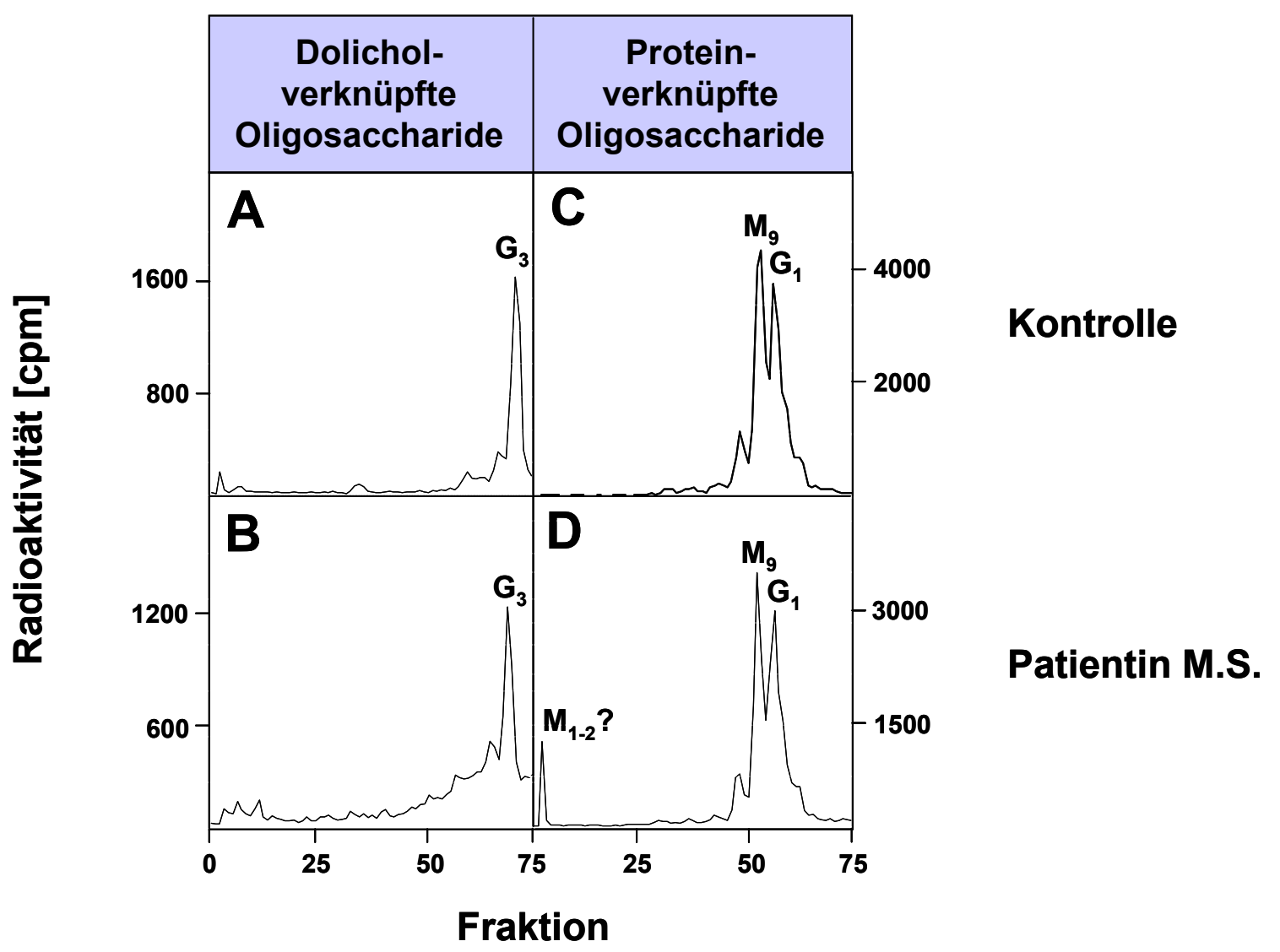

Abb. 10: HPLC-Analyse Dolichol-verknüpfter und Protein-verknüpfter Oligosaccharide der Patientin M.S und einer Kontrolle

A und B: Analyse der Lipid-verknüpften Oligosaccharide der Kontrolle (A) und der Patientin M.S. (B). Fibroblasten einer Kontrolle und der Patientin wurden metabolisch mit $\left[2{ }^{3} \mathrm{H}\right]$ Man markiert und die markierten Oligosaccharide anschließend von den LLOs durch milde Säurebehandlung freigesetzt und durch HPLC analysiert. $\mathrm{G}_{3}$ bezieht sich auf die Freisetzung von $\mathrm{Glc}_{3}-\mathrm{Man}_{9}-\mathrm{GlcNAc}_{2}$.

$C$ und D: Analyse der Protein-verknüpften Oligosaccharide der Kontrolle (C) und der Patientin M.S. (D). Fibroblasten einer Kontrolle und der Patientin wurden metabolisch mit $\left[2-{ }^{3} \mathrm{H}\right]$ Man markiert und die markierten Oligosaccharide anschließend vom Protein mittels PNGase F-Verdau abgespalten und durch HPLC analysiert. $M_{9}$ und $G_{1}$ beziehen sich auf die Freisetzung von Man ${ }_{9}-G_{c}{ } A c_{2}$ bzw. $G_{1} c_{1}-$ $\mathrm{Man}_{9}-\mathrm{GlcNAc}_{2} \cdot \mathrm{M}_{1-2}$ ? steht für die vermutete Verbindung $\mathrm{Man}_{1-2}-\mathrm{GlcNAc}_{2}$.

und die anschließende Auswertung der HPLC-Fraktionen im SzintillationsMessgerät. Wie in der Literatur beschrieben (für CDG-Ic: Körner et al., 1998c; für CDG-Id: Körner et al., 1999; für CDG-le: Imbach et al., 2000/ Kim et al., 2000; für CDG-If: Schenk et al., 2001/ Kranz et al., 2001; für CDG-Ig: Thiel et al., 2002/ 
Chantret et al., 2002/ Grubenmann et al., 2002), wären im Falle von CDG-Ic, Id, le, If und Ig folgende Akkumulationen von $\left[2-{ }^{3} \mathrm{H}\right]$ Oligosacchariden zu erwarten gewesen: CDG-Ic: [2- $\left.{ }^{3} \mathrm{H}\right] \mathrm{Man}_{9}-\mathrm{GICNAc}_{2}$, CDG-Id und CDG-le: [2- $\left.{ }^{3} \mathrm{H}\right] \mathrm{Man}_{5}-\mathrm{GlcNAc}_{2}$, CDG-If: [2$\left.{ }^{3} \mathrm{H}\right] \mathrm{Man}_{5}-\mathrm{GlcNAc}_{2}$ und $\left[2-{ }^{3} \mathrm{H}\right] \mathrm{Man}_{9}-\mathrm{GlcNAc}_{2}$, CDG-Ig: [2- $\left.{ }^{3} \mathrm{H}\right] \mathrm{Man}_{7}-\mathrm{GlcNAc}_{2}$.

Wie die Abb. 10 (A, B) zeigt, wiesen die $\left[2{ }^{3} \mathrm{H}\right]$ Mannose markierten Oligosaccharide der Patientin $(10 \mathrm{~B})$ keine der bisher beschriebenen Akkumulationen verkürzter Dolichol-verknüpfter Oligosaccharide auf. Sie synthetisierte mit der Kontrolle (10 A) vergleichbare Mengen an vollständigem Oligosaccharid $\mathrm{Glc}_{3}-\mathrm{Man}_{9}-\mathrm{GlcNAc}_{2}-\mathrm{PP}-\mathrm{Dol}$. Damit konnten alle bekannten Ursachen für CDG-I im Fall der Patientin M.S. ausgeschlossen werden.

\subsubsection{HPLC-Analyse Protein-verknüpfter Oligosaccharide der Patientin M.S.}

Da durch Vorversuche alle bekannten CDG-I Fälle ausgeschlossen werden konnten, bestand die Möglichkeit, daß bei der Patientin ein Defekt in der Übertragung an vollständigen lipidverknüpften Zuckerketten auf naszierende Proteine durch die Oligosaccharyltransferase (OST) vorlag. Daher wurden proteinverknüpfte, [2- ${ }^{3} \mathrm{H}$ ]Mannose-markierte Oligosaccharide mit Hilfe eines PNGase F-Verdaus von den neusynthetisierten Glkyoproteinen abgespalten und mittels HPLC analysiert (siehe Abb. $10 \mathrm{C}, \mathrm{D}$ ), wobei sich bei der Patientin M.S. und der Kontrolle vergleichbare Mengen an $\mathrm{Glc}_{1}-\left[{ }^{3} \mathrm{H}\right] \mathrm{Man}_{9}-\mathrm{GlcNAc}_{2}$ und $\left[{ }^{3} \mathrm{H}\right] \mathrm{Man}_{9}-\mathrm{GlcNAc}_{2}$-Formen zeigten, was auf eine normale OST-Aktivität hinwies. Die OST katalysiert die Übertragung vollständiger Zuckerketten auf wachsende Proteine (Kornfeld und Kornfeld, 1985). Nach der Übertragung der Oligosaccharide setzen Trimmingreaktionen durch Glucosidasen und Mannosidasen ein, wodurch die terminalen zwei bis drei Glucosereste sowie der terminale Mannoserest abgespalten werden (Parodi, 2000). Daraus resultiert, daß auf neusynthetisierten Glykoproteinen zu einem großen Teil $\mathrm{Glc}_{1}-\mathrm{Man}_{9}-\mathrm{GlcNAc}_{2}$ und $\mathrm{Man}_{9}-\mathrm{GlcNAc}_{2}$ detektiert wird. Weiterhin ist oftmals auch eine Akkumulation von $\mathrm{Man}_{8}-\mathrm{GlcNAc}_{2} \mathrm{zu}$ finden. Dies ist auch hier der Fall. Alle drei Verbindungen sind Anzeichen dafür, daß die unter 4.2.4 detektierten vollständigen lipidverknüpften Oligosaccharide der Form $\mathrm{Glc}_{3}-\mathrm{Man}_{9}$ $\mathrm{GICNAc}_{2}$ auch tatsächlich von der OST übertragen wurden. Bei der Patientin M.S. zeigte sich eine weitere Akkumulation einer frühen Zuckerverbindung (10 D, links; $\operatorname{Man}_{1-2}$ ?), die bei der Kontrolle nicht zu detektieren war. Bei der Akkumulation konnte es sich um so frühe Intermediate wie $\left.{ }^{3} \mathrm{H}\right] \mathrm{Man}_{1-2}-\mathrm{GICNAc}_{2}$ handeln. Diese Ergebnisse 
deuteten darauf hin, daß statt eines Defekts in der Übertragung der lipidverknüpften Oligosaccharide durch die OST ein Defekt in einem frühen Schritt in der Synthese der LLOs für die Erkrankung der Patientin verantwortlich sein könnte. Weiterführende Untersuchungen betrafen die ersten Übertragungsschritte von Mannoseresten auf das lipidverknüpfte Oligosaccharid.

\subsubsection{Dünnschichtchromatographie kurzkettiger, lipidverknüpfter Oligosaccharide}

Mit Hilfe der durchgeführten HPLC-Analyse für radioaktiv-markierte, langkettige, lipid(siehe 4.2.4) und proteinverknüpfte Oligosaccharide (siehe 4.2.5) ließen sich aufgrund der Aufarbeitungsmethode des Probenmaterials kurze $\left[2-{ }^{3} \mathrm{H}\right]-$ Mannosemarkierte, Dolichol-verknüpfte Oligosaccharidstrukturen nicht detektieren. Aus diesem Grund wurden im weiteren Verlauf dieser Arbeit die kurzkettigen mit $\left[2-{ }^{3} \mathrm{H}\right]-$ Mannose-markierten, Dolichol-veknüpften Oligosaccharide mittels Dünnschichtchromatographie untersucht. Fibroblasten der Patientin M.S. und einer Kontrolle wurden mit $\left[2-{ }^{3} \mathrm{H}\right]$ Mannose metabolisch markiert, durch Ultraschall aufgeschlossen, der Dol-P-Man sowie kurze $\left[2-{ }^{3} \mathrm{H}\right]$ Mannose-markierte LLOs enthaltende apolare Extrakte isoliert und anschließend mit Hilfe der Dünnschichtchromatographie analysiert (siehe Abb. 11). Dabei ist die Wanderungsgeschwindigkeit des mit Mannosen verknüpften Dol-PP-GIcNAc ${ }_{2}$ direkt abhängig von der Anzahl der übertragenen Mannosereste.

'RF-Start' markiert den Auftragspunkt der apolaren Extrakte der Patientin M.S. bzw. der Kontrolle. Dünnschichtchromatographisch erfaßt wurde eine Strecke von $14 \mathrm{~cm}$. Nicht an Dolichol-Phosphat gebundene $\left[2-{ }^{3} \mathrm{H}\right]$ Mannose zeigt unter den gegebenen Laufbedingungen keine Migration in der Dünnschichtchromatographie. Sowohl bei der Patientin M.S. als auch bei der Kontrolle ist ungebundene $\left[2-{ }^{3} \mathrm{H}\right]$ Mannose bei RFStart zu erkennen. Weiterhin zeigen Patientin und Kontrolle eine schwache Akkumulation von an Dolichol-Phosphat gebundene $\left[2-{ }^{3} \mathrm{H}\right]-$ Mannose, die aufgrund der Laufbedingungen und ihrer Hydrophobizität am weitesten in der Chromatographie gelaufen ist und $8 \mathrm{~cm}$ von RF-Start lokalisiert ist. Im Gegensatz zur Kontrolle, bei der keine Zwischenprodukte akkumulieren, sind bei der Patientin zwei weitere Spots in der Chromatographie zu erkennen, wovon sich der erste Spot $1 \mathrm{~cm}$ und der zweite, stärkere Spot $2 \mathrm{~cm}$ nach RF-Start zeigt. Bei diesen Akkumulationen 
könnte es sich um [2- $\left.{ }^{3} \mathrm{H}\right] \mathrm{Man}_{1}-\mathrm{GlcNAc}_{2}-\mathrm{PP}-\mathrm{Dol}$ sowie um [2- $\left.{ }^{3} \mathrm{H}\right] \mathrm{Man}_{2}-\mathrm{GlCNAc}_{2}-\mathrm{PP}$ Dol handeln, wobei Dol-PP-GlcNAc 2 mit nur einem verknüpften Mannoserest aufgrund größerer Hydrophobizität weiter laufen würde als Dol-PP-GIcNAc 2 mit zwei

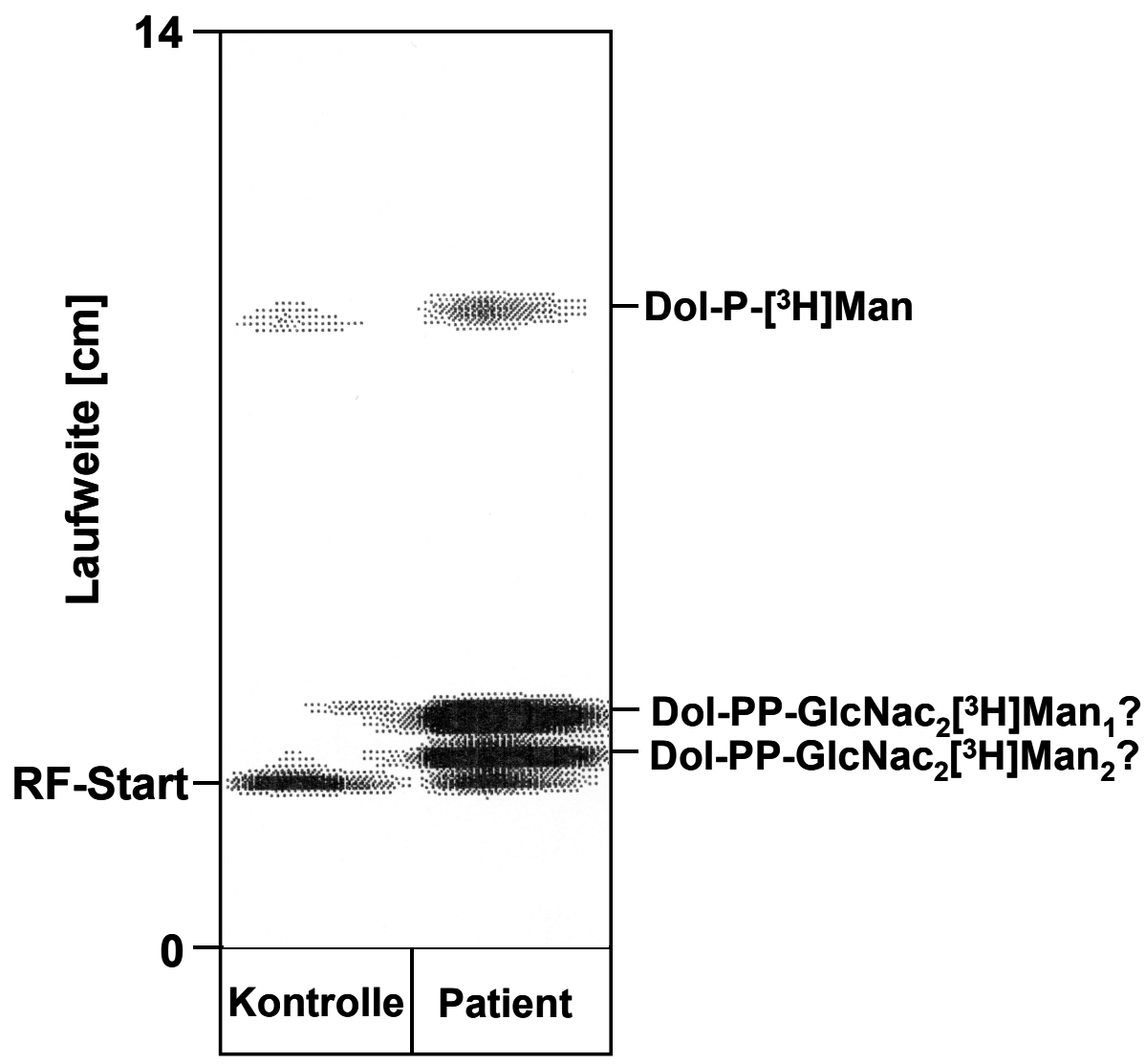

Abb. 11: Auftrennung kurzkettiger, lipidverknüpfter Oligosaccharide mittels Dünnschichtchromatographie

Mit [2- $\left.{ }^{3} \mathrm{H}\right]$ Mannose markierte, kurzkettige LLOs der Patientin M.S. und einer Kontrolle wurden mit Hilfe der Dünnschichtchromatographie aufgetrennt. Die Analyse der Chromatogramme mit Hilfe des Analysegerätes 'Tracemaster $20^{\prime}$ ergab im Falle der Patientin M.S. die Akkumulation zweier Substanzen, die bei den Kontrollen nicht detektiert werden konnten.

angehängten Mannoseresten. Das Ergebnis der Dünnschichtchromatographie, das die Akkumulation von zwei frühen Intermediaten der N-Glykosylierung zeigt, war der erste Beweis für einen tatsächlich vorliegenden Defekt in den ersten Schritten der Dolichol-verknüpften Oligosaccharidbiosynthese bei der Patientin M.S. Massenspektrometrische Untersuchungen der kurzkettigen, lipidverknüpften Oligosaccharide sollten Aufschluß über die akkumulierenden Verbindungen bei M.S. geben. 


\subsubsection{HPLC-Auftrennung kurzkettiger, lipidverknüpfter Oligosaccharide der} Patientin M.S. und massenspektrometrische Analyse der Verbindungen

Die unter 3.2.3.13 erhaltenen Überstände, die Dol-P-Man[2- $\left.{ }^{3} \mathrm{H}\right]$ sowie die $\left[2-{ }^{3} \mathrm{H}\right]$ Mannose-markierten, kurzkettigen LLOs enthielten, wurden einer milden Säurebehandung unterzogen und anschließend mittels HPLC analysiert. Die einzelnen Fraktionen wurden gesammelt und nachfolgend zur Massenspektrometrie eingesetzt, um anhand der hierbei detektierten Massen auf die unter 4.2.6 detektierten, akkumulierenden Zuckerverbindungen rückschließen zu können.

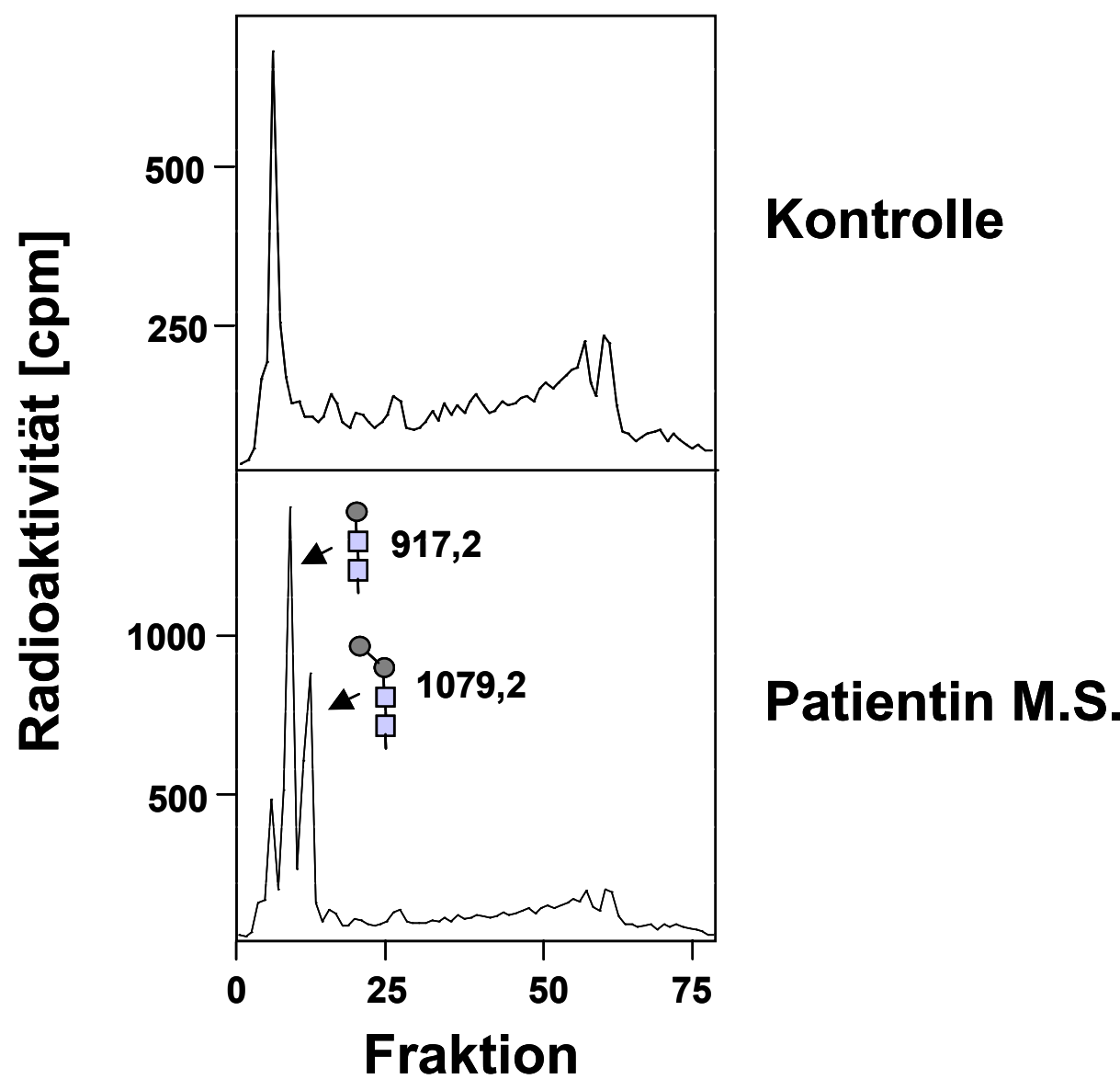

Abb. 12: HPLC und massenspektroskopische Analyse kurzkettiger, Dolichol-verknüpfter Oligosaccharide nach metabolischer Markierung mit $\left[2-{ }^{3} \mathrm{H}\right]$ Mannose

Kontroll- und Patientenfibroblasten wurden metabolisch mit $\left[2{ }^{3} \mathrm{H}\right]$ Mannose für $30 \mathrm{~min}$. markiert. Anschließend wurden kurzkettige Dolichol-verknüpfte Oligosaccharide mit Hilfe eines Chloroform/Methanol(3:2)-Gemisches extrahiert, der Oligosaccharidanteil mittels mildsaurer Hydrolyse in $20 \mathrm{mM} \mathrm{HCl}$ für $30 \mathrm{~min}$. bei $95^{\circ} \mathrm{C}$ vom Lipid-Anteil abgespalten und mit Hilfe der HPLC aufgetrennt. Die Oligosaccharide der zusätzlichen Peakfraktionen im Falle der Patientin M.S. wurden mit PMP verknüpft und zur massenspektrometrischen Analyse eingesetzt. Die Werte neben den HPLCPeakfraktionen geben die detektierten Massen in $\mathrm{Da}$ an. Die Quadrate stellen NAcetylglucosaminreste dar, während die Kreise Mannosereste symbolisieren. 
Die Kontrolle zeigt einen Hauptpeak am Anfang des Laufs von 650cpm, der die freie, nicht eingebaute Mannose darstellt und charakteristisch ist für die Auftrennung der kurzkettigen Zuckerketten durch HPLC. Die weiteren Peaks mit Werten zwischen100-220cpm zeigen die unterschiedlich langen Intermediate der Dolicholverknüpften Oligosaccharidbiosynthese an. Bei der Patientin M.S. treten neben der freien, nicht eingebauten Mannose mit 490cpm zwei weitere Peakfraktionen mit cpmWerten von 1400 für den ersten Peak und $820 \mathrm{cpm}$ für den zweiten Peak auf. Dieses HPLC-Ergebnis bestätigte das Ergebnis der Dünnschichtchromatographie für die kurzkettigen LLOs der Patientin M.S., in der ebenfalls die Akkumulation zweier sehr früher Intermediate der Dolichol-verknüpften Oligosaccharidsynthese gefunden wurden.

In Zusammenarbeit mit Herrn Dr. Alfred Peng wurden die mittels HPLC aufgetrennten und nachfolgend isolierten, unbekannten Peakfraktionen der kurzkettigen Dolichol-verknüpften Oligosaccharide der Patientin M.S. mit PMP gekoppelt und anschließend massenspektrometrisch mittels MALDI-TOF-Analyse untersucht. Hierbei ließen sich die bei der Patientin M.S. akkumulierenden Verbindungen anhand ihrer spezifischen Massen identifizieren. Die hierbei detektierte Masse von 917,2Da entspricht der Masse von Man ${ }_{1}-\mathrm{GlcNAc}_{2}-\mathrm{PMP}_{2}$. Durch die Addition eines weiteren Mannoserests an Man ${ }_{1}-\mathrm{GlcNAc}_{2}-\mathrm{PMP}_{2}$ ergibt sich die Verbindung $\mathrm{Man}_{2}-\mathrm{GlcNAc}_{2}-\mathrm{PMP}_{2}$, die eine errechnete Masse von 1079,2Da besitzt. Neben 917,2Da ist auch diese Masse mittels MALDI-TOF detektiert worden. Das Ergebnis der massenspektrometrischen Analyse der kurzkettigen Oligosaccharide der Patientin M.S. deutete zusammen mit den Ergebnissen der Dünnschichtchromatographie und der HPLC-Analyse der kurzkettigen Oligosaccharide daraufhin, daß in den Fibroblasten der Patientin M.S. eine Akkumulation auf $\mathrm{Man}_{1}-\mathrm{GlCNAc}_{2}$ und $\mathrm{Man}_{2}-\mathrm{GlcNAc}_{2}$ auftrat. 


\subsection{Molekularbiologische Untersuchungen}

Die Ergebnisse der proteinbiochemischen Untersuchungen deuteten im Fall der Patientin M.S. auf einen frühen Defekt in der N-Glykosylierung von Proteinen hin. Die Ergebnisse der Dünnschichtchromatographie, der HPLC sowie der massenspektrometrischen Analyse wiesen auf einen partiellen Defekt in der Übertragung von Mannoseresten vom Donorsubstrat Dolichol-Phosphat-Mannose auf $\mathrm{Man}_{1}-\mathrm{GlcNAc}_{2}$-PP-Dol und auf $\mathrm{Man}_{2}-\mathrm{GlcNAc}_{2}$-PP-Dol hin.

\subsubsection{Orthologe zum ALG2-Protein der Hefe}

Die frühen Schritte der N-Glykosylierung wurden bisher nur in niederen Eukaryonten wie Saccharomyces cerevisiae und Rhizomucor pusillus untersucht. Die Übertragung der Mannosereste auf Man 1 -GlcNAc 2 -PP-Dol und Man $_{2}-$ GlcNAc$_{2}$-PP-Dol wird in der Bäckerhefe vom ALG2-Protein katalysiert (Jackson et al., 1989), dessen Ortholog in dem Pilz Rhizomucor pusillus die entsprechenden Übertragungen der nukleotidaktivierten Zucker katalysiert (Yamazaki et al., 1998).

Zum ALG2-Protein der Hefe (Acc.No.: NP_011450) sind in der Datenbank eine ganze Reihe sequenzhomologer Proteine zu finden, deren Funktion allerdings noch nicht nachgewiesen worden ist. Neben dem bereits erwähnten Pilz Rhizomucor pusillus (Acc.No.: BAA34296) lassen sich potentielle hALG2-Proteine auch beim Menschen (Acc.No.: CAC07999; AAH15126), in der Maus (Acc.No.: AK010673), Schizosaccharomyces pombe (Acc.No.: NP_595620), Neurospora crassa (Acc.No.: CAD21070), Xanthomonas axonopodis (Acc.No.: NP_642880) und campestris (Acc.No.: NP_637788) oder auch Caenorhabditis elegans (Acc.No.: NP_495010) finden. Die Homologie der potentiellen hALG2-Proteine von Mensch und Maus zu Saccharomyces cerevisiae beträgt nach der Clustal-Methode 32\% (durchgeführt mit Protean, einem Unterprogramm von DNA-Star). Schizosaccharomyces pombe sowie Neurospora crassa zeigen eine 34\%ige und Rhizomucor pusillus eine 36\%ige Homologie zu der Hefe. Bei den beiden Xanthomonas-Stämmen sowie Caenorhabditis elegans wird eine 10\%ige bzw. 19\%ige Homologie berechnet. Ein Alignment von potentiellen ALG2-Proteinen verschiedener Spezies wird in Abb. 13 dargestellt.

Während in der Datenbank für die oben genannten Proteine der einzelnen Spezies nur jeweils ein Protein aufgeführt wird, wird beim Menschen neben einer langen 
potentiellen ALG2-Isoform mit einer Länge von 417 Aminosäuren (Acc.No.: CAC07999) eine weitere kurze Isoform beschrieben, die die terminalen 249 Aminosäuren des C-Terminus der langen Isoform umfaßt (Acc.No.: AAH15126). Aufgrund der Homologie der humanen Proteine zum ALG2 der Hefe wird von den Autoren postuliert, daß es sich bei den humanen Proteinen um Orthologe zur HefeALG2-Mannosyltransferase handeln könnte (Babbage, 2000; Isogai und Otsuki, 2002; Strausberg, 2001). Die lange hALG2-Form hat eine Masse von 47097Da, die kurze Isoform eine Masse von 28123Da. Beide hALG2-Isoformen werden von demselben Genlocus auf Chromosom 9q22 kodiert. Die mRNA für die

\begin{tabular}{|c|c|c|}
\hline Mensch & MAEE- -QGRERDSVPKPSVLFLHPDLGVGGAERLVLDAALALQARGCSVKIWTAHYDPGH & 58 \\
\hline Maus & MAEN- - LYRARSRVYSPSVLFLHPDMGIGGAERLVLDAALALQEYGCDVKIWTAHYDPNH & 58 \\
\hline Sac.cerevisiae & MIEK--DKR-- - - - -TIAFIHPDLGIGGAERLVVDAALGLQQQGHSVI IYTSHCDKSH & 50 \\
\hline \multirow[t]{2}{*}{ Schizosac.pombe } & MSQENSVHRSSTKKTPIKIAFIHPDLGIGGAERLVVDAAVGLQSLGKEVVVFTSHCDKKH & 60 \\
\hline & $*:: \quad * \quad \quad:{ }^{*}: * * * *: * * * * * *: * * *: . * * \quad * \quad * \quad:: * * * \quad *$ & \\
\hline Mensch & CFAESR - -ELPVRCAGDWLPRGLGWGGRGAAVCAYVRMVFLALYVLFLADEEFD-VVVCD & 115 \\
\hline Maus & CFIETR - -ELSVQCAGDWLPRSLGWGGRGAAICSYVRMVFLALYVLFLSGEEFERGWVCD & 116 \\
\hline Sac.cerevisiae & CFEEVKNGQLKVEVYGDFLPT- -NFLGRFFIVFATIRQLYLVIQLILQKKVNAYQLIIID & 108 \\
\hline \multirow[t]{2}{*}{ Schizosac.pombe } & CFEEIRDGTIKVKVYGDWLPS- -SIFGRLSIFCSSLRQVYLT--MILLTNYMHFDAIIVD & 116 \\
\hline & 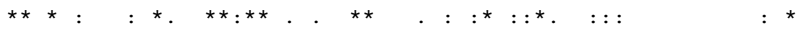 & \\
\hline Mensch & QVSACI PVFRLARRRKKILFYCHFPDLLLTKRDSFLKRLYRAPIDWIEEYTTGMADCILV & 175 \\
\hline Maus & QVSACI PVFKLARRRKRVLFYCHFPDLLLTQRNSALKKFYRAPIDWIEEYTTGMADRILV & 176 \\
\hline Sac.cerevisiae & QLSTCIPLLHIFSS-ATLMFYCHFPDQLLAQRAGLLKKIYRLPFDLIEQFSVSAADTVVV & 167 \\
\hline \multirow[t]{2}{*}{ Schizosac.pombe } & QLSTCVPFLLLASQ - MILFYCHFPDKYLAKRGGILKKLYRIPFDTVEAESVRLADRIVV & 174 \\
\hline & $*: * *^{*}: .:: \quad \quad:: * * * * * * \quad *:: * \quad * *:: * * *: * \quad: * \quad: . \quad * *:: *$ & \\
\hline Mensch & NSQFTAAVFKETFKSLSHIDPDVLYPSLNVTSFDSV - - - -VPEKLDDLVPKGKKFLLLSI & 231 \\
\hline Maus & NSQYTASVFKETFKTLSHRNPDVLYPSLNIGSFDLA- - - - IPEKIDDLVPKGKQFLFLSI & 232 \\
\hline Sac.cerevisiae & NSNFTKNTFHQTFKYLSN-DPDVIYPCVDLSTIEIED---IDKKFFKTVFNEGDRFYLSI & 223 \\
\hline \multirow[t]{2}{*}{ Schizosac.pombe } & NSKFTASVFKKAFPKIRK-PLRIVHPCVDIEAASKPLEFQLPEKILYLRYSQRK-LLISV & 232 \\
\hline & 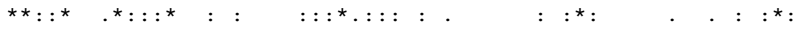 & \\
\hline Mensch & NRYERKKNLTLALEALVQLRGRLTSQDWERVHLIVAGGYDERVLENVEHYQELKKMVQQ- & 290 \\
\hline Maus & NRYERKKNLPLALRSLVQLRNRLPSQEWDKVHLFMAGGYDDRIPENVEHYKELKKMVQE- & 291 \\
\hline Sac.cerevisiae & NRFEKKKDVALAI KAFALSEDQIN - - - -DNVKLVICGGYDERVAENVEYLKELQSLADEY & 279 \\
\hline \multirow[t]{2}{*}{ Schizosac.pombe } & NRFERKKDIRLAIDAFSALR-DLSANRFPEYLLLVAGGYDIRVSENRRYLKELQEFCEQK & 291 \\
\hline & 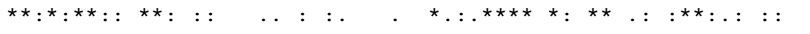 & \\
\hline Mensch & - - - - - - - FLRSFSDKQKISLLHSCTCVLYTPSNEHFGI & 329 \\
\hline Maus & 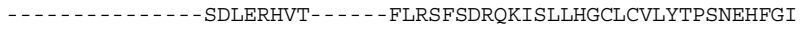 & 330 \\
\hline Sac.cerevisiae & ELSHTTIYYQEIKRVSDLESFKTNNSKIIFLTSISSSLKELLLERTEMLLYTPAYEHFGI & 339 \\
\hline \multirow[t]{2}{*}{ Schizosac.pombe } & DLSYTTVKDN- - - -WDNITVAPSTN- -VLFLLSVPSKVRDALISSSRILLYTPENEHFGI & 345 \\
\hline & 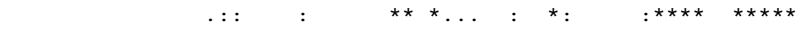 & \\
\hline Mensch & VPLEAMYMQCPVIAVNSGGPLESIDHSVTG- - - - - FLCEPDPVHFSEAIEKFIREP- & 380 \\
\hline Maus & VPLEAMYMQCPVIAVNNGGPLESIVHKVTG- - - - - FLCEPDPVHFSEAMEKFIHKP- & 381 \\
\hline Sac.cerevisiae & VPLEAMKLGKPVLAVNNGGPLETIKSYVAGENESSATGWLKPAVPIQWATAIDESRKILQ & 399 \\
\hline \multirow[t]{2}{*}{ Schizosac pombe } & VPLEAMLRKVPVLAQTNGGPLETVIDGKNG- - - - - - WLRPRDAKIWGNVIYEATTSTT & 397 \\
\hline & 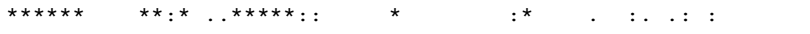 & \\
\hline Mensch & SLKATMGLAGRARVKEKFSPEAFTEQLYRYVTKLLV- & 416 \\
\hline Maus & SLKATMGLAGKARVAEKFSADAFADQLYQYVTKLV- & 416 \\
\hline Sac.cerevisiae & NGSVNFERNGPLRVKKYFSREAMTQSFEENVEKVIWKEK--KYYPWEIFGISFSNFILHM & 457 \\
\hline \multirow[t]{2}{*}{ Schizosac.pombe } & YDTAAMGEAGSEWVKNEFSTDAMARKFESEIMSGIRSITPEKRLMRRVNGLLAVFVLFML & 457 \\
\hline & $\ldots: \quad * \quad * \quad * *: *:: \quad .: \quad: \quad \cdot:$ & \\
\hline Mensch & & \\
\hline Maus & - - & \\
\hline Sac.cerevis & AFIKILPNNPWPFLFMATFMVLYFKNYLWGIYW-AFVFALSYPYEEI-.-.-- 503 & \\
\hline Schizosac.pombe & FWGTCIIAATVPFAIIKLYFAQTYSSVKLGFMLGTCIVSVSFLTFTVYAKLTNL 511 & \\
\hline
\end{tabular}

\section{ABB.13: Protein-Alignment von ALG2-Proteinen versch. Spezies}

Die Proteinsequenzen von ALG2 des Menschen (in der langen Form), der Maus, der Bäckerhefe Saccharomyces cerevisiae und von Schizosaccharomyces pombe wurden nach der Clustal-Methode miteinander verglichen (http://www.ebi.ac.uk/clustalw/). 
lange Form hat eine Länge von 1835bp (Acc.No.: AK027417). Die mRNA für die kurze Isoform hat dagegen eine Länge von 2203bp (Acc.No.: AK027814). Der für das lange hALG2-Protein kodierende Bereich der halg2-cDNA hat eine Länge von $1251 \mathrm{bp}$. Das halg2-Gen für die lange Isoform umfaßt einen Bereich vom Start- bis zum Stop-Codon von 3960bp und besteht aus zwei Exons und einem dazwischen liegenden 2710bp-Intron. Das erste Exon hat einen kodierenden Bereich von 348bp und das zweite Exon von 903bp. Über die zum Gen gehörenden 5'- sowie 3'untranslatierten Bereiche lassen sich nur Vermutungen anstellen. Das Computerprogramm 'CBS Promotor 2.0' (www.cbs.dtu.dk/services/promotor) ist durch Sequenzvergleiche eines zu überprüfenden Gens mit in seiner Datenbank gespeicherten Genen in der Lage, Transkriptionsstartpunkte vorherzusagen. Für das halg2-Gen wurde der Startpunkt der Transkription, ausgehend vom Start-Codon der langen Isoform, auf genomischer Ebene auf -76bp vorhergesagt.

Der kodierende Bereich der cDNA für die kurze Isoform von hALG2 mit 249 Aminosäuren hat eine Größe von 747bp, wobei das Start-Codon an Position nt502504 des kodierenden Bereichs der langen Isoform liegt. Auffällig ist, daß der 5'untranslatierte Bereich für die kurze Isoform im Intron zwischen den beiden Exons für die lange Isoform beginnt. Beide Isoformen verwenden das gleiche Stop-Codon, weiterhin ist der 3'-UTR-Bereich bei beiden Isoformen identisch. Der Transkriptionsstart für die kurze Isoform wurde von dem 'CBS Promotor 2.0Programm' auf -1326nt ausgehend vom Start-Codon der kurzen Isoform vorhergesagt.

\subsection{2 Überprüfung des humanen alg2-Locus' durch Sequenzierung}

Um zu überprüfen, ob ein Defekt in dem für das humane ALG2-Protein kodierenden Genlocus die Ursache für eine verminderte Übertragung des zweiten und dritten Mannoserests bei der Patientin M.S. sein könnte, wurde die mRNA für die lange Isoform von hALG2 der Patientin M.S., deren Eltern sowie von Kontrollen mittels RTPCR und anschließender Sequenzierung untersucht. Die reverse Transkription wurde mit Primer R1 und die zwei PCR-Runden zur Amplifikation der hierbei synthetisierten cDNA mit Primern F1/ R1 und F2/ R2 durchgeführt. Die entstandenen PCR-Produkte mit einer Größe von 1313 bp wurden nach Gelextraktion mit den Primern F2, R2, Ex1-O und Ex2-L sequenziert. 
Genomische DNA
cDNA lange Isoform
cDNA

kurze Isoform

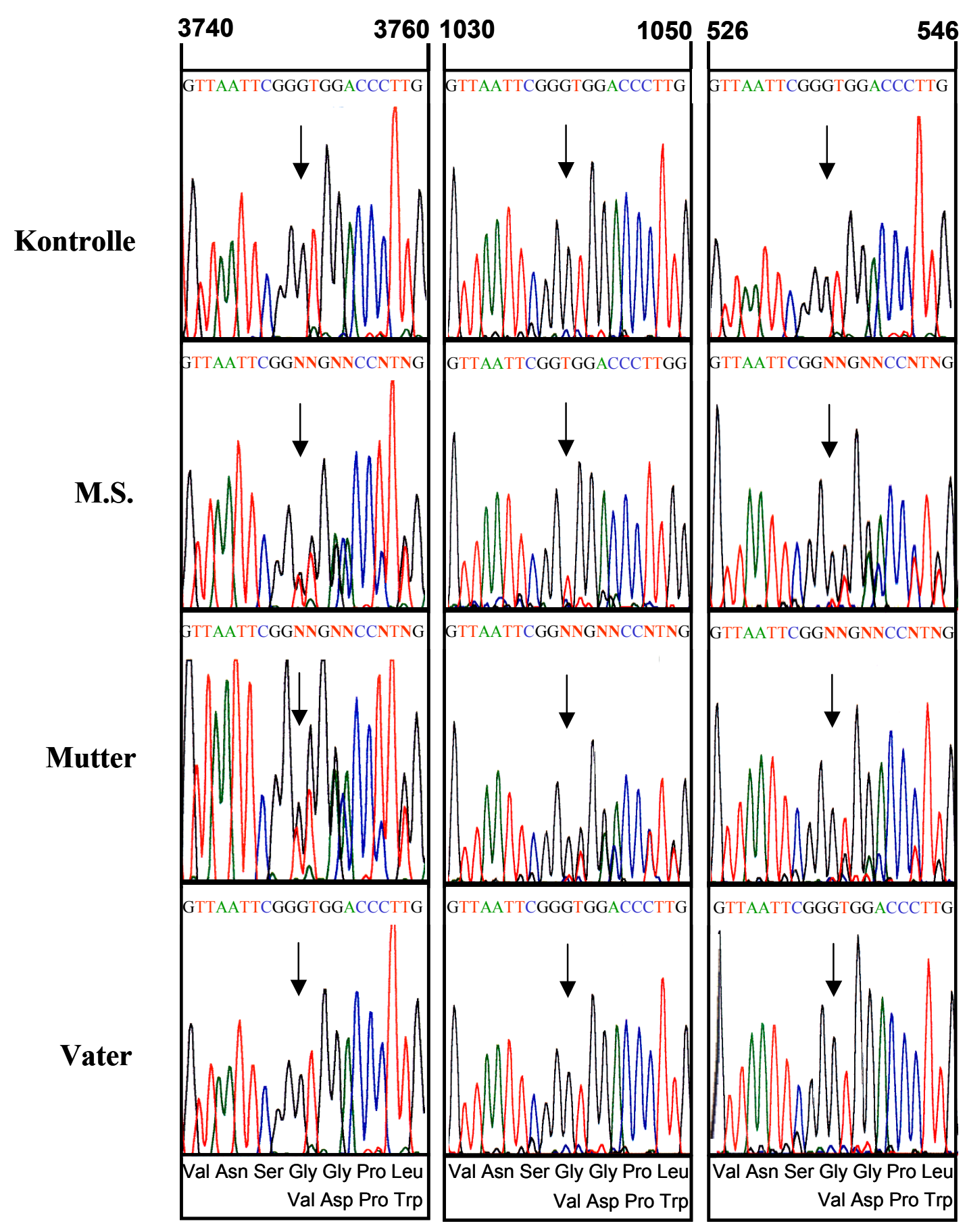

Abb.14 Identifizierung der Deletionsmutation $(\Delta 1040 \mathrm{G} / \Delta 536 \mathrm{G})$ bei Patientin M.S., die zu dem Verlust der terminalen 70 Aminosäuren in beiden hALG2-Isoformen führt.

Dargestellt sind Sequenzvergleiche der cDNAs der kurzen und langen Isoform sowie der genomischen DNA von Patientin M.S., deren Eltern und einer Kontrolle. Die hier dargestellte Kontrolle steht repräsentativ für zehn untersuchte Kontrollpersonen. Der Pfeil weist auf den Mutationsbereich hin. Die Zahlen über den jeweiligen Sequenzen geben den Ort der Mutation im Gen bzw. den beiden 
cDNAs an, wobei sie sich bei der genomischen DNA sowie der cDNA für die lange Isoform auf das Startcodon der langen Isoform beziehen. Bei der cDNA der kurzen Isoform beziehen sie sich auf das Startcodon der kurzen Isoform.

In der cDNA für die lange Isoform zeigte sich bei der Patientin der Verlust der Base Guanin an Position 1040bp ( $(1040 \mathrm{G})$. Die Mutter zeigte an gleicher Nukleotidposition eine Überlagerung in ihrer Sequenz, was auf die Deletionsmutation auf einem ihrer beiden Allele hindeutete. Der Vater und die Kontrollen zeigten die WT-Sequenz für halg2. Um Aufschluß darüber zu gewinnen, inwieweit auch die kurze Isoform des hALG2-Proteins der Patientin von der Deletionsmutation betroffen ist, wurde die cDNA für die kurze Isoform ebenfalls mittels RT-PCR und Sequenzierung überprüft. Aufgrund eines unterschiedlichen $5^{\prime}$-untranslatierten Bereichs von beiden Isoformen war es möglich, spezifisch die kurze halg2-Isoform durch RT-PCR zu amplifizieren. Als Primer in der reversen Transkription wurde der an beide mRNA-Formen bindende Primer R1 eingesetzt, so daß hier zunächst die cDNAs für beide Isoformen synthetisiert wurden. Die spezifische Amplifikation der kurzen halg2-Isoform erfolgte dann während der sich anschließenden zwei PCRRunden mit den Primerpaaren Genom-ForwA/R1 in der ersten und GenomForwB/R2 in der zweiten PCR-Runde. Die 1356bp-langen PCR-Produkte wurden mit Primer Ex2-L sequenziert. Der Vater wies -wie die Kontrollen- die Wildtyp-Sequenz für halg2 auf. Bei Patientin M.S. konnte ebenso wie bei der Mutter eine Überlagerung in der cDNA-Sequenz für die kurze Isoform aufgrund des Verlustes einer Guaninbase an Position $536(\Delta 536 \mathrm{G})$ detektiert werden. Guanin 536 in der kurzen Isoform entspricht Guanin 1040 in der langen Isoform. Dies zeigte das Vorliegen der gleichen Basendeletion in dem für beide hALG2-Isoformen kodierenden halg2-Gen hin. Im weiteren Verlauf der Arbeit wird, wenn von der Deletionsmutation in den cDNAs beider Isoformen die Rede ist, folgende Benennung eingeführt: $\Delta 1040 G / \Delta 536 G$ (Mutation in der langen Isoform/ Mutation in der kurzen Isoform). Das Ergebnis der Sequenzierung der cDNA der kurzen Isoform, in dem zum einen ein WT-Transkript und zum anderen ein mutiertes Transkript erhalten wurden, stand im Widerspruch zu den erhaltenen Daten für die lange Isoform der Patientin, bei der die 1040G-Mutation scheinbar in beiden Transkripten bei der Patientin M.S. detektiert worden war.

Die Analyse der genomischen DNA für das betroffene Gen der Patientin, ihrer Eltern und der Kontrollpersonen sollte Aufschluß über das Vorliegen der Deletionsmutation 
in homo- oder heterozygoten Zustand bringen. Durch PCR erfolgte die Amplifikation des Genabschnitts, in dem die Mutation bei der Patientin gefunden worden war. Hierzu wurden zwei PCR-Runden mit den Primern Intron 1/R1 und den "nested“ Primern Intron 2/R2 gefahren. Die 976bp-langen PCR-Produkte wurden durch Sequenzierung mit Primer Ex2-L analysiert.

Die Sequenzierung der genomischen PCR-Produkte zeigte bei der Mutter den erwarteten heterozygoten Zustand des bereits zuvor in den cDNAs für beide Isoformen detektierten Basenverlusts, was bewies, daß die $\Delta$ 1040G/A536G-Mutation der Patientin M.S. vom maternalen Allel stammte. Der Vater sowie die Kontrollen zeigten keine Veränderung in ihrer genomischen Sequenz, wodurch auch das Ergebnis ihrer cDNA-Sequenzierungen bestätigt wurde. Bei der Patientin wurde -wie bei der Mutter- eine Überlagerung in ihrer Sequenz detektiert, was auf den Verlust der Base Guanin auf nur einem ihrer Allele hinwies. Damit konnte zum einen das Ergebnis der cDNA-Sequenzierung von der kurzen Isoform der Patientin M.S. bestätigt werden. Zum anderen bewies es, daß bei der Patientin M.S. beide Allele für die kurze Isoform abgelesen und ein WT-Transkript vom paternalen Allel sowie ein mutiertes Transkript mit der $4536 \mathrm{G}-M u t a t i o n$ vom maternalen Allel erhalten wurden. Der Widerspruch zwischen den Ergebnissen der cDNA-Sequenzierung für die lange

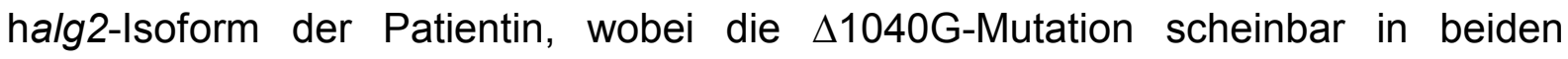
Transkripten vorzuliegen schien, auf der einen Seite und den Daten der Sequenzierung für die kurze Isoform $(\Delta 536 \mathrm{G})$ und der genomischen DNA, bei der sich diese Mutation in heterozygotem Zustand zeigte, auf der anderen Seite ließ sich durch eine Mutation auf dem vom Vater stammenden Allel erklären, die zu einem instabilen Transkript für die lange Isoform führte.

Der bei der Patientin M.S. detektierte $\Delta$ 1040G/A536G-Basenverlust liegt im gemeinsamen kodierenden Bereich für die kurze und lange halg2-Isoform. Die Mutation führt zu einer Verschiebung des Leserahmens und nachfolgend zu einem vorzeitigen Translationsstop. In der langen Isoform werden die Aminosäuren 347372, in der kurzen Isoform die Aminosäuren 179-204 durch 26 neue Aminosäuren ersetzt, bevor es durch ein neuentstandenes Stop-Codon zu einem vorzeitigen Translationsstop und nachfolgend zum Verlust der terminalen 44 Aminosäuren im Protein kommt. Durch den Verlust der C-terminalen 70 Aminosäuren gehen für die lange Isoform $17 \%$ und für die kurze Isoform $28 \%$ der WT-Proteinsequenz verloren, 
wovon auch die putative Dolichol-Bindungsstelle am C-Terminus beider hALG2Isoformen betroffen wäre (siehe auch Abb. 15).

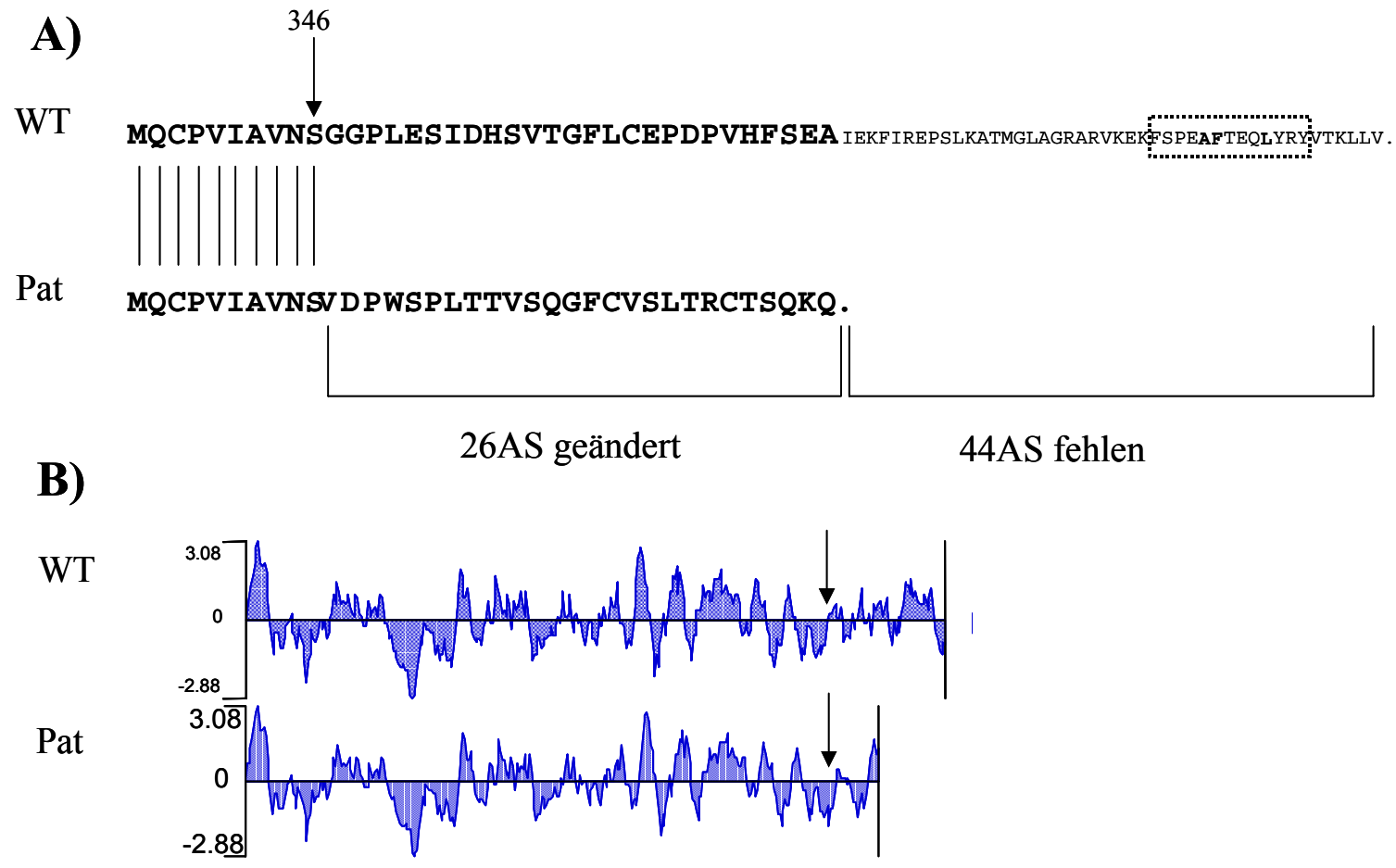

Abb. 15: Partielles hALG2-Alignment und Hydrophilizitätsplot nach Kyte-Doolittle von WThALG2 und mutiertem hALG2

A) Dargestellt ist ein partielles Alignment der Proteinsequenzen der langen Isoform des Wildtyp- und des Patienten-Proteins am C-Terminus. Der Pfeil an Aminosäureposition 346 weist auf den Beginn der veränderten Aminosäuresequenz in Folge der 1040G-Mutation hin, wobei kursive Schrift die vertauschten 26 Aminosäurereste bei der Patientin M.S. anzeigt. Die C-terminalen 44 Aminosäurereste fehlen dem hALG2 der Patientin vollständig. Eine mögliche Dolichol-Bindungsstelle am C-Terminus des WT-hALG2 ist durch Kasten und fettgedruckte Buchstaben hervorgehoben.

B) Gezeigt ist ein Hydrophilizitätsplot nach Kyte-Doolittle, wobei dem langen WT-hALG2-Protein das mutierte hALG2-Protein von M.S. gegenüber gestellt ist. Die Pfeile weisen auf den Aminosäurerest Serin 346 im WT- bzw. Patienten-Protein hin.

\subsubsection{Identifizierung einer Mutation auf dem paternalen Allel}

Um die Mutation zu identifizieren, die vom Vater an die Tochter weitergegeben wurde und die für ein instabiles Transkript verantwortlich ist, wurde das halg2-Gen der Patientin, deren Eltern sowie von Kontrollen sequenziert. Hierbei wurde der Bereich 400bp stromaufwärts des vom 'CBS Promotor 2.0-Programm' vorhergesagten Transkriptionsstarts für die lange Isoform bis zum Stop-Codon für beide Isoformen 
überprüft. Dabei wurde ein Bereich von 4437bp abgedeckt. Nach der oben beschriebenen Methode wurden zunächst spezifische Genbereiche durch PCR amplifiziert und die PCR-Produkte anschließend sequenziert.

Die Kombinationen der verschiedenen Primer für die PCRs, die Größe der entstandenen PCR-Produkte nach der zweiten PCR-Runde sowie die verwendeten Primer zur Sequenzierung sind in Tabelle 5 aufgeführt.

Tab. 5: Primerkombinationen für die PCR mit genomischer DNA, Größe der entstandenen PCR-Fragmente und verwendete Sequenzierungsprimer

\begin{tabular}{|l|l|l|l|}
\hline $\begin{array}{c}\text { Primerkombination } \\
\text { 1. PCR-Runde }\end{array}$ & $\begin{array}{c}\text { Primerkombination } \\
\text { 2. PCR-Runde }\end{array}$ & $\begin{array}{l}\text { Größe des 2. } \\
\text { PCR-Produktes }\end{array}$ & $\begin{array}{l}\text { Sequenzierungs- } \\
\text { primer }\end{array}$ \\
\hline Intron J/ Ex1-O-rev & Intron K/ Ex1-N-rev & $799 \mathrm{bp}$ & Intron K; F1 \\
\hline Ex1-P/ Intron E & Ex1-N/ Intron E & $688 \mathrm{bp}$ & Ex1-P \\
\hline Intron D/ Intron F-rev & Intron D/ Intron F-rev & $1085 \mathrm{bp}$ & Intron D; Intron M \\
\hline Intron A/ Ex2-H-rev & Intron B/ Ex2-H-rev & $1596 \mathrm{bp}$ & $\begin{array}{l}\text { Intron B; Genom-Forw-A; } \\
\text { Ex2-H }\end{array}$ \\
\hline Genom-Fw-A/ R1 & Genom-Fw-B/ R2 & $1356 \mathrm{bp}$ & Intron1; Ex2-H; Ex2-L \\
\hline
\end{tabular}

Bei der Patientin sowie beim Vater konnte eine Mutation in ihrer genomischen DNA identifiziert werden (Abb.16, linke Spalte), für die beide heterozygot waren und die weder bei der Mutter noch bei den untersuchten 10 Kontrollpersonen detektiert werden konnte. In der Abb. 16 steht die Kontrolle stellvertretend für die anderen 9 untersuchten Kontrollpersonen. Es handelt sich bei der Mutation um einen Basenaustausch einer Guaninbase gegen eine Thyminbase und ist 44bp stromabwärts vom Beginn des zweiten Exons für die lange Isoform (G393T in der cDNA) und $111 \mathrm{bp}$ vor dem Start-Codon im 5'-UTR-Bereich für die kurze Isoform gelegen (G-111T in der cDNA). Für den weiteren Verlauf der Arbeit wird die Benennung G393T/G-111T eingeführt, wenn von der gleichen Mutation in den cDNAs beider hALG2-Isoformen die Rede ist. Die G393T-Mutation in der cDNA für die lange Isoform würde zu einem Austausch von Lysin zu Serin an Position $131 \mathrm{im}$ Protein führen (Lys131Ser). In der kurzen Isoform kann sich die gefundene Mutation nicht auf die Proteinsequenz auswirken. Bei Annahme, daß diese vom Vater stammende Mutation zu einem instabilen halg2-Transkript für die lange Isoform führt, durfte sich in der entsprechenden cDNA beim Vater und der Patientin lediglich die 
WT-Sequenz von halg2 finden lassen. Dagegen sollte die G-111T-Mutation im 5'UTR-Bereich der kurzen Isoform in heterozygotem Zustand detektierbar sein.

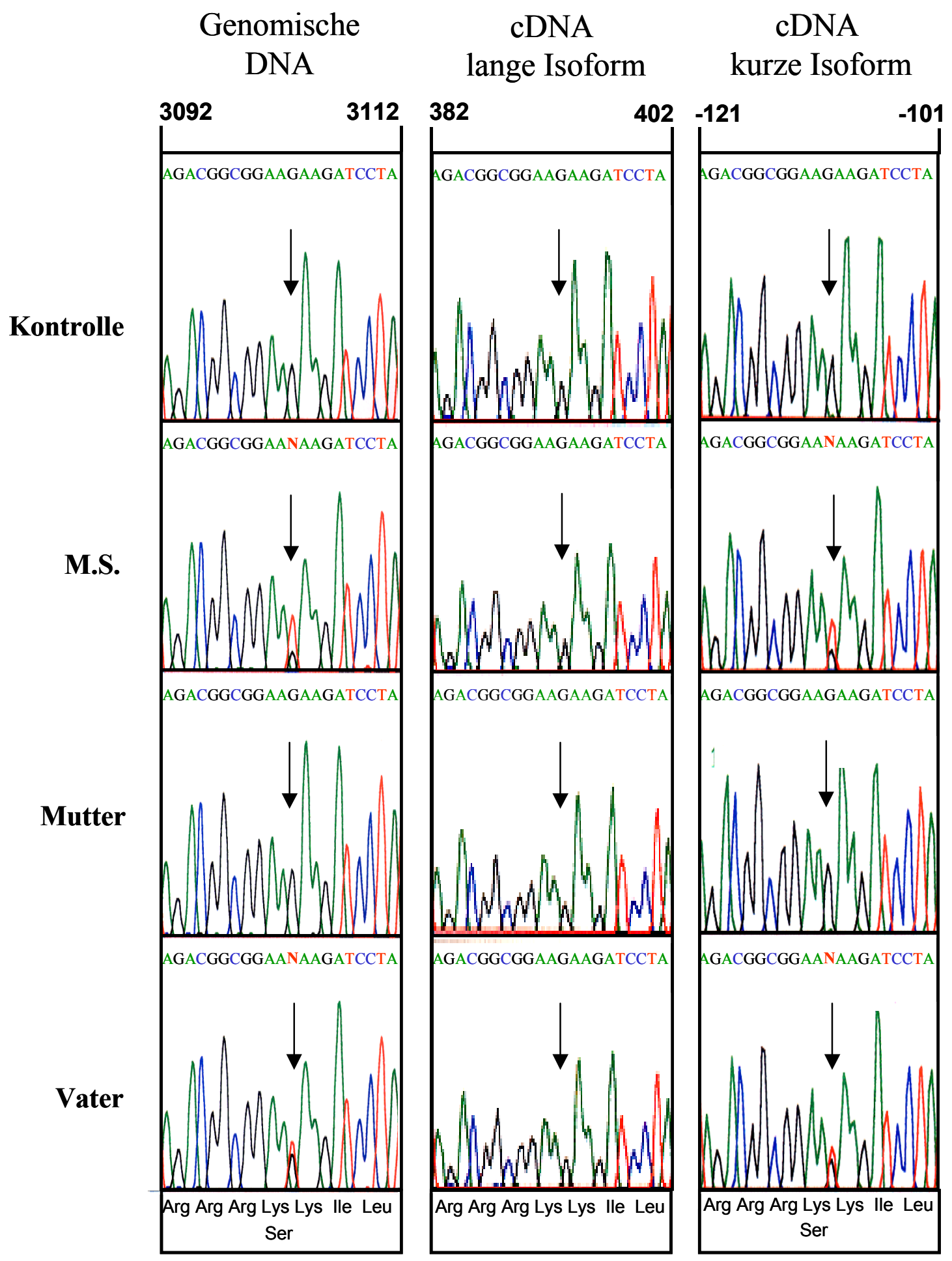

Abb.16 Identifizierung der Mutation G393T/G-111T bei Patientin M.S., die vermutlich zum Verlust des Transkripts für die lange hALG2-Isoform führt.

Dargestellt sind Sequenzvergleiche der cDNAs der kurzen und langen Isoform sowie der genomischen DNA von Patientin M.S., deren Eltern und einer Kontrolle. Die hier dargestellte Kontrolle steht repräsentativ für zehn untersuchte Kontrollpersonen. Der Pfeil weist auf das mutierte Nukleotid 
hin. Die Zahlen über den jeweiligen Sequenzen geben den Ort der Mutation im Gen bzw. den beiden cDNAs an, wobei sie sich bei der genomischen DNA sowie der cDNA für die lange Isoform auf das Startcodon der langen Isoform beziehen. Bei der cDNA der kurzen Isoform beziehen sie sich auf das Startcodon der kurzen Isoform.

In der cDNA für die kurze Isoform von Vater und Patientin M.S. zeigte sich die Mutation (G-111T) im 5'-UTR-Bereich, was anhand des Doppelpeaks in der jeweiligen cDNA-Sequenz zu erkennen ist (Abb.16, rechte Spalte). Die Doppelpeaks bei Vater und Patientin wiesen auf das Vorliegen zweier stabiler Transkripte für die kurze halg2-Isoform hin. Sequenzvergleiche der genomischen DNA von Vater und Patientin M.S. mit denen der cDNA für die lange Isoform (Abb.16, mittlere Spalte) zeigten, daß sowohl beim Vater als auch bei der Patientin die G393T-Mutation in der cDNA für diese Isoform tatsächlich nicht detektiert werden konnte. Dieses Ergebnis belegte, daß der Vater ein instabiles Transkript für die lange hALG2-Isoform an die Patientin M.S. vererbt hat.

\subsection{4 Überprüfung der Expression der langen und kurzen halg2-Form mittels Northern Blot}

Da die Resultate der cDNA- und genomischen DNA-Analyse auf ein instabiles Transkript für die lange halg2-Isoform im Fall der Patientin M.S. hindeuteten, wurde zur Kontrolle der entsprechenden RNA ein Northern Blot durchgeführt. Parallel zu der Patientin M.S. wurden vier Kontrollen überprüft. Neben der Überprüfung der Expression für die lange Isoform wurde gleichzeitig die Expressionshöhe für die kurze Isoform untersucht, um ein eventuell von den Kontrollen abweichendes Heraufoder Herunterregeln für eine der beiden Isoformen der Patientin zu untersuchen. Um sicherzustellen, daß gleiche Konzentrationen an Gesamt-RNA für den Northern Blot eingesetzt wurden, wurde eine gegen ß-Actin spezifische Sonde eingesetzt. Die verwendete halg2-Sonde war ein 563bp langes PCR-Fragment (amplifiziert mit Primern Ex2-L und R1) und interagierte sowohl mit dem $3^{\prime}$-Ende des kurzen als auch mit dem 3'-Ende des langen halg2-Transkripts. Die ß-Actin-Sonde war ein den gesamten kodierenden Bereich umfassendes PCR-Produkt. 


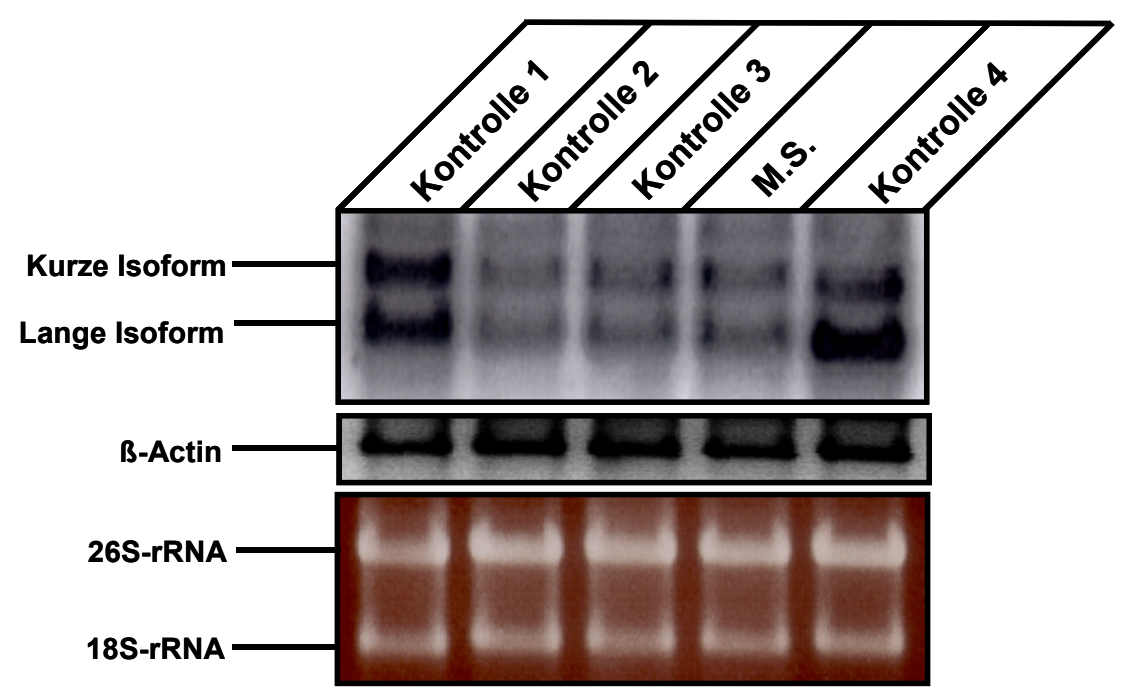

Abb. 17: Northern Blot

Ein Northern Blot mit Gesamt-RNA von Kontrollen und der Patientin M.S. wurde mit einer für beide halg2-Transkripte spezifischen PCR-Sonde hybridisiert. Um sicherzustellen, daß gleiche Konzentrationen an Gesamt-RNA eingesetzt wurden, wurde nachfolgend eine Hybridisierung mit einer ß-Actin-Sonde durchgeführt.

Der Northern Blot zeigt das Vorliegen beider halg2-Isoformen bei der Patientin und den Kontrollen, wobei die mRNA der kurzen Isoform mit 2203bp (Acc.No.: AK027814) länger ist und damit im Agarosegel langsamer läuft als die mRNA der langen Isoform mit 1835bp (Acc.No.: AK027417). Ein Unterschied in der Signalstärke der langen Isoform der Patientin ist verglichen mit den Signalen der langen Isoformen der Kontrollen nicht erkennbar. Auch die Expression für die kurze Isoform zeigt bei der Patientin keine Auffälligkeit gegenüber den Kontrollen. Kontrolle 4 zeigt sogar eine weitaus stärkere Expression für die lange halg2-Isoform als die Patientin M.S. (Abb. 17, oben). Weiterhin ist anhand der Bandenstärke für ß-Actin (Abb. 17, Mitte) sowie der Bandenstärke der 26S- und 18S-rRNA im Agarosegel (Abb.17, unten) ersichtlich, daß gleiche Konzentrationen an Gesamt-RNA für den Northern Blot eingesetzt wurden. Das Ergebnis zeigt, daß die Konzentration an dem langen halg2-Transkript bei der Patientin nicht, wie erwartet, deutlich reduziert war, sondern auf einem mit den Kontrollen vergleichbaren Level gehalten wurde. 


\subsubsection{Expression der WT-cDNA und der $\triangle 1040 G-c D N A$ für die lange hALG2-} Isoform in den Hautfibroblasten der Patientin

Die Deletionsmutation, die mit dem maternalen Allel an die Patientin M.S. weitergegeben wurde, wirkt sich sowohl auf die lange wie auch auf die kurze Isoform aus $(\Delta 1040 \mathrm{G} / \Delta 536 \mathrm{G})$. Vom paternalen Allel stammt eine Mutation (G393T/G-111T), die wahrscheinlich zu einem instabilen Transkript für die lange Isoform bei der Patientin führt. Um zu überprüfen, ob die $\Delta 1040 \mathrm{G} / \Delta 536 \mathrm{G}-M u t a t i o n$ für die Unterglykosylierung von Proteinen verantwortlich ist, wurde zum einen die Wildtypund zum anderen die ${ }_{1040 G-c D N A}$ für die lange Isoform in den Hautfibroblasten der Patientin mit Hilfe eines retroviralen Expressionssystems exprimiert. Die mit der Wildtyp-cDNA, der 1 1040G-cDNA bzw mit dem pLNCXII-Vektor stabil transfizierten Patientenfibroblasten sowie die mock-transfizierten Kontrollfibroblasten wurden mit $\left[2-{ }^{3} \mathrm{H}\right]$ Mannose radioaktiv markiert, Dol-P-Man und die kurzen Dolichol-verknüpften Oligosaccharide wurden isoliert und anschließend mittels Dünnschichtchromatographie analysiert.

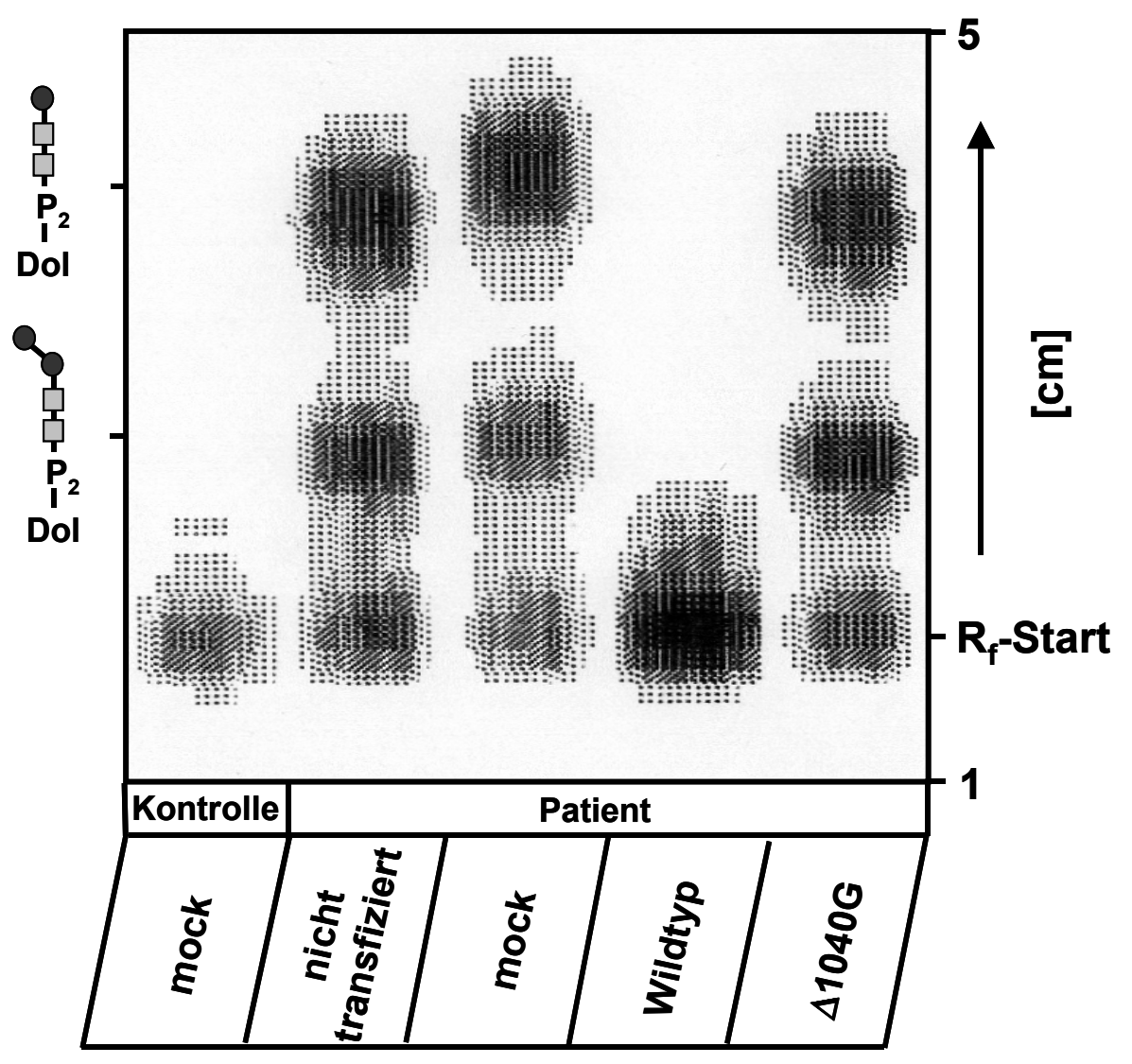

Abb. 18: Komplementation des GDP-Man:Man ${ }_{1-2}-$ GICNAC $_{2}$-PP-Dol Mannosyltransferase Defekts Aus Fibroblasten einer Kontrolle sowie der Patientin M.S., die den retroviralen Vektor alleine (mock), die Wildtyp- oder die $\triangle 1040 G-c D N A$ für die lange hALG2-Isoform exprimierten, wurden 
$\left[2-{ }^{3} \mathrm{H}\right]$ Mannose-markierte, Dolichol-verknüpfte Oligosaccharide isoliert und mittels Dünnschichtchromatographie analysiert. Die mögliche Struktur der Zuckerketten ist links im Bild dargestellt. Quadrate stehen für N-Acetylglucosamin, Kreise stehen für Mannose.

Die mock-transfizierten Kontrollfibroblasten zeigten lediglich einen Spot in der Dünnschichtchromatographie, der für eine Verunreinigung der Probe mit längerkettigen LLOs bzw. freier $\left[2-{ }^{3} \mathrm{H}\right]$ Mannose charakteristisch ist, da diese aufgrund des verwendeten Dünnschichtchromatographielaufmittels nicht aufgetrennt werden können. Die unbehandelten sowie die mock-transfizierten Patientenfibroblasten wiesen zwei weitere Spots für [2- $\left.{ }^{3} \mathrm{H}\right] \mathrm{Man}_{1}-\mathrm{GlcNAc}_{2}-\mathrm{PP}-\mathrm{Dol}$ sowie $\left[2-{ }^{3} \mathrm{H}\right] \mathrm{Man}_{2}-\mathrm{GlcNAc}_{2}-\mathrm{PP}$-Dol auf. Das Auftreten dieser für die Patientin M.S. typischen Spots wurde schon unter 4.2.6 beschrieben. Dieses Ergebnis zeigt, daß die Transfektion mit dem retroviralen Vektor allein (mock) keine Auswirkungen auf die Glykosylierung von Proteinen hat. Infiziert man Patienten-Fibroblasten mit der 1 1040G-cDNA, zeigt sich ebenfalls kein Effekt in der Dünnschichtchromatographie im Vergleich zu den nicht-transfizierten bzw. den mock-transfizierten Fibroblasten der Patientin M.S., was darauf hindeutet, daß die cDNA mit der $\triangle 1040 \mathrm{G}-M u t a t i o n$ der Patientin für ein inaktives Protein kodiert. Gleiches ist auch für die $\Delta 536 \mathrm{G}-M u t a t i o n$ für die kurze Isoform anzunehmen. Bringt man hingegen die halg2-WT-cDNA in die Patienten-Fibroblasten ein, so zeigt sich ein Spot in der Dünnschichtchromatographie, der vergleichbar mit der mock-transfizierten Kontrolle ist. Akkumulationen der frühen Zwischenstufen der N-Glykosylierung von $\mathrm{Man}_{1-2^{-}}$ GlcNAc $_{2}$-PP-Dol (s.o.) treten in den komplementierten Patienten-Fibroblasten nicht mehr auf. Dieses Ergebnis zeigt, daß es sich bei der von der Mutter an die Patientin M.S. weitergegebenen Mutation $(\Delta 1040 \mathrm{G} / \Delta 536 \mathrm{G})$ tatsächlich um die Mutation handelt, die auch für die Unterglykosylierung von Protein verantwortlich ist.

\subsubsection{Zusammenfassung der Ergebnisse}

Es konnte gezeigt werden, daß bei der Patientin M.S. die Übertragung von Mannose

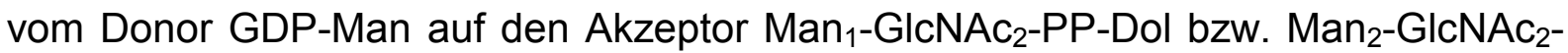
PP-Dol gestört ist. Der Defekt konnte auf Mutationen im für die GDP-Man: Man $_{1-2}$ GlcNAc $_{2}$-PP-Dol Mannosyltransferase (hALG2) kodierenden Gen zurückgeführt werden. 


\section{Diskussion}

Die Glykosylierung von Proteinen ist eine im gesamten Tier- und Pflanzenreich häufig vorkommende Proteinmodifikation. Beim Menschen sind an der $\mathrm{N}$ glykosidischen Verknüpfung von Zuckerketten auf Proteine vermutlich über 300 verschiedene Glykosyltransferase, Glykosidasen und Transportproteine beteiligt. Es ist daher wahrscheinlich, daß die Anzahl der in den letzten sieben Jahren identifizierten 11 molekularen Ursachen der N-Glykosylierungsdefekte beim Menschen nur die Spitze eines Eisbergs darstellen.

Von den bisher beschriebenen sieben CDG-I-Typen (CDG-la bis CDG-Ig) sind die Typen CDG-Id (Körner et al., 1999a) sowie CDG-lg (Thiel et al., 2002; Chantret et al., 2002; Grubenmann et al., 2002) auf die verminderten Aktivitäten von Mannosyltransferasen zurückzuführen, die die Übertragungen von Mannoseresten von GDP-Mannose auf das lipidverknüpfte Vorläuferoligosaccharid im endoplasmatischen Retikulum katalysieren. Im Folgenden wird die Aufklärung eines neuen Mannosyltransferase-Defekts vorgestellt.

\subsection{Die Unterglykosylierung von Glykanen der Patientin M.S. basiert auf keinem der bisher bekannten CDG-Typen}

Der klinische Phänotyp der Patientin M.S. präsentierte sich mit einer multisystemischen Erkrankung, die mit einer Mikrozephalie, Entwicklungsstörungen, Krampfanfällen und Dysmorphien einherging. Aufgrund der Ergebnisse klinischchemischer Untersuchungen, die verlängerte Blutgerinnungszeiten (PTT) und einen stark verminderten Blutgerinnungsfaktor XI-Spiegel zeigten, wie sie bereits für eine Reihe anderer CDG-Typen beschrieben worden waren (z.B. Hanßke et. al, 2002 für CDG-IId), wurde eine Analyse des Serumtransferrins der Patientin durchgeführt. Serumtransferrin ist ein eisenbindendes $77 \mathrm{kDa}$ Protein an das im Normalfall zwei biantennäre N-Glykanketten vom Komplextyp gebunden sind. Der Verlust der terminalen Sialinsäurereste durch Verkürzung (CDG-Ila, CDG-Ild) oder komplettes Fehlen dieser Zuckerketten (CDG-la bis CDG-lg) führt zum einen zum Verlust negativer Ladung und zum anderen zu einer verminderten Masse des Transferrins, die durch isoelektrische Fokussierung bzw. Western Blot nachgewiesen werden können. 
Die Analyse des Serum-Transferrins der Patientin M.S. mittels isoelektrischer Fokussierung sowie Western Blot ergab ein im Vergleich zu den Kontrollen verändertes Laufmuster für das Markerprotein. Das Auftreten von asialo-, disialound tetrasialo Banden in der IEF, sowie der beobachtete Massenverlust von ca. 2000Da bzw. ca. 4000Da im Western Blot bei der Patientin M.S. deutete auf einen partiellen Verlust eines oder beider N-Glykane (MG eines N-Glykans vom biantennären Komplex-Typ ca. 2000Da) auf ihrem Serum-Transferrin hin, wie er bei Patienten mit CDG-la bis CDG-lg beschrieben wurde (Jaeken et al., 1984; Niehues et al., 1998; Körner et al., 1998c; Körner et al., 1999a; Imbach et al., 2000; Kim et al., 2000; Schenk et al., 2001; Kranz et al., 2001; Thiel et al., 2002; Chantret et al., 2002; Grubenmann et al., 2002). Da der partielle Verlust eines oder beider N-Glykane ein Charakteristikum für die Typ I Defekte der CDG darstellt, konnte ein CDG-II Defekt bei der Patientin M.S. somit ausgeschlossen werden. Im weiteren Verlauf der Arbeit wurde daher überprüft, ob die Patientin M.S. unter einer der bekannten CDG-Typ I Erkrankungen litt.

Bei der enzymatischen Bestimmung der Aktivität der Phosphomannomutase 2 von M.S. zur Überprüfung des am häufigsten vorkommenden CDG-Typs, CDG-la, zeigte sich bei der Patientin eine PMM2-Aktivität von 1,53U/mg Protein, die im Vergleich zu den Kontrollen, die über eine gemittelte Aktivität von $0,89 \mathrm{mU} / \mathrm{mg}$ Protein verfügten, um 71\% über der Norm lag. Dieser Wert scheint hier zwar erhöht, er liegt aber im oberen Normbereich für die von unserer Arbeitsgruppe zuvor bestimmten PMM2Aktivitäten von 55 anderen Kontrollpersonen, bei denen der Bereich der Aktivität von 0,8 bis 1,6 schwankte (Körner et al., 1997-2002, unveröffentlichte Labordaten). Für die Patientin M.S. konnte CDG-la als Ursache für ihre Erkrankung ausgeschlossen werden.

Als weiteres konnte CDG-lb, ein Defekt der Phosphomannose Isomerase (PMI) ausgeschlossen werden. Die Aktivität der PMI von M.S. mit 11,32 mU/mg Protein lag auch hier im Vergleich zu den überprüften Kontrollen, die über eine gemittelte Aktivität von 9,57 mU/mg Protein verfügten, im Normbereich.

Die CDG-Typen Ic, Id, le, If und Ig können mit Hilfe der metabolischen Markierung von Hautfibroblasten mit [2- $\left.{ }^{3} \mathrm{H}\right]$ Mannose und anschließender Analyse der Dolicholverknüpften $\left[2-{ }^{3} \mathrm{H}\right]$ Oligosaccharide mittels HPLC identifiziert werden, wobei charakteristische Akkumulationen verkürzter Dolichol-verknüpfter Oligosaccharide 
gefunden werden. Eine Akkumulation von Man M $_{9} \mathrm{ICNAC}_{2}-\mathrm{PP}-\mathrm{Dol}$ deutet auf CDG-IC (Körner et al., 1998c; Imbach et al., 1998) hin. Eine Anhäufung von Man ${ }_{5}-\mathrm{GlcNAc}_{2}-$ PP-Dol läßt auf CDG-Id (Körner et al., 1999a) oder CDG-le (Imbach et al., 2000; Kim et al., 2000) schließen, wohingegen bei CDG-If (Schenk et al., 2001; Kranz et al., 2001) eine $\mathrm{Man}_{5}$ - sowie eine $\mathrm{Man}_{9}-\mathrm{GlcNAc}_{2}$-PP-Dol-Akkumulation erwartet wird. Akkumuliert Man $_{7}-$ GlcNAc$_{2}$-PP-Dol ist das ein Hinweis auf die Erkrankung CDG-Ig (Thiel et al., 2002; Chantret et al., 2002; Grubenmann et al., 2002). Da die HPLCAnalyse der $\left[2-{ }^{3} \mathrm{H}\right]$ Mannose-markierten Dolichol-verknüpften Oligosaccharide der Patientin M.S. keine verkürzten Formen aufwies, wie sie für andere CDG-I Typen beschrieben worden waren, konnten neben CDG-la und CDG-lb auch alle anderen bisher bekannten CDG-I-Defekte, CDG-Ic bis CDG-Ig, als molekulare Ursache für die Erkrankung der Patientin M.S. ausgeschlossen werden.

\subsection{Die molekulare Ursache der Erkrankung der Patientin M.S. ist auf einen} frühen Defekt in der Biosynthese Dolichol-verknüpfter Oligosaccharide zurückzuführen

Eine mögliche Erklärung für die normale Synthese von Dolichol-verknüpften Oligosacchariden bei gleichzeitigem Verlust kompletter N-Glykanketten auf Glykoproteinen wie im Falle unserer Patientin wäre ein Defekt der Oligosaccharyltransferase (OST), die die Übertragung des Oligosaccharids $\mathrm{Glc}_{3^{-}}$ $\mathrm{Man}_{9}-\mathrm{GlcNAC}_{2}$ vom Dolichol-PP Carrier auf naszierende Proteine katalysiert. Dabei dienen Asparaginreste innerhalb der Konsensussequenz Asn-X-Ser/ Thr als Akzeptoren, wobei $X$ für jede Aminosäure mit Ausnahme von Prolin stehen kann (Kornfeld und Kornfeld, 1985). Die Oligosaccharyltransferase wurde in der Hefe Saccharomyces cerevisiae als ein Enzymkomplex aus neun Untereinheiten (OST1-6, STT3, Wbp1 und Swp1) beschrieben, von denen die vier Untereinheiten OST1, OST2 Wbp1 und Swp1 essentiell zum Überleben sind (Knauer und Lehle, 1999). Da beim Menschen bereits die humanen Orthologe zu diesen vier essentiellen Untereinheiten der Hefe identifiziert werden konnten (Ribophorin I und II, OST48 und DAD1; Fu und Kreibich, 2000) und sich weiterhin in der Datenbank potentielle Orthologe zu den anderen fünf Untereinheiten finden lassen, ist davon auszugehen, daß es auch beim Menschen weitere zum OST-Komplex gehörende Proteine gibt.

Um eine verminderte Übertragung von $\mathrm{Glc}_{3}-\mathrm{Man}_{9}-\mathrm{GlCNAc}_{2}$-Resten vom Dol-PPCarrier auf naszierende Polypeptide zu untersuchen, wurden metabolisch mit 
$\left[2-{ }^{3} \mathrm{H}\right]$ Mannose markierte, neusynthetisierte Glycoproteine aus Kontroll- und Patientenfibroblasten nach dem Entfernen von kurzkettigen und langkettigen Dolichol-verknüpften ${ }^{3} \mathrm{H}$-Oligosacchariden mit Peptid-N-Glycosidase $\mathrm{F}$ (PNGase F) inkubiert. PNGase $\mathrm{F}$ ist ein Enzym aus Flavobaccterium meningosepticum, das praktisch alle in einem Glykoprotein vorhandenen N-glykosidisch-verknüpften Kohlehydratketten zwischen dem proximalen $\mathrm{N}$-Acetylglucosaminrest und dem Asparaginrest abspaltet, wobei letzteres zu Asparaginsäure modifiziert wird.

Die Auftrennung der aus neusynthtisierten Glykoproteinen durch PNGase F abgespaltenen $\mathrm{N}$-glykosidisch-verknüpften Kohlenhydratketten mittels HPLC zeigte $\mathrm{Glc}_{1}-\mathrm{Man}_{9}-\mathrm{GlcNAc}_{2}$ - sowie $\mathrm{Man}_{9}-\mathrm{GlcNAc}_{2}$-Peakfraktionen die auf die Aktivitäten der ER-Glucosidasen I und II und somit auf die Übertragung der vollständigen $\mathrm{Glc}_{3^{-}}$ $\mathrm{Man}_{9}$-GlcNAc${ }_{2}$-Zuckerkette auf das naszierende Protein durch die OST hinweist (Parodi, 2000). Darüberhinaus zeigte diese Untersuchungen, dass im Falle der Patientin M.S. im Vergleich zu Kontrollen ähnliche Mengen an $\mathrm{Glc}_{3}-\mathrm{Man}_{9}-\mathrm{GlCNAc}_{2}-$ Resten auf neusynthetisierte Glykoproteine übertragen wurden, was nicht auf eine OST-Defizienz hindeutet.

Gegen einen OST-Defekt bei der Patientin M.S. sprechen außerdem die Erkenntnisse, die durch knock-out- sowie Mutations-Untersuchungen der OSTKomplexe in Saccharomcyes cerevisiae oder auch der Maus gewonnen wurden. Schaltet man beispielsweise in der Hefe die nicht-essentiellen Untereinheiten OST3 und OST6 oder die essentiellen Untereinheiten OST1 (Silberstein et al., 1995) bzw. WBP1 (te Heesen et al., 1993) durch knock-out aus, so zeigt sich zum einen eine starke Unterglykosylierung auf den untersuchten Glykoproteinen. Zum anderen lassen sich aber in der HPLC-Analyse der LLOs auch Akkumulationen von verschiedenen Intermediaten der $\mathrm{N}$-Glykanbiosynthese von $\mathrm{Man}_{5}-\mathrm{GlCNAc}_{2}$-PP-Dol bis $\mathrm{Glc}_{3}-\mathrm{Man}_{9}-\mathrm{GlcNAc}_{2}-\mathrm{PP}$-Dol klar nachweisen, wovon besonders $\mathrm{Man}_{5}-\mathrm{GlcNAc}_{2}-$

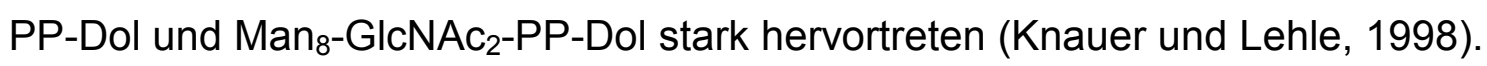

Neben den $\mathrm{Glc}_{1}-\mathrm{Man}_{9}-\mathrm{GlcNAc}_{2}$ - und Man ${ }_{9}-\mathrm{GlcNAc}_{2}-$ Resten konnte bei der Patientin M.S. im Vergleich zu Kontrollen in mehreren Experimenten ein zusätzlicher Peak in frühen HPLC-Fraktionen detektiert werden, der daraufhindeutete, dass sehr kurze [2${ }^{3} \mathrm{H}$ ]Mannose-markierte Oligosaccharide wie z.B. $\mathrm{Man}_{1}$ - oder $\mathrm{Man}_{2}-\mathrm{GICNAC}_{2}$ auf neusynthetisierte Proteine übertragen werden. Jackson et al. (1989) konnten für die Bäckerhefe Saccharomyces cerevisiae zeigen, daß in einer Hefemutante die verkürzten aber nicht glucosylierten Vorläuferoligosaccharide der $\operatorname{Man}_{1-}$ - und Man $_{2}$ - 
$\mathrm{GlcNAc}_{2}$ Form auf Proteine übertragen werden. Man $2_{2}^{-}$und Man $_{1}-\mathrm{GlcNAc}_{2}$ stellen in der Hefe demnach ein Substrat für den OST-Komplex dar. Es bleibt allerdings dahingestellt, wie effektiv die Übertragung dieser verkürzten Zuckerketten ist. Murphy und Spiro konnten 1981 in vitro sowie Burda und Aebi 1998 in vivo zeigen, daß das vollständige Oligosaccharid $\mathrm{Glc}_{3}-\mathrm{Man}_{9}-\mathrm{GlcNAc}_{2}$-PP-Dol besonders gut von dem OST-Komplex erkannt wird und daß gerade die terminale, dritte Glucose in a1,2Orientierung für eine effektive Übertragung des vollständigen Oligosaccharids auf das naszierende Protein in der Hefe notwendig ist. Übertragen werden können allerdings auch so verkürzte Strukturen wie $\operatorname{Man}_{5} \mathrm{GlcNAc}_{2}, \mathrm{Glc}_{1}-\mathrm{Man}_{5}-\mathrm{GlcNAc}_{2}$ oder Glc $_{1}-M^{-} n_{8}-$ GlcNAc$_{2}$ (Parodi, 2000). Auch bei CDG-Patienten konnten verkürzte Zuckerketten auf Proteinen detektiert werden, die zuvor von der OST übertragen worden sind. So zeigte sich beispielsweise auf dem Serum-Transferrin des CDG-IdPatienten $\mathrm{Man}_{5}-\mathrm{GlcNAc}_{2}$ und $\mathrm{Glc}_{1}-\mathrm{Man}_{5}-\mathrm{GlcNAc}_{2}$ (Körner et al., 1999). Hingegen wurde bei den CDG-Ic-Patienten, die Mang-GlcNAc 2 -PP-Dol akkumulieren (Körner et al., 1998c; Imbach et al., 1998), keine Übertragung der verkürzten Oligosaccharide nachgewiesen, was die Bedeutung der Glucosylierung für die Erkennung und anschließende Übertragung des Oligosaccharids durch die OST unterstreicht. Eine Übertragung der stark verkürzten Oligosaccharidstrukturen $\mathrm{Man}_{2}-\mathrm{GlcNAc}_{2}$ oder $M_{1}-G_{1}{ }_{1} A_{2}$ auf Proteine wie sie bei der Patientin M.S. offenbar stattfindet, konnte bisher beim Menschen noch nicht nachgewiesen werden. Bei der Annahme, daß bei der Patientin M.S. der Defekt in der Übertragung von Mannoseresten vom Donor GDP-Man auf den Akzeptor Man $_{1}-$ bzw. Man $2-$ GlcNAc $_{2}-P P-D o l ~ z u$ finden ist, könnten die für die Anheftung der drei Glucosereste wichtigen Mannosereste, die in a1,2Stellung auf den in a1,3-verknüpften Mannoserest übertragen werden, nicht angehängt werden, da sie vermutlich keinen entsprechenden Akzeptor für die ERGlucosyltransferasen ALG6, ALG8 und ALG10 darstellen. Bei der im Falle der Patientin M.S. gefundenen verkürzten Zuckerkette auf dem Protein handelt es sich daher eventuell um einen unspezifischen Transfer durch die OST.

Fraglich ist weiterhin, ob durch so stark verkürzte Strukturen wie $\operatorname{Man}_{2-}$ und Man $_{1-}$ $\mathrm{GlcNAc}_{2}$ auf dem Protein überhaupt das Passieren der Qualitätskontrolle (Calnexin/ Calreticulin) in der Zelle möglich ist. Hammond et al. (1994) haben postuliert, daß Glykoproteine solange von den Lektinen Calnexin und/ oder Calreticulin im ER festgehalten und glucosyliert sowie deglucosyliert werden, wie sie noch nicht die korrekte Zusammensetzung ihrer Glykanstruktur erhalten haben. Proteine, die sich 
nicht korrekt glykosylieren lassen, sollen dann abgebaut werden. Neuere Erkenntnisse stellen diese Vorstellung inzwischen in Frage. So konnte neben Saccharomyces cerevisiae (Hong et al., 1996; Jörgensen et al., 1999) auch in Melanoma-Zellen (Petrescu et al., 1997; Branza-Nichita et al., 1999) gezeigt werden, daß auch falsch gefaltete Proteine zu ihren Zielorten transportiert und nicht abgebaut werden.

Im Falle der Patientin M.S. wäre es vorstellbar, daß Teile der NGlykosylierungsstellen der Glykoproteine mit $\mathrm{Man}_{2}-$ und $\mathrm{Man}_{1}-\mathrm{GlcNAc}_{2}$-Strukturen besetzt sind, die nicht weiter prozessiert werden können. Wenn diese Proteine im Rahmen der Qualitätskontrolle nicht abgebaut und die vollständigen N-Glykane auf den anderen Glykosylierungsstellen normal getrimmt und prozessiert würden, könnte dies das isoelektrische Fokussierungsmuster des Serum-Transferrins der Patientin M.S. erklären, in dem neben der tetrasialo-Bande, die bei gesunden Menschen die Hauptbande darstellt, vor allem disialo und asialo Formen des Transferrins auftreten, die in diesem Fall auf eine starke Verkürzung der N-Glykane zurückzuführen wären.

Durch die auf Proteine übertragenen, verkürzten Zuckerketten, die mit Hilfe des PNGase F Verdaus detektiert worden waren, ergab sich für den weiteren Verlauf der Arbeit die Theorie, daß bei der Patientin ein früher Defekt in der N-GlykanBiosynthese vorlag, wobei beispielsweise die Übertragung eines der ersten Mannosereste auf das Vorläuferoligosaccharid $\mathrm{Man}_{1}-$ bzW. Man ${ }_{2}-\mathrm{GlcNAc}_{2}$-PP-Dol betroffen wäre.

Da sich diese Oligosaccharide mit unserer HPLC-Analytik aufgrund der Aufreinigungsmethode nicht detektieren lassen, erfolgte im Weiteren eine Analyse kurzkettiger, [2- $\left.{ }^{3} \mathrm{H}\right]$ Mannose-markierter, Dolichol-verknüpfter Oligosaccharide mit Hilfe der Dünnschichtchromatographie in Gegenwart des apolaren Laufmittels Chloroform/Methanol/Wasser (65/25/4). Nach unserer Arbeitshypothese erwarteten wir dabei im Falle der Patientin M.S. neben $\left[2-{ }^{3} \mathrm{H}\right] \mathrm{Dol}-\mathrm{P}-\mathrm{Man}$, dem Mannosedonor im Lumen des ER, auch die Detektion von [2- $\left.{ }^{3} \mathrm{H}\right] \mathrm{Man}_{1}-\mathrm{GlcNAc}_{2}-\mathrm{PP}-\mathrm{Dol}$ oder [2${ }^{3} \mathrm{H}_{\mathrm{Man}} \mathrm{M}_{2}-\mathrm{GlcNAc}_{2}$-PP-Dol. Dabei sollte [2- $\left.{ }^{3} \mathrm{H}\right] \mathrm{Man}_{1}-\mathrm{GlcNAc}_{2}-\mathrm{PP}-\mathrm{Dol}$ aufgrund der höheren Hydrophobizität ein schnelleres Laufverhalten in der Dünnschichtchromatographie aufweisen als [2- $\left.{ }^{3} \mathrm{H}\right] \mathrm{Man}_{2}-\mathrm{GlcNAc}_{2}-\mathrm{PP}-\mathrm{Dol}$. Überraschenderweise konnten bei der Patientin M.S. neben dem erwarteten Spot für $\left[2-{ }^{3} \mathrm{H}\right] \mathrm{Dol}-\mathrm{P}-\mathrm{Man}$ im Vergleich zu einer Kontrolle, die Akkumulation von zwei weiteren 
Verbindungen gezeigt werden, bei denen es sich um die eben erwähnten radioaktiv markierten $\mathrm{Man}_{1}$ - sowie $\mathrm{Man}_{2}-\mathrm{GlcNAc}_{2}$-PP-Dol-Verbindungen handeln konnte. Neben der zuvor gezeigten Übertragung verkürzter Zuckerketten auf Proteine, deutete auch das Ergebnis der Dünnschichtchromatographie auf einen frühen Defekt in der Übertragung von Mannoseresten auf das Vorläuferoligosaccharid hin, wobei auch hier die genaue Identifizierung der akkumulierenden Verbindungen nicht möglich war. Anders als im PNGase F-Verdau zeigte sich bei der DünnschichtAnalyse die Akkumulation von zwei frühen Vorstufen der Dolichol-verknüpften Oligosaccharid Biosynthese. Der Befund, daß bei der HPLC-Analyse der proteinverknüpften Oligosaccharide nur eine Peakfraktion im Bereich der kurzen Oligosaccharidstrukturen detektiert werden konnte, könnte daraufzurückzuführen sein, daß eine der beiden in der Dünnschichtchromatographie akkumulierenden Verbindungen kein Substrat für den OST-Komplex darstellt und folglich nicht übertragen wird.

Letzlich konnte nur eine massenspektrometrische Analyse der akkumulierenden Substanzen Aufschluß darüber geben, auf welcher Stufe der Mannoseresteübertragung von GDP-Man auf das Vorläuferoligosaccharid der Transfer zum Erliegen kommt. Zur Vorbereitung auf die Massenspektrometrie wurden die bei der Patientin M.S. akkumulierenden kurzkettigen, $\left[2-{ }^{3} \mathrm{H}\right]$ Mannosemarkierten, Dolichol-verknüpften Oligosaccharide mit Hilfe der mildsauren Hydrolyse vom Lipidcarrier abgespalten und über HPLC aufgetrennt, wobei drei frühe Peakfraktionen detektiert werden konnten. Bei der ersten dieser Peakfraktionen, die bei Kontrolle und Patient gefunden wurde, handelt es wahrscheinlich um freie [2${ }^{3} \mathrm{H}$ ]Mannose, während es sich bei den beiden zusätzlichen Peakfraktionen im Falle der Patientin M.S. um Man ${ }_{1}$ - und $\mathrm{Man}_{2}-\mathrm{GlcNAc}_{2}$-Reste handeln konnte. Die Analyse dieser beiden Peaks erfolgte nach Kopplung an PMP durch Massenspektrometrie (MALDI-TOF ) und ergab Molekulargewichte von 917Da bzw. 1075Da, die der Masse von $\mathrm{Man}_{1}$ - bzW. Man ${ }_{2}-\mathrm{GlcNAc}_{2}$-PP-PMP entsprachen. Dieses Resultat deutete daraufhin, daß bei der Patientin M.S. tatsächlich ein früher Defekt in der NGlykosylierung von Proteinen vorlag, bei dem die Übertragung von Mannoseresten vom Donor GDP-Man auf die Vorläuferoligosaccharide $\mathrm{Man}_{1}$ - bzW. Man ${ }_{2}-\mathrm{GlcNAc}_{2}-$ PP-Dol betroffen war.

Die Biosynthese der lipidverknüpften N-Glykane ist ein geordneter Prozeß, in dem die einzelnen Zuckerreste in einer bestimmten Reihenfolge auf das wachsende 
Oligosaccharid übertragen werden (Hubbard und Ivatt, 1981; Kornfeld und Kornfeld, 1985). Hierbei wird der erste Mannoserest in $B 1,4-O r i e n t i e r u n g$ an $\mathrm{GlCNAC}_{2}$-PP-Dol angehängt. Anschließend erfolgt die Übertragung des zweiten Mannosrestes in a1,6Stellung und des dritten Mannoserestes in a1,3-Stellung auf den ersten Mannoserest (Parodi, 2000).

\subsection{Die Überprüfung des humanen Orthologs zum Hefe alg2-Gen der Patientin}

\section{M.S. zeigte zwei Mutationen}

In der Bäckerhefe Saccharomyces cerevisiae katalysiert das ALG2-Protein (Acc.No.: NP_011450) die Übertragung des zweiten und dritten Mannoserests vom Donor GDP-Man auf das Vorläuferoligosaccharid Man 1 -GlcNAc 2 -PP-Dol und $\mathrm{Man}_{2}-$ GlcNAc $_{2}$-PP-Dol. Bei einer Hefemutante, die über Mutationen im alg2-Gen verfügte, traten Akkumulationen von $\mathrm{Man}_{1}-\mathrm{GlcNAc}_{2}$-PP-Dol sowie $\mathrm{Man}_{2}-\mathrm{GlcNAc}_{2}$-PP-Dol auf (Huffacker und Robbins, 1983). Entsprechende Akkumulationen konnten auch bei einer Mutante des Pilzes Rhizomucor pusillus gezeigt werden, in dem das Ortholog zum Hefe-ALG2-Protein mutiert war (Yamazaki et al., 1998). Für die Hefe konnte weiterhin belegt werden, daß diese verkürzten, nicht glucosylierten Zuckerketten auch auf Proteine übertragen werden (Jackson et al., 1989).

Dies deutete auf einen Defekt der Patientin M.S. in dem humanen Ortholog zum Hefe ALG2-Protein hin. In der Datenbank waren für den Menschen zwei potentielle Orthologe zum Hefe-ALG2-Protein aufgeführt, deren Funktion allerdings noch nicht bestimmt worden war. Es handelte sich hierbei um eine lange ALG2-Isoform mit einer Länge von 417 Aminosäuren (Acc.No.: CAC07999) sowie eine kurze Isoform mit einer Länge von 249 Aminosäuren, die mit dem C-Terminus der langen Isoform identisch war (Acc.No.: AAH15126). Weiterhin ließen sich die Sequenzen der mRNAs für die lange Isoform (Acc.No.: AK027417) und die kurze Isoform (Acc.No.: AK027814) aus der Datenbank entnehmen. Beide Isoformen werden vom gleichen Genlocus auf Chromosom 9q22 kodiert.

Sequenzüberprüfungen des alg2-Genlocus' ergaben, daß die Patientin M.S. auf ihrem maternalen Allel eine Mutation trägt, die in dem gemeinsamen C-terminalen Bereich der kurzen $(\Delta 536 \mathrm{G})$ und langen ALG2-Isoform ( $\triangle 1040 \mathrm{G})$ liegt. Diese Mutation führt zu einer Verschiebung des Leserahmens und nachfolgend zu einem vorzeitigen Translationsstop, wodurch jeweils die terminalen 70 Aminosäurereste beider Isoformen verloren gehen. Bei der langen Isoform mit 417 Aminosäuren 
entspricht dieser Verlust 17\% am Wildtypprotein, wohingegen bei der kurzen Isoform $28 \%$ der WT-Proteinsequenz verloren gehen. Für beide mutierten Isoformen gilt, daß 19 geladene Aminosäurereste (R, K, H, Y, C, D, E), 18 hydrophobe Aminosäurereste $(A, I, L, F, W, V)$, neun saure Aminosäurereste $(D, E)$ und sieben basische Aminosäurereste $(K, R)$ durch die Verschiebung des Offenen Leserahmens verloren gehen. Bei der langen Isoform der Patientin M.S. wirkt sich der Aminosäureverlust dahingehend aus, daß das ALG2-Protein statt einer Masse von 47097Da nur 42126Da zeigt. Gravierender erscheint, daß sich auch der isoelektrische Punkt des Proteins der Patientin von $\mathrm{pH}$ 6,89 auf $\mathrm{pH}$ 7,26 verschiebt und sich letztlich auch die Ladung des Proteins von -0,58 (bei $\mathrm{pH} 7,0$ ) auf $+1,04$ (bei $\mathrm{pH} \mathrm{7,0)} \mathrm{ändert.} \mathrm{Bei} \mathrm{der}$ kurzen Isoform vermindert sich im Falle des ALG2-Proteins der Patientin M.S. die Masse von 28123Da auf 23152Da. Der isoelektrische Punkt verschiebt sich von $\mathrm{pH}$ 6,45 auf pH 6,83 für das mutierte Protein. Die Ladung des WT-ALG2 bei pH 7,0 beträgt -2,05. Das verkürzte Protein der Patientin hat bei $\mathrm{pH} \mathrm{7,0} \mathrm{eine} \mathrm{Ladung} \mathrm{von}$ -0,43 (Daten errechnet mit Protean, einem Unterprogramm von DNA-Star). Es erscheint fraglich, ob ein Protein, dem 17\% bzw. 28\% an der WT-Sequenz der jeweiligen ALG2-Isoform fehlen, was auch zum Verlust von vier der potentiellen 16 Phosphorylierungsseiten führt (http://www.cbs.dtu.dk/services/NetPhos/), überhaupt noch katalytisch aktiv sein kann. Hinzu kommt weiterhin, daß den mutierten ALG2Proteinen der Patientin M.S. die putative Dolichol-Bindungsstelle fehlt (siehe Abb. 15), die sich innerhalb der letzten 20 Aminosäurereste des humanen Proteins befindet. Die in der Literatur vorgeschlagenen Consensussequenzen der Bindungsstellen für Saccharomyces cerevisiae sind zum einen LFVxFxxIPFxFY, wobei $x$ hier für jede Aminosäure stehen kann (Albright et al., 1989). Zum anderen wird die Sequenz ILFIxFXXlabxF, wobei a entweder $\mathrm{P}$ und b F bzw.Y ist, oder a aber I oder $L$ und b für die Aminosäure P steht, beschrieben (Jackson et al., 1993). Die Dolichol-Bindungsstelle des humanen ALG2-Proteins weist drei übereinstimmende Aminosäurereste mit der zuletzt genannten Hefe-Sequenz aus 13 Aminosäureresten auf (XXX-FSPEAFTEQL్YRY-XXX, übereinstimmende $A S$ hier fett und unterstrichen). Da der Konservierungsgrad von Hefeproteinen zu den humanen Orthologen aber maximal $30 \%$ beträgt, wäre eine stärkere Übereinstimmung auch unwahrscheinlich. In höheren Organismen ist bisher noch keine alternative Consensussequenz für die Dolichol-Bindungsstelle beschrieben worden. 
Durch eine ALG2-Hefemutante, in der die Aminosäuren 377Gly und 386Gln gegen Arg bzw. Lys ausgetauscht waren, konnte gezeigt werden, daß diese beiden Veränderungen in der Aminosäuresequenz bereits ausreichten, um zu den

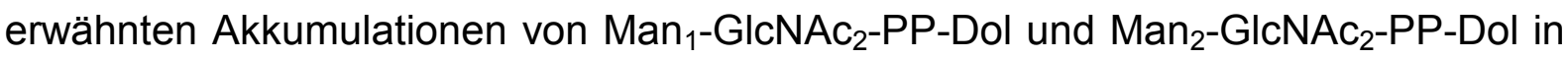
der Hefe zu führen (Jackson et al., 1993). In ALG2-Mutanten des Pilzes Rhizomucor pusillus zeigten sich ebenfalls die bei der Hefe auftretenden kurzkettigen, lipidverknüpften Oligosaccharide, obwohl auch hier nur einzelne Aminosäuren entsprechend zu der Hefemutante ausgetauscht worden sind. Bei der Patientin M.S. muß dies letztlich zu der Annahme führen, daß bei einem Verlust von 70 Aminosäuren die beiden ALG2-Isoformen, die vom maternalen Allel kodiert werden, biochemisch inaktiv sein müssen.

Auf dem paternalen Allel konnte bei der Patientin M.S. eine Mutation identifiziert werden, die in der langen Isoform zum Austausch von Lysin131 zu Serin führen würde. Da sich der entsprechende Basenaustausch G353T weder bei der Patientin noch bei dem Vater in der für die lange Isoform kodierenden cDNA identifizieren ließ, führte das zu der Annahme, daß das vom paternalen Allel kodierte Transkript für die lange Isoform instabil sein mußte. In diese Richtung gehend war auch die Beobachtung, daß sich die gleiche Mutation bei Vater und Patientin in heterozygoter Form im 5'-UTR-Bereich der cDNA (G-111T) für die kurze Isoform detektieren ließ, was bedeutete, daß hier sowohl das paternale als auch das maternale Allel abgelesen und stabile Transkripte synthetisiert worden sind. Es bleibt zu klären, ob es sich bei der auf dem paternalen Allel identifizierten Mutation (G353T/ G-111T) tatsächlich um die Mutation handelt, die auch zu der Instabilität der mRNA für die lange Isoform führt. Die Literatur besagt dazu, daß bereits eine einzelne Basenmutation im Exonbereich eines Gens ausreicht, um Transkripte instabil werden oder gar nicht erst entstehen zu lassen (so u.a. Mendell und Dietz, 2001). Die Annahme, daß der Patientin M.S. das vom paternalen Allel kodierte lange alg2Transkript fehlt, ließ vermuten, daß sich im Northern Blot für alg2 Auffälligkeiten in Bezug auf die Expression der beiden Isoformen von M.S. erkennen ließen. Erwartet wurde hier, daß die Patientin etwa $50 \%$ weniger Transkript für die lange Isoform aufzuweisen hatte als die Kontrollen. Dies war nicht der Fall. Vielmehr zeigte der Northern Blot, daß keinerlei Unterschiede in der Expression der beiden untersuchten Isoformen der Patientin im Vergleich zu den Kontrollen vorhanden waren. Erklärbar ist das allein durch eine erhöhte Transkription der mRNA für die lange Isoform, die 
vom maternalen Allel abgelesen wird. Wäre dagegen die Transkription des paternalen alg2-Locus erhöht worden, hätte sich im Laufe der zahlreichen Sequenzierungen der cDNA für die lange Isoform zumindest in einigen Fällen das WT-Transkript neben dem mutierten $\Delta 1040 G$-Transkript zeigen müssen. Dies ist jedoch nicht eingetreten.

\subsection{Die Expression der WT-cDNA für die lange hALG2-Isoform in den} Patientenfibroblasten führte zur Normalisierung des Glykosylierungsmusters

Durch die retrovirale Expression der WT-cDNA für die lange hALG2-Isoform in den Patientenfibroblasten konnte eine Normalisierung des Glykosylierungsmusters der Dolichol-verknüpften Oligosaccharide herbeigeführt werden. Dieser Befund zeigte, daß es sich bei dem putativen hALG2-Protein des Menschen tatsächlich um das Ortholog zum Hefe ALG2 handelte. Weiterhin konnte durch die Expression der mutierten cDNA ( $\Delta 1040 G)$ für die lange Isoform des hALG2 in den Patientenfibroblasten keine Normalisierung des Glykosylierungsmusters der LLOs erzielt werden, was darauf hindeutet, daß es sich bei den mutierten hALG2Proteinen, die vom maternalen Allel kodiert werden, höchstwahrscheinlich um inaktive Proteine handelt. Mit diesem Ergebnis konnte die molekulare Ursache für die Erkrankung der Patientin M.S. als Defekt des hALG2 funktionell belegt werden. Somit stellt die Erkrankung stellt einen neuen CDG-Typ, CDG-Ih, dar.

Für die Patientin M.S. bedeuten alle erhaltenen Ergebnisse zusammengenommen, daß sie aufgrund der von den Eltern vererbten Mutationen wahrscheinlich keine biochemisch-aktive lange ALG2-Isoform besitzt, da vom Vater ein instabiles Transkript und von der Mutter eine mutierte und inaktive Form weitergegeben wurde. In Bezug auf die kurze ALG2-Isoform der Patientin M.S. ist zu sagen, daß sie aufgrund der Mutation, die vom maternalen Allel stammt, ebenfalls ein inaktives Protein für die kurze Isoform synthetisiert. Die kurze Isoform, die vom paternalen Allel kodiert wird, sollte dagegen vollständig aktiv sein.

Durch den wahrscheinlich kompletten Ausfall der langen und den partiellen Ausfall der kurzen hALG2-Isoform kommt es im Falle der Patientin M.S. zur Akkumulationen von Man $_{1}-G_{c N A c}-P P-D o l$ und Man $_{2}-$ GlcNAc $_{2}-P P-D o l$, was vermutlich zu einer verminderten Bereitstellung von $\mathrm{Glc}_{3} \mathrm{Man}_{9}-\mathrm{GlCNAc}_{2}-\mathrm{PP}$-Dol für die N-GlykanBiosynthese im ER und damit zu einer Unterglykosylierung von Glykoproteinen führt. Unser Befund, dass die Menge an $\mathrm{Glc}_{3} \mathrm{Man}_{9}-\mathrm{GlcNAc}_{2}-\mathrm{PP}-\mathrm{Dol}$ in 
Patientenfibroblasten im Vergleich zu Kontrollen relativ normal ist, läßt sich entweder durch eine Restaktivität der mutierten hALG2 oder die Aktivität der einen verbleibenden normalen kurzen hALG2 Isoform erklären. Allerdings ist es wahrscheinlich, dass in anderen Organen mit hoher Glykoproteinbiosyntheserate,

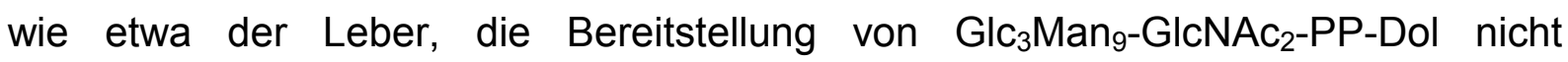
ausreichend ist.

Eine weitere Möglichkeit für die pathologischen Effekte von CDG-Ih ist eine mögliche Toxizität des akkumulierenden Man $_{1}-\mathrm{GlcNAc}_{2}-\mathrm{PP}-\mathrm{Dol}$ und $\mathrm{Man}_{2}-\mathrm{GlcNAc}_{2}-\mathrm{PP}-\mathrm{Dol}$, über die in der Literatur allerdings bisher nichts beschrieben wurde.

In der vorliegenden Arbeit wurde gezeigt, daß das humane ALG2-Protein sowohl die

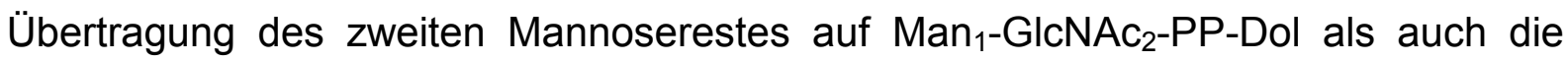
Übertragung des dritten Mannoserestes auf Man $_{2}-\mathrm{GlcNAc}_{2}-\mathrm{PP}-\mathrm{Dol}$ katalysiert. Bislang war nur vom ALG9-Protein aus Saccharomyces cerevisiae, daß zum einen die Übertragung von Mannoseresten von Dol-P-Man auf Man ${ }_{6}-G_{c N A c}-P P-D o l$ sowie auf $\mathrm{Man}_{8}-\mathrm{GlcNAc}_{2}$-PP-Dol katalysiert, bekannt, daß das gleiche Enzym zwei Übertragungsschritte in der Biosynthese von N-Glykanen katalysiert (Cipollo und Trimble, 2000). Im Gegensatz zu ALG2 wurde hier allerdings nur eine einzige Form von ALG9 beschrieben. Weiterhin muß erwähnt werden, daß die Mannosereste, die von ALG9 übertragen werden, beide in $\alpha 1,2-$ Orientierung angehängt werden, wohingegen im Falle von hALG2 ein Mannoserest in a1,6-Stellung und ein Mannoserest in a1,3-Orientierung an den ersten Mannoserest auf dem lipidverknüpften Oligosaccharid angehängt wird (Parodi, 2000). Es erscheint fraglich, ob das gleiche Protein zwei so unterschiedlich Verknüpfungsarten katalysieren kann. Hier ergibt sich allerdings auch Raum zu der Annahme, daß gerade dies der Grund dafür sein kann, daß es zwei Isoformen von ALG2 gibt, von der die eine Isoform die a1,6- und die andere die a1,3-Übertragung der Mannosereste katalysiert. Da bei der Patientin M.S. zuletzt Man $_{2}-$ GlcNAc$_{2}$-PP-Dol akkumuliert, bedeutet dies, daß die Übertragung des zweiten Mannoserestes von GDP-Man auf Man $_{1}-$ GlcNAc$_{2}-P P-D o l$ stattfindet. Da die Patientin nur über eine aktive kurze Isoform von ALG2 verfügt, ließe sich annehmen, daß die kurze ALG2-Isoform die Übertragung des Mannoserestes in $\alpha 1,6$-Orientierung katalysiert, wohingegen die lange Isoform, deren Aktivität bei der Patientin M.S. komplett fehlt, für die Anheftung des dritten Mannoserestes in a1,3-Stellung zuständig wäre. 


\section{Zusammenfassung}

Ziel dieser Arbeit war die Identifizierung der molekularen Ursache eines bis dahin unbekannten Typs aus der Gruppe der 'Congenital Disorders of Glycosylation (CDG)' bei einer Patientin, die unter einer multisystemischen Erkrankung mit schwerpunktmäßig neurologischen Störungen litt.

Im Vorfeld wurde eine Untersuchung des Serumtransferrins der Patientin M.S. mit Hilfe der isoelektrischen Fokussierung und des Western Blots durchgeführt, wobei sich der Verdacht auf einen Defekt aus der Gruppe der 'Congenital Disorders of Glycosylation' vom Typ I ergab. Im weiteren Verlauf der Arbeit konnten durch die Bestimmung der enzymatischen Aktivitäten der Enzyme PMM2 bzw. PMI die CDGTypen la und $\mathrm{lb}$ als Ursache für die Unterglykosylierung des Transferrins ausgeschlossen werden. Weiterhin konnte mit Hilfe der HPLC-Analytik keine Akkumulation längerkettiger $\left[2-{ }^{3} \mathrm{H}\right]$ Mannose-markierter Dolichol-verknüpfter Oligosaccharide nachgewiesen werden, wie sie für die CDG-Typen lc, Id, le, If und Ig beschrieben worden sind. Bei der anschließenden dünnschichtchromatographischen Auftrennung kurzkettiger Dolichol-verknüpfter $\left[2{ }^{3} \mathrm{H}\right]$ Oligosaccharide konnte im Fall der Patientin M.S. die Akkumulation von zwei Substanzen nachgewiesen werden, die im weiteren Verlauf der Untersuchungen mit Hilfe der HPLC und anschließender Massenspektrometrie als Dol-PP-GIcNAc $-\mathrm{Man}_{1}$ und Dol-PP-GIcNAc $-\mathrm{Man}_{2}$ identifiziert werden konnten. Aus der Hefe Saccharomyces cerevisiae war bekannt, daß im Verlauf der Biosynthese Dolichol-verknüpfter Oligosaccharide die Übertragung des zweiten Mannoserestes von GDP-Man auf Dol-PP-GIcNAc -Man $_{1}$ durch das Genprodukt des alg2-Gens katalysiert wird. Das humane Ortholog zum Hefe-alg2-Gen war bisher nur in der Datenbank beschrieben worden, ohne daß die Funktionalität des Enzyms nachgewiesen wurde.

Bei der molekulargenetischen Untersuchung des alg2-Gens in Kontrollpersonen konnte gezeigt werden, daß -zumindest beim Menschen- eine lange Isoform des Enzyms mit 417 Aminosäuren sowie eine kurze Isoform mit 249 Aminosäuren existieren, wobei die 249 Aminosäuren der kurzen Isoform der terminalen Hälfte der langen Isoform entsprechen. Beide Isoformen des Enzyms werden von dem selben Genlocus kodiert, weisen aber unterschiedliche Transkriptionsstartpunkte auf. Das längere alg2-Transkript wird von zwei Exons, das kürzere Transkript hingegen nur von einem Teil des zweiten Exons der langen Isoform kodiert. 
Im Falle der Patientin M.S. konnte auf einem Allel eine Deletionsmutation identifiziert werden, die in dem gemeinsamen kodierenden terminalen Bereich der langen und der kurzen Isoform liegt $(\triangle 1040 G$ in der cDNA der langen und $\triangle 536 G$ in der cDNA der kurzen Isoform). Der Basenverlust führt zu einer Leserasterverschiebung und einem vorzeitigen Translationsstop. Die Sequenz der C-terminalen 70 Aminosäuren der kurzen und langen Isoform gehen verloren und werden durch eine Sequenz von 26 neuen Aminosäuren ersetzt. Die $\Delta$ 1040G/A536G-Mutation wurde von der Mutter vererbt.

Die Mutation, die sich auf dem vom Vater vererbten Allel befindet, liegt im translatierten Bereich der langen Isoform (G393T), bzw. im 5'-untranslatierten Bereich der kurzen Isoform (G-111T). Diese Mutation führt bei der langen Isoform zum Austausch von Lys131Ser. Da diese Mutation bei der Patientin M.S. und beim Vater in der RNA der langen Isoform nicht detektiert werden konnte, nehmen wir an, daß die G393T-Mutation das Transkript für die lange Isoform destabilisiert.

Während die kurze Isoform, die durch das maternale Allel weitergegeben wird, die Mutation $\triangle 536 \mathrm{G}$ trägt, weist die kurze Isoform, die durch das paternale Allel weitergegeben wird, keine Mutation auf. Dies erklärt vermutlich das normale LLOProfil der Patientin in Bezug auf die Anwesenheit von $\mathrm{G}_{3}-\mathrm{Man}_{9}-\mathrm{GICNAc}_{2}-\mathrm{PP}-\mathrm{Dol}$.

Um nachzuweisen, daß die $\Delta$ 1040G-Mutation, die vom maternalen Allel stammt, tatsächlich zum Verlust der Enzymaktivität der langen Isoform des humanen ALG2Proteins führt, wurde zum einen die Wildtyp- und zum anderen die $\Delta 1040 \mathrm{G}-c D N A$ der langen Isoform in den Hautfibroblasten der Patientin mit Hilfe eines retroviralen Expressionssystems exprimiert. In Zellen, die die Wildtyp-cDNA exprimierten, konnte keine Akkumulation von $\mathrm{Man}_{1}-\mathrm{GlcNAc}_{2}$-PP-Dol und $\mathrm{Man}_{2}-\mathrm{GICNAc}_{2}-\mathrm{PP}-\mathrm{Dol}$ nachgewiesen werden, während Zellen, die die $\Delta 1040 G-c D N A$ exprimierten, nach

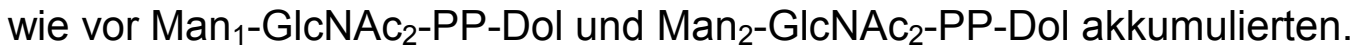

Diese Befunde belegen zum einen, daß es sich bei der in der Datenbank veröffentlichten cDNA-Sequenz um das humane Ortholog zum Hefe alg2-Gen handelt. Zum anderen zeigen sie, daß die molekulare Ursache der Erkrankung der Patientin M.S. und die damit verbundene Akkumulation von Man ${ }_{1}-$ GICNAc $_{2}-\mathrm{PP}-\mathrm{Dol}$ $\mathrm{Man}_{2}-\mathrm{GlcNAc}_{2}$-PP-Dol auf Mutationen in diesem Gen zurückzuführen sind.

Es bleibt bislang unklar, warum im Falle der Patientin neben Man $_{1}-$ GlcNAc$_{2}-\mathrm{PP}-\mathrm{Dol}$ auch $\mathrm{Man}_{2}$-GlcNAc${ }_{2}-\mathrm{PP}-\mathrm{Dol}$ akkumuliert. Die Übertragung des dritten Mannoserests sollte durch ein weiteres, bisher unbekanntes Enzym katalysiert werden, da es sich 
in diesem Fall um einen $\alpha-1,3$ glykosidisch-verknüpften Mannoserest handelt, während der zweite Mannoserest $\alpha-1,6$ glykosidisch mit Dol-PP-GlcNAc Man $_{1}$ verknüpft ist. Wahrscheinlicher ist allerdings, daß die humanen ALG2-Proteine sowohl den zweiten als auch den dritten Mannoserest übertragen. 


\section{Ausblick}

Die molekulare Ursache des Defekts in der N-Glykosylierung der Patientin M.S. konnte im Rahmen dieser Arbeit zunächst biochemisch charakterisiert und anschließend molekulargenetisch aufgeklärt werden.

Bei weiterführenden Untersuchungen sollen alle ungeklärten CDG-Verdachtsfälle mit Hilfe der dünnschichtchromatographischen Auftrennung kurzkettiger, [2-3H]Mannose-markierter, Dolichol-verknüpfter Oligosaccharide analysiert werden, die wie die Patientin M.S. ein CDG-Typ I Muster in der isoelektrischen Fokussierung aufweisen und keine Verkürzungen ihrer Oligosaccharidstruktur in der HPLC-Analyse längerkettiger Dolichol-verknüpfter Oligosaccharide zeigen.

Parallel dazu gilt es zu klären, welcher gewebs- und entwicklungsspezifischen Kontrolle die Expression der kurzen bzw. langen Isoform des ALG2-Proteins unterliegt und welche Funktion den N-terminalen 168 Aminosäuren der langen Isoform zukommt. Hierzu könnte die Generierung eines Mausmodels hilfreich sein, in dem die lange Isoform ausgeschaltet, die Funktion der kurzen Isoform aber erhalten bleibt. Um eine mögliche frühe embryonale Letalität in der Entwicklung der Mäuse zu verhindern, sollte ein konditionaler knock-out von ALG2, beispielsweise mit Hilfe des Cre/ loxP-Systems, generiert werden.

Weiterhin ist in Zusammenarbeit mit Prof. Ludwig Lehle in Regensburg geplant, Analysen zur Aktivität des humanen ALG2 in Hefestämmen durchzuführen. Dabei soll überprüft werden, ob das ALG2-Protein des Menschen tatsächlich neben der Übertragung des zweiten Mannoserests auf Man $_{1}-\mathrm{GlcNAc}_{2}-\mathrm{PP}-\mathrm{Dol}$ auch die sich direkt anschließende Reaktion der Übertragung des dritten Mannoserests auf Man $_{2}-$ GlcNAc2-PP-Dol katalysiert. Eine weitere interessante Fragestellung betrifft die Überprüfung der zeitlichen Abfolge der Verknüpfung des zweiten und dritten Mannoserests in alpha1,6- oder in alpha1,3-Stellung, die durch die acetolytischen Spaltung der säurelabilen alpha-1,6-Bindung an aufgereinigtem $\mathrm{Man}_{2}-\mathrm{GlcNAc}_{2}-\mathrm{PP}$ Dol und $\mathrm{Man}_{3} \mathrm{GlcNAc}_{2}$-PP-Dol aus den entsprechenden Hefemutanten untersucht werden soll. 


\section{Literaturverzeichnis}

Aebi M, Helenius A, Schenk B, Barone R, Fiumara A, Berger EG, Hennet T, Imbach T, Stutz A, Bjursell C, Uller A, Wahlstrom JG, Briones P, Cardo E, Clayton P, Winchester B, Cormier-Dalre V, de Lonlay P, Cuer M, Dupre T, Seta N, de Koning T, Dorland L, de Loos F, Kupers L, et al.

Carbohydrate-deficient glycoprotein syndromes become congenital disorders of glycosylation: an updated nomenclature for CDG. First International Workshop on CDGS. Glycoconj J. 1999:669-71.

Albright CF, Orlean P, Robbins PW.

A 13-amino acid peptide in three yeast glycosyltransferases may be involved in dolichol recognition. Proc Natl Acad Sci USA1989;86:7366-9

Anand M, Rush JS, Ray S, Doucey MA, Weik J, Ware FE, Hofsteenge J, Waechter CJ, Lehrman MA

Requirement of the Lec35 gene for all known classes of monosaccharide-P-dolicholdependent glycosyltransferase reactions in mammals. Mol Biol Cell. 2001;12:487501

Babbage, A

Acc.No.: CAC07999, Direct Submission, Sanger Centre, Hinxton, Cambridgeshire, $\mathrm{GB}, 2000$

\section{Bachmann BJ}

Linkage map of Escherichia coli K12, Edition 7; in: Escherichia coli and Salmonella typhimurium - cellular and molecular biology 1987, (Neidhardt, F.C./ ed.); ASM, Washington D.C. 2: 807-876

Bergen HR, Lacey JM, O'Brien JF, Naylor S.

Online single-step analysis of blood proteins: the transferrin story. Anal Biochem. 2001;296:122-9

\section{Berger, SL}

The use of Cerenkov radiation for monitoring reactions performed in minute volumes: Examples for recombination DNA technology. Anal. Biochem 1984; 136: 515-519

\section{Bradford MM}

A rapid and sensitive method for the quantitation of microgram quantities of protein utilizing the principle of protein-dye binding. Anal. Biochem. 1976; 72: 248-254

Branza-Nichita N, Petrescu AJ, Dwek RA, Wormald MR, Platt FM, Petrescu SM. Tyrosinase folding and copper loading in vivo: a crucial role for calnexin and alphaglucosidase II. J Biochem Biophys Res Commun.;261:720-5.

\section{Burda P, Aebi M.}

The ALG10 locus of Saccharomyces cerevisiae encodes the alpha-1,2 glucosyltransferase of the endoplasmic reticulum: the terminal glucose of the lipidlinked oligosaccharide is required for efficient $\mathrm{N}$-linked glycosylation. Glycobiology. 1998;8: 455-62 
Burda P, Jakob CA, Beinhauer J, Hegemann JH, Aebi M

Ordered assembly of the asymmetrically branched lipid-linked oligosaccharide in the endoplasmic reticulum is ensured by the substrate specifity of the individual glycosyltransferases. Glycobiology 1999; 9, 617-625

Burda P, te Heesen S, Brachat A, Wach A, Dusterhoft A, Aebi M.

Stepwise assembly of the lipid-linked oligosaccharide in the endoplasmic reticulum of Saccharomyces cerevisiae: identification of the ALG9 gene encoding a putative mannosyl transferase. Proc Natl Acad Sci 1996; 93: 7160-5

Chantret I, Dupre T, Delenda C, Bucher S, Barnier A, Charollais A, Heron D, Bader-Meunier B, Danos O, Seta N, Durand G, Oriol R, Codogno P, Moore SE Congenital disorders of glycosylation type Ig is defined by a deficiency in dolichyl-Pmannose:Man7GIcNAc2-PP-dolichyl mannosytransferase, J Biol Chem. 2002; 277: 25815-22

Cipollo JF, Trimble RB.

The accumulation of Man(6)GlcNAc(2)-PP-dolichol in the Saccharomyces cerevisiae Deltaalg9 mutant reveals a regulatory role for the Alg3p alpha1,3-Man middle-arm addition in downstream oligosaccharide-lipid and glycoprotein glycan processing. J Biol Chem. 2000;275:4267-77

de Lonlay P, Seta N, Barrot S, Chabrol B, Drouin V, Gabriel BM, Journel H, Kretz M, Laurent J, Le Merrer M, Leroy A, Pedespan D, Sarda P, Villeneuve N, Schmitz J, van Schaftingen E, Matthijs G, Jaeken J, Körner C, Munnich A, Saudubray JM, Cormier-Daire V

A broad spectrum of clinical presentations in congenital disorders of glycosylation I: a series of 26 cases. J Med Genet. 2001; 38: 14-19

De Praeter CM, Gerwig GJ, Bause E, Nuytinck LK, Vliegenthart JF, Breuer W, Kamerling JP, Espeel MF, Martin JJ, De Paepe AM, Chan NW, Dacremont GA, Van Coster RN

A novel disorder caused by defective biosynthesis of $\mathrm{N}$-linked oligosaccharides due to glucosidase I deficiency. Am J Hum Genet. 2000; 66: 1744-56

Dugaiczyk A, Boyer HW, Goodman HM

Ligation of EcoRI endonuclease-generated DNA-fragments into linear and circular structures. J Mol Biol 1975; 96: 171-84

Etzioni A, Frydman M, Pollack S, Avidor I, Phillips ML, Paulson JC, GershoniBaruch R

Brief report: recurrent severe infections caused by a novel leukocyte adhesion deficiency. N Engl J Med. 1992; 327: 1789-92

Frydman M, Etzioni A, Eidlitz-Markus T, Avidor I, Varsano I, Shechter Y, Orlin JB, Gershoni-Baruch R

Rambam-Hasharon syndrome of psychomotor retardation, short stature, defective neutrophil motility, and Bombay phenotype. Am J Med Genet. 1992; 44: 297-302 


\section{Fu J und Kreibich G}

Retention of Subunits of the Oligosaccharyltransferase Complex in the Endoplasmic Reticulum. J. Biol. Chem. 2000; 275: 3984-3990

\section{Gabius HJ.}

Vertebrate lectins and their possible role in fertilization, development and tumor biology In Vivo. 1987; 75-83.

\section{Grubenmann CE, Frank CG, Kjaergaard S, Berger EG, Aebi M, Hennet T}

ALG12 mannosyltransferase defect in congenital disorder of glycosylation type Ig. Hum Mol Genet. 2002; 11: 2331-2339

\section{Hammond C, Braakman I, Helenius A}

A Role of $\mathrm{N}$-linked oligosaccharid recognition, glucose trimming, and calnexin in glykoprotein folding and quality control. Proc. Natl. Acad. Sci. USA 1994, 91, 913-917

Hanefeld F, Körner C, Holzbach-Eberle U, von Figura K

Congenital disorder of glycosylation-lc: case report and genetic defect. Neuropediatrics. 2000: 60-2

\section{Hansen SH, Frank SR, Casanova Je}

Cloning and characterization of human phosphomannomutase, a mammalian homologue of yeast SEC53. Glycobiology 1997; 7: 829-34

Hanßke B, Thiel C, Lübke T, Hasilik M, Honing S, Peters V, Heidemann PH, Hoffmann GF, Berger EG, von Figura K, Körner C

Deficiency of UDP-galactose: $\mathrm{N}$-acetylglucosamine beta-1,4-galactosyltransferase I causes the congenital disorder of glycosylation type Ild. J Clin Invest. 2002; 109: 725-33

\section{Hirschberg CB, Robbins PW, Abeijon C}

Transporters of nucleotide sugars, ATP, and nucleotide sulfate in the endoplasmic reticulum and Golgi apparatus. Annu Rev Biochem. 1998; 67: 49-69.

\section{Hogan B, Constantini F, Lacy E}

Manipulating the mouse, a laboratory manual, Cold Spring Harbor Laboratory 1986, Cold spring Harbor, N.Y.

Hubbard SC, Ivatt RJ.

Synthesis and processing of asparagine-linked oligosaccharides. Annu Rev Biochem. 1981;50:555-83.

\section{Imbach T, Burda P, Kuhnert P, Wevers RA, Aebi M, Berger EG, Hennet T} A mutation in the human ortholog of the Saccharomyces cerevisiae ALG6 gene causes carbohydrate-deficient glycoprotein syndrome type-lc. Proc Natl Acad Sci U S A. 1999; 96: 6982-7

Imbach T, Schenk B, Schollen E, Burda P, Stutz A, Gr]unewald S, Bailie NM, King MD, Jaeken J, Matthijs G, Berger EG, Aebi M, Hennet T

Deficiency of dolichol-phosphate-mannose synthase-1 causes congenital disorder of glycosylation type le. J Clin Invest. 2000; 105: 233-9. 


\section{Inoue $\mathbf{H}$, Nojima $\mathrm{H}$}

Okayama H High efficiency transformation of Escherichia coli with plasmids. Gene 1990; 96: 23-28

\section{Isogai T and Otsuki T}

Acc.No.: BAB55099, Direct Submission, Helix Research Institute, Yana, Kisarazu, Japan, 2002

\section{Jackson BJ, Warren CD, Bugge B, Robbins P}

Synthesis of lipid-linked Oligosaccharides in Saccharomyces cerevisiae: $\mathrm{Man}_{2} \mathrm{GlcNAc}_{2}$ and $\mathrm{Man}_{1} \mathrm{GlcNAc}_{2}$ are transferred from Dolichol to protein in Vivo. Arch Biochem Biophys 1989; 272: 203-209

\section{Jackson BJ, Kukuruzinska MA, Robbins P.}

Biosynthesis of asparagine-linked oligosaccharides in Saccharomyces cerevisiae: the alg2 mutation. Glycobiology. 1993;3:357-64.

\section{Jaeken J, Vanderschueren-Lodeweyckx M, Casaer P}

Familial psychomotor retardation with markedly fluctuating serum proteins, $\mathrm{FSH}$ and GH levels, partial TGB deficiency, increased serum arylsulfatase A and increased CSF protein: a new syndrom? Pediatr Res. 1980; 14: 179

Jaeken J, van Eijk HG, van der Heul C, Corbeel L, Eeckels R, Eggermont E. Sialic acid-deficient serum and cerebrospinal fluid transferrin in a newly recognized genetic syndrome. Clin Chim Acta. 1984; 144: 245-7

Jaeken J, Carchon H.

The carbohydrate-deficient glycoprotein syndromes: an overview. J Inherit Metab Dis. 1993; 16: 813-20

\section{Jaeken J, Schachter H, Carchon H, De Cock P, Coddeville B, Spik G}

Carbohydrate deficient glycoprotein syndrome type II: a deficiency in Golgi localised N-acetyl-glucosaminyltransferase II. Arch Dis Child. 1994; 71:123-7

Jesse $\mathbf{J}$

Use of competent cells of DNA transformation. Fucos 1984; 6: 5-6

Jörgensen MU, Emr SD, Winther JR.

Ligand recognition and domain structure of $V p s 10 p$, a vacuolar protein sorting receptor in Saccharomyces cerevisiae. Eur J Biochem. 1999;260:461-9.

Kim S, Westphal V, Srikrishna G, Mehta DP, Peterson S, Filiano J, Karnes PS, Patterson MC, Freeze HH.

Dolichol phosphate mannose synthase (DPM1) mutations define congenital disorder of glycosylation le (CDG-le) J Clin Invest. 2000; 105: 191-8.

\section{Kepes F und Schekman R}

The yeast SEC53 gene encodes phosphomannomutase. J. Biol. Chem. 1988, 263: 9155-61 


\section{Knauer R und Lehle L}

The Oligosaccharyltransferase complex from Saccharomyces cerevisiae. J Biol Chem 1999; 274: 17249-17256

\section{Körner C, Lehle L, von Figura K}

Abnormal synthesis of mannose 1-phosphate derived carbohydrates in carbohydratedeficient glycoprotein syndrome type I fibroblasts with phosphomannomutase deficiency. Glycobiology 1998a; 8:165-71

\section{Körner C, Lehle L, von Figura K}

Carbohydrate-deficient glycoprotein syndrome type 1: correction of the glycosylation defect by deprivation of glucose or supplementation of mannose. Glycoconj J. 1998b: 499-505.

\section{Körner C, Knauer R, Holzbach U, Hanefeld F, Lehle L, von Figura K}

Carbohydrate-deficient glycoprotein syndrome type $\mathrm{V}$ : deficiency of dolichyl-PGlc:Man9GIcNAc2-PP-dolichyl glucosyltransferase. Proc Natl Acad Sci U S A. 1998c; 95: 13200-5

\section{Körner C, Knauer R, Stephani U, Marquardt T, Lehle L, von Figura K}

Carbohydrate deficient glycoprotein syndrome type IV: deficiency of dolichyl-PMan:Man(5)GlcNAc(2)-PP-dolichyl mannosyltransferase. EMBO J. 1999;18: 6816-22

\section{Kornfeld R, Kornfeld S}

Assembly of asparagine-linked oligosaccharides. Annu Rev Biochem. 1985; 54: 63164

Kranz C, Denecke J, Lehrman MA, Ray S, Kienz P, Kreissel G, Sagi D, PeterKatalinic J, Freeze HH, Schmid T, Jackowski-Dohrmann S, Harms E, Marquardt T.

A mutation in the human MPDU1 gene causes congenital disorder of glycosylation type If (CDG-If).J Clin Invest. 2001; 108: 1613-9

\section{Laemmli UK}

Cleavage of structural proteins during the assembly of head of bacteriophage T4. Nature 1970, 680-685

\section{Lennarz, W.}

Glycoprotein Synthesis and embryonic development. Crit. Rev. Biochem. 1993; 14: 257-272

\section{Lübke T, Marquardt T, von Figura K, Körner C}

A new type of carbohydrate-deficient glycoprotein syndrome due to a decreased import of GDP-fucose into the golgi. J Biol Chem. 1999; 274: 25986-9

\section{Lübke T, Marquardt T, Etzioni A, Hartmann E, von Figura K, Körner C}

Complementation cloning identifies CDG-IIc, a new type of congenital disorders of glycosylation, as a GDP-fucose transporter deficiency. Nat Genet. 2001; 28: 73-6

MacGillivray RTA, Mendez E, Shewale JG, Sinha SK, Lineback-Zins J, Brew K. 
The primary structure of human serum transferrin. J. Biol. Chem. 1983; 258: 35433553

Marquardt T, Luhn K, Srikrishna G, Freeze HH, Harms E, Vestweber D.

Correction of leukocyte adhesion deficiency type II with oral fucose. Blood. 1999;94:3976-85

Matthijs G, Schollen E, Pardon E, Veiga-Da-Cunha M, Jaeken J, Cassiman JJ, Van Schaftingen

E Mutations in PMM2, a phosphomannomutase gene on chromosome 16p13, in carbohydrate-deficient glycoprotein type I syndrome (Jaeken syndrome) Nat Genet. 1997: 88-92

Matthijs G, Schollen E, Van Schaftingen E, Cassiman JJ, Jaeken J.

Lack of homozygotes for the most frequent disease allele in carbohydrate-deficient glycoprotein syndrome type 1A. Am J Hum Genet. 1998; 62: 542-50

Matthijs G, Schollen E, Bjursell C, Erlandson A, Freeze H, Imtiaz F, Kjaergaard S, Martinsson T, Schwartz M, Seta N, Vuillaumier-Barrot S, Westphal V, Winchester B.

Mutations in PMM2 that cause congenital disorders of glycosylation, type la (CDGla). Hum Mutat. 2000: 386-94.

Mayatepek E, KohImuller D.

Mannose supplementation in carbohydrate-deficient glycoprotein syndrome type I and phosphomannomutase deficiency. Eur J Pediatr. 1998; 157: 605-6

Mendell JT, Dietz HC.

When the message goes awry: disease-producing mutations that influence mRNA content and performance. Cell. 2001;107:411-4.

Miller DG, Miller AD

A family of retroviruses that utilize related phosphate transporters for cell entry. J. Virol. 1994; 68: 8270-6

Murphy LA, Spiro RG.

Transfer of glucose to oligosaccharide-lipid intermediates by thyroid microsomal enzymes and its relationship to the $\mathrm{N}$-glycosylation of proteins. J. Biol Chem.; 1981;256:7487-94.

Niehues R, Hasilik M, Alton G, Korner C, Schiebe-Sukumar M, Koch HG, Zimmer KP, Wu R, Harms E, Reiter K, von Figura K, Freeze HH, Harms HK, Marquardt T

Carbohydrate-deficient glycoprotein syndrome type lb. Phosphomannose isomerase deficiency and mannose therapy. J Clin Invest. 1998; 101: 1414-20

Panneerselvam K, Freeze HH

Mannose corrects altered $\mathrm{N}$-glycosylation in carbohydrate-deficient glycoprotein syndrome fibroblasts. J Clin Invest. 1996; 97: 1478-87 


\section{Panneerselvam K, Etchison JR, Freeze HH}

Human fibroblasts prefer mannose over glucose as a source of mannose for $\mathrm{N}$ glycosylation. Evidence for the functional importance of transported mannose. J Biol Chem. 1997; 272: 23123-9

\section{Parodi, AJ}

Role of $\mathrm{N}$-oligosaccharide endoplasmic reticulum processing reactions in glycoprotein folding and degradation. Biochem. J. 2000, 348, 1-13

Peters V, Penzien JM, Reiter G, Körner C, Hackler R, Assmann B, Fang J, Schaefer JR, Hoffmann GF, Heidemann

$\mathrm{PH}$ Congenital disorder of glycosylation IId (CDG-IId) -a new entity: clinical presentation with Dandy-Walker malformation and myopathy. Neuropediatrics. 2002; 33: $27-32$

Petrescu SM, Petrescu AJ, Titu HN, Dwek RA, Platt FM.

Inhibition of $\mathrm{N}$-glycan processing in B16 melanoma cells results in inactivation of tyrosinase but does not prevent its transport to the melanosome. J Biol Chem. 1997; 272:15796-803

Powell LD, Paneerselvam K, Vij R, Diaz S, Manzi A, Buist N, Freeze H, Varki A Carbohydrate-deficient glycoprotein syndrome: not an $\mathrm{N}$-linked oligosaccharide processing defect, but an abnormality in lipid-linked oligosaccharide biosynthesis? J Clin Invest. 1994; 94: 1901-9

Ramaekers VT, Stibler H, Kint J, Jaeken J.

A new variant of the carbohydrate deficient glycoproteins syndrome. J Inherit Metab Dis. 1991;14: 385-8

\section{Rearick JI, Fujimoto K, Kornfeld S.}

Identification of the mannosyl donors involved in the synthesis of lipid-linked oligosaccharides. J Biol Chem. 1981;256: 3762-9.

Rosenblum BB, Lee LG, Spurgeon SL, Khan SH, Menchen SM, Heiner CR, Chen SM

New dye-labeled terminators for improved DNA sequencing patterns. Nucleic Acids Research 1997; 25: 4500-4504

Saiki RK, Scharf S, Faloona, F, Mullis KB, Horn GT, Ehrlich HA, Arnheim N Enzymatic amplification of ß-globin genomic sequences and restriction site analysis for diagnosis of sickle cell anemia. Science 1985; 230: 1350-1354

\section{Sambrook J, Fritsch EF, Maniatis T}

Molecular cloning: a laboratory manual, $2^{\text {nd }}$ edition 1989, Cold Spring Harbor Laboratory, Cold Spring, N.Y.

Schenk B, Imbach T, Frank CG, Grubenmann CE, Raymond GV, Hurvitz H, Raas-Rotschild A, Luder AS, Jaeken J, Berger EG, Matthijs G, Hennet T, Aebi M.

MPDU1 mutations underlie a novel human congenital disorder of glycosylation, designated type If. J Clin Invest. 2001; 108: 1687-95. 


\section{Silberstein S, Collins PG, Kelleher DJ, Rapiejko PJ, Gilmore R}

The alpha subunit of the Saccharomyces cerevisiae oligosaccharyltransferase complex is essential for vegetative growth of yeast and is homologous to mammalian ribophorin I. J Cell Biol 1995; 128: 525-36

\section{Southern EM}

Measurements of DNA length by gelelectrophoresis; Anal. Biochem. 1979, 100: 319323

\section{Strausberg R.}

Acc.No.: AAH15126, Direct Submission, National Institutes of Health (MGC), Bethesda, USA 2001

Tatu U, Helenius A

Interactions between newly synthesized glycoproteins, calnexin and a network of resident chaperones in the endoplasmic reticulum. J Cell Biol. 1997 10; 136: 555-65

\section{te Heesen S, Knauer R, Lehle L, Aebi M}

Yeast Wbp1p and Swp1p form a protein complex essential for oligosaccharyl transferase activity. EMBO J 1993; 12: 279-284

Thiel C, Schwarz M, Hasilik M, Grieben U, Hanefeld F, Lehle L, Von Figura K, Körner C

Deficiency of dolichyl-P-Man:Man7GlcNAc2-PP-dolichyl mannosyltransferase causes congenital disorder of Glycosylation-Ig. Biochem J. 2002; 367: 195-201

\section{Turco SJ, Stetson B, Robbins PW.}

Comparative rates of transfer of lipid-linked oligosaccharides to endogenous glycoprotein acceptors in vitro. Proc Natl Acad Sci U S A. 1977; 74: 4411-4.

\section{Van Schaftingen E, Jaeken J}

Phosphomannomutase deficiency is a cause of carbohydrate-deficient glycoprotein syndrome type I. FEBS Lett. 1995; 377: 318-20.

\section{Varki A}

Biological roles of oligosaccharides: all of the theories are correct. Glycobiology. 1993; 3: 97-130.

\section{Westermeier $\mathbf{R}$}

Isoelectric focusing. Methods Mol. Biol. 1996; 59: 239-248

Westphal V, Peterson S, Patterson M, Tournay A, Blumenthal A, Treacy EP, Freeze HH.

Functional significance of PMM2 mutations in mildly affected patients with congenital disorders of glycosylation la. Genet Med. 2001;3:393-8

\section{Yamashita K, Ohkura T, Ideo H, Ohno K, Kanai M.}

Electrospray ionization mass spectrometric analysis of serum transferrin isoforms in patients with carbohydrate deficient glycoprotein syndrome. J. Biochem. 1993; 114: 766-9 
Yamazaki H, Shiraishi N, Takeuchi K, Ohnishi Y, Horinouchi S

Characterization of alg2 encoding a mannosyltransferase in the zygomycete fungus Rhizomucor pusillus. Gene 1998; 221: 179-184 


\section{Danksagung}

An dieser Stelle möchte ich mich zunächst bei Herrn Prof. Dr. Kurt von Figura für die Vergabe des interessanten Themas und für sein umfassendes Engagement bei der Betreuung dieser Arbeit bedanken. Sowohl seine zahlreichen Anregungen als auch seine immerwährende Diskussionsbereitschaft haben maßgeblich zum Erfolg beigetragen.

Bei Herrn Prof. Dr. Gerhard Gottschalk bedanke ich mich für die bereitwillige Übernahme des Korreferats.

Herrn PD. Dr. Christian Körner danke ich für die hervorragende wissenschaftliche Betreuung, das freundschaftliche Verhältnis in seiner Arbeitsgruppe und für die zahlreichen zusammen angestellten großen und kleinen Streiche, die das Arbeiten im Institut verschönt haben. Bei den anderen Mitgliedern im Institut entschuldige ich mich hiermit.

Für das freundschaftliche Klima in unserer Arbeitsgruppe möchte ich mich weiterhin bei Torben Lübke, Bengt Hanßke, Martin Hasilik, Jan Rindermann, Christina Hellbusch und Jürgen Lübbehusen danken.

Frau Poldi Sander sei an dieser Stelle ganz besonders für ihren stetigen Unterstützungswillen und ihre Fürsorglichkeit gedankt.

Meiner Mutter, Oma und meinen Schwiegereltern danke ich für die ständige liebevolle Unterstützung und Hilfen bei den angefallenen großen und kleinen Problemen während dieser Doktorandenzeit.

Der größte, herzlichste Dank gilt meiner Liebsten. 


\section{Veröffentlichungen}

Schöber U, Thiel C, Jendrossek D.

Poly(3-hydroxyvalerate) depolymerase of Pseudomonas lemoignei.

Appl Environ Microbiol. 2000;66:1385-92.

Hanßke B, Thiel C, Lübke T, Hasilik M, Höning S, Peters V, Heidemann PH, Hoffmann GF, Berger EG, von Figura K, Körner C.

Deficiency of UDP-galactose: $\mathrm{N}$-acetylglucosamine beta-1,4-galactosyltransferase I causes the congenital disorder of glycosylation type Ild. J Clin Invest. 2002;109:72533

Thiel C, Schwarz M, Hasilik M, Grieben U, Hanefeld F, Lehle L, Von Figura K, Körner C.

Deficiency of dolichyl-P-Man:Man7GIcNAc2-PP-dolichyl mannosyltransferase causes congenital disorder of Glycosylation-Ig. Biochem J. 2002; 367: 195-201

Die Daten dieser Dissertation stehen zur Veröffentlichung an. 


\section{Lebenslauf}

Name:

Christian Thiel

Anschrift:

Schöneberger Straße 15, 37085 Göttingen

Geboren:

04.09.1972 in Göttingen

Staatsangehörigkeit:

deutsch

Familienstand: verheiratet mit Anja Schlesier-Thiel, geb. Schlesier; zwei Kinder, geb. 10.09.2000 und 05.02.2002

\section{Schulausbildung:}

1979-1983

Brüder Grimm Schule Göttingen

1983-1985

Orientierungsstufe Göttingen Nord

1985-1992

Theodor-Heuss-Gymnasium Göttingen

20.05.1992

Abitur

01.07.1992-30.06.1993

Wehrdienst beim Panzergrenadierbataillon 12, Osterode

\section{Studium:}

WS 1993-SS 1999 Biologiestudium an der Georg-August-Universität Göttingen 12.07.1999 Diplom im Studiengang Biologie Titel der Diplomarbeit: "Molekularbiologische Untersuchungen zur Substratspezifität der PHV-Depolymerase aus Pseudomonas lemoignei"

15.07.1999-30.09.2000

Stipendiat im Graduiertenkolleg "Molekularbiologische Analyse pathophysiologischer Prozesse" in der Abt. Biochemie II, Universität Göttingen

ab 01.10.2000

Doktorand (BAT Ila/2)

in der Abt. Biochemie II, Universität Göttingen 